\title{
Revision of the Tomoderinae (Coleoptera: Anthicidae). Part III. New species and records of Macrotomoderus Pic, 1901 from China and a key to the Palaearctic species
}

\author{
Dmitry TELNOV ${ }^{\circledR}$ \\ Department of Life Sciences, Natural History Museum, Cromwell Road, \\ SW7 5BD, London, United Kingdom. \\ Institute of Biology, University of Latvia, O. Vācieša iela 4, LV-1004, Rīga, Latvia. \\ Coleopterological Research Center, Institute of Life Sciences and Technology, \\ Daugavpils University, Vienības iela 13, LV-5401, Daugavpils, Latvia. \\ Email: anthicus@gmail.com
} urn:1sid:zoobank.org:author:F78B0D3E-E409-4054-A834-E6C06918B62F

\begin{abstract}
Descriptions of the following 23 species of Macrotomoderus Pic, 1901 new to science, from continental China, are provided as an addition to the recently published review of the genus from China and Taiwan (Telnov 2018): M. angelinii, M. belousovi, M. bicrispus, M. boops, M. bordonii, M. dali, $M$. daxiangling, $M$. femoridens, $M$. hajeki, M. hartmanni, . hengduan, . imitator, $M$. kabaki, M. korolevi, M. lapidarius, M. muli, M. palaung, M. similis, M. tenuis, M. transitans, M. truncatulus, M. usitatus, and $M$. wudu spp. nov. Additional records are provided for some poorly known species. The identification key to the species of Macrotomoderus from China, the Japanese Archipelago, and Taiwan is herewith significantly supplemented and updated. Biogeographical peculiarities and altitudinal gradient of Macrotomoderus distribution in continental China are briefly discussed.
\end{abstract}

Keywords. Taxonomy, identification, morphology, new records, checklist.

Telnov D. 2022. Revision of the Tomoderinae (Coleoptera: Anthicidae). Part III. New species and records of Macrotomoderus Pic, 1901 from China and a key to the Palaearctic species. European Journal of Taxonomy 797: 1-100. https://doi.org/10.5852/ejt.2022.797.1667

\section{Introduction}

This is the third revisional work devoted to the Palaearctic species of Macrotomoderus Pic, 1901 (see Telnov 2007b, 2018), the second most species-rich among the seven genera of Tomoderinae Bonadona, 1961 (Chandler 2010; Telnov 2018).

Macrotomoderus was originally erected to include one species from the Greater Sunda Islands (Sumatra) (Pic 1901), and until recently most species in this genus were described, in part under the name of Derarimus Bonadona, 1978 (junior synonym of Macrotomoderus according to Telnov 2007a), from the Indo-Australian Archipelago and mainland SE Asia (Uhmann 1993, 1994a, 1994b, 1994c, 1996a, 1996b, 
1998, 1999; Telnov 2004, 2007a) and much fewer from the Philippines (Uhmann 1994a), or the Indian Subcontinent (Bonadona 1978). Up to now Macrotomoderus includes 116 species (89 Oriental (author's unpublished checklist) and 27 Palaearctic (Telnov 2020; M. andibani Telnov, 2007 is omitted from the last version of the Palaearctic catalogue)), not counting the 23 new Palaearctic species described in the present paper.

The critical features of Macrotomoderus were discussed by Telnov (2007a) and are not repeated here. Generally, Macrotomoderus are rather uniform beetles with a limited selection of distinctive features. The M. gracilicollis group is the only delimited informative species group in its genus, with features and a key given by Telnov (2007a).

The cryptic radiation of these forest-litter-dwelling, generally apterous anthicids in China was uncovered recently (Telnov 2018), when a total of 24 species were confirmed and keyed for continental China, and one more species for Taiwan. As of Telnov (2018, 2020 (see note above)), 16 of a total of 25 species of Macrotomoderus in continental China and Taiwan are considered to be restricted to montane ridges of Yunnan.

Recently available and surprisingly rich new material from continental China is represented by new records of several previously known species, as well as 23 species of Macrotomoderus new to science, which are described and illustrated below: M. angelinii, M. belousovi, M. bicrispus, M. boops, M. bordonii, M. dali, M. daxiangling, M. femoridens, M. hajeki, M. hartmanni, M. hengduan, M. imitator, M. kabaki, M. korolevi, M. lapidarius, M. muli, M. palaung, M. similis, M. tenuis, M. transitans, M. truncatulus, M. usitatus, and M. wudu spp. nov. Consequently, the latest identification key to Macrotomoderus from China and Taiwan (Telnov 2018) is supplemented and critically updated (also including the species from the Japanese Archipelago), and is presented here.

\section{Material and methods}

All taxa are listed in alphabetical order (except in the key), since a phylogenetic arrangement is not yet possible. All reproduced labels are printed. All label text is reproduced verbatim, with no corrections or additions. Labels (if more than one for the same specimen) are separated by double slash. Author's comments are given in square brackets. Each type specimen of a newly described species is provided with a black framed label on red paper "HOLOTYPUS" or "PARATYPUS", respectively.

The exposed cranial neck of some species is included in total body length but neck length is not provided separately.

For morphological studies, a Leica S6D binocular stereo microscope with an attached external Canon EOS 77D SLR camera was used. Genitalia were studied using a Meiji optical microscope. Habitus digital images made with a Canon 77D SLR camera mounted on a stand, a Canon MP-E $65 \mathrm{~mm}$, and a Laowa $25 \mathrm{~mm}$ lenses, while images of genital organs and terminal abdominal segments were studied using a Meiji light microscope with a Sony DSC-WX100 digital camera attached to a microscope. Helicon Focus ver. 7 software was used for image stacking. Further image manipulations were performed using the GNU Image Manipulation Program (GIMP).

The material discussed below is housed in the following collections:

DTC = Collection Dmitry Telnov, Rīga, Latvia

NMP = Národní muzeum Praha, Czech Republic

ZIN = Zoological Institute Russian Academy of Sciences, St Petersburg, Russia 


\section{Results}

\section{Morphology}

For the first time presence of conspicuous gonopore armature has been unveiled in male genitalia of Macrotomoderus, based on discussed specimens. The presence of gonopore armature in male aedeagi provides new powerful features for treating habitually similar taxa of Macrotomoderus.

It is observed for the first time for Macrotomoderus, that the abdominal tergites (with exception of the terminal ones) are membranous, almost colourless and transparent. The abdomen of most studied specimens is balloon-like, inflated and occupies the whole abdominal space under the elytra (since the Chinese species are apterous, the under-elytral space usually occupied by metathoracic wings is occupied by the inflated abdomen in Chinese species of Macrotomoderus.

\section{Taxonomy}

Class Insecta Linnaeus, 1758

Order Coleoptera Linnaeus, 1758

Suborder Polyphaga Emery, 1886

Superfamily Tenebrionoidea Latreille, 1802

Family Anthicidae Latreille, 1819

Subfamily Tomoderinae Bonadona, 1961

Genus Macrotomoderus Pic, 1901

Macrotomoderus Pic, 1901: 741. Type species: Macrotomoderus latipennis Pic, 1901: 741, by monotypy.

Derarimus Bonadona, 1978: 655, synonymy proposed by Telnov (2007a). Type species: Derarimus carinatus Bonadona, 1978: 655, original designation.

Macrotomoderus angelinii sp. nov.

urn:1sid:zoobank.org:act:8E264897-1526-4DB8-A6CA-BF9888A270EA

Figs 1-2

\section{Differential diagnosis}

This species falls in a group of species from continental China with the lateral fovea of pronotum not or only poorly visible in dorsal view, not forming deep notches at both sides of the lateral constriction. Among these species, Macrotomoderus bukejsi Telnov, 2018, M. chingpo Telnov, 2018, and M. gracilis Telnov, 2018 have slender and elongate pronotum. The pronotum is medially longitudinally carinate at the constriction area in the two first species, non-carinate in $M$. angelinii sp. nov. The pronotum is peculiarly modified in M. gracilis, with the median part of the anterior margin of it elevated and strongly projecting anteriad, provided with a group of 7 -shaped (bent) setae directed anteriad (both modifications are not present in M. angelinii sp. nov.). Macrotomoderus tenuis sp. nov. (see description below) has the lateral foveae of the pronotum short and narrow, but well-visible in dorsal view (this includes denticles of the fovea), the median setae on the anterior margin of the male pronotum either straight and anteriadpointed or slightly $\mathrm{C}$-shaped (curved) in their apical portion.

\section{Etymology}

Patronymic. This species named after the famous Italian coleopterist and my good colleague Fernando Angelini who has passed away on 28 May 2021 aged 72 . 


\section{Type material}

Holotype

CHINA - गे; "CHINA, Yunnan, $11.3 \mathrm{~km}$ W Laiping, SE Lajing, 3.4km SSE Jiaolieshan, $3405 \mathrm{~m}$, 20.v.2018, I. Belousov \& I. Kabak leg. // 26²6'50"N 99¹8'19"E”; ZIN.

Paratypes ( 2 specimens)

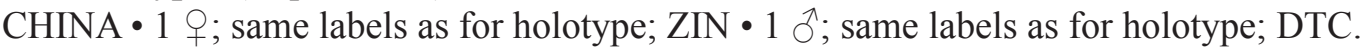

\section{Description}

Measurements. Holotype, total body length $3.48 \mathrm{~mm}$; head $0.88 \mathrm{~mm}$ long, across eyes $0.6 \mathrm{~mm}$ broad, pronotum $0.8 \mathrm{~mm}$ long, maximum width $0.5 \mathrm{~mm}$, minimum width $0.2 \mathrm{~mm}$, elytra $1.8 \mathrm{~mm}$ long, $1.2 \mathrm{~mm}$ combined wide.

Dorsum and venter uniformly pale brown. Mouthparts, antennae, palps and legs yellow. Head ovoid with moderately large, ovoid compound eyes, which are not protruding beyond head outline laterally. Head rounded in broad arc posterior to eyes. Head dorsal punctures minute and inconspicuous. Head dorsal setae inconspicuous, sparse. Antennae nearly extending towards base of pronotum. Antennomere three about as long as antennomere two, antennomeres 8-10 transverse, of which penultimate antennomere strongly transverse. Terminal antennomere asymmetrically triangular with rounded apex, nearly twice as long as penultimate antennomere. Terminal maxillary palpomere slightly securiform. Pronotum elongate and slender, with broad, medially slightly notched (in dorsal view) postmedian lateral constriction. Front margin of anterior lobe very broadly rounded, dorsally without anterior rim, medially with a bunch of yellowish, moderately long, D-shaped (curved), posterodorsad-pointed setae (Fig. 1B-C). Anterior lobe slightly convex in lateral view (Fig. 1C). Lateral constriction continues onto disc in lateral view, shallow (Fig. 1C). Lateral pronotal fovea narrow at lower external margin of pronotum, strongly widens upwards towards pronotal disc in lateral view, external margins protruding into a pair of inconspicuous, obtuse (in lateral view), glabrous, narrowly separated denticles (in lateral view). Cavity in lateral wall of pronotum between lateral denticles small, narrowly rectangular. In dorsal view, lateral pronotal fovea narrow, anterior and posterior pair of denticles poorly visible, glabrous (Fig. 1B). Pronotal punctures minute on disc; lateral constriction dorsally with dense, moderately large to large circular punctures separated by about their diameters. Dorsal pronotal setae inconspicuous, moderately long. Scutellar shield minute, triangular. Elytra dorsally elliptical, convex in lateral view, strongly widened laterally around midlength, lateral margins evenly broadly rounded, shoulders obsolete (apterous species). Elytral punctures much stronger and larger than those on dorsal forebody but somewhat less coarse than dorsal punctures on lateral pronotal constriction. Elytral setae long and sparse, suberect. Male and female tergite and morphological sternite VII broadly rounded at posterior margin. Aedeagus as in Fig. 2, rather narrow and slender, with very delicate, tube-like encapsulated gonopore armature.

\section{Sexual dimorphism}

Female anterior margin of pronotum without modifications.

\section{Ecology}

Collected at 3405 m elevation.

\section{Distribution}

Known only from northern part of Yunnan Province, SW China. 

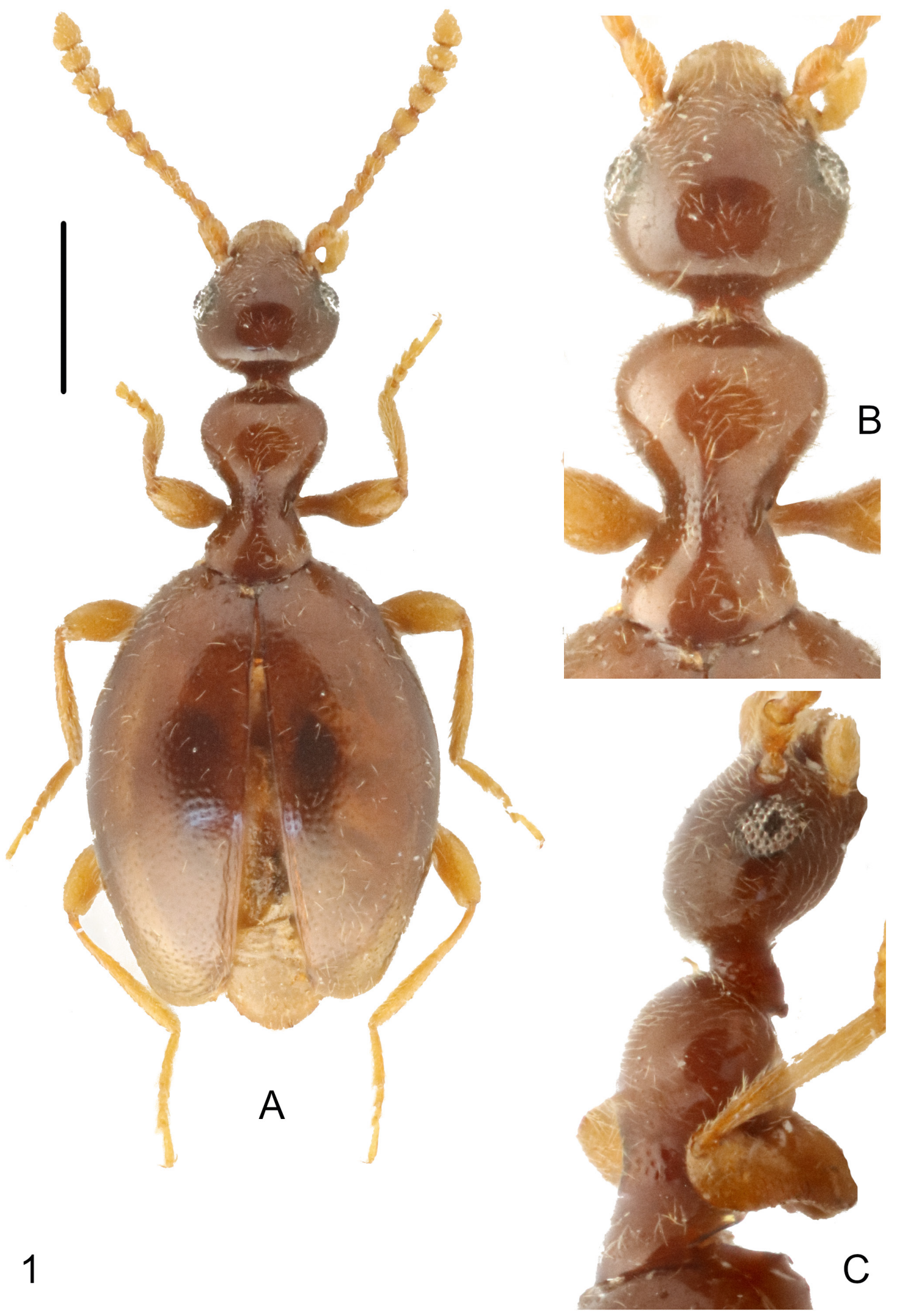

Fig. 1. Macrotomoderus angelinii sp. nov., holotype, §̊ (ZIN). A. Habitus, dorsal view. B. Forebody, dorsal view. C. Ditto, lateral view. Scale bar: A $=1 \mathrm{~mm}$; $\mathrm{B}-\mathrm{C}=$ not to scale. 


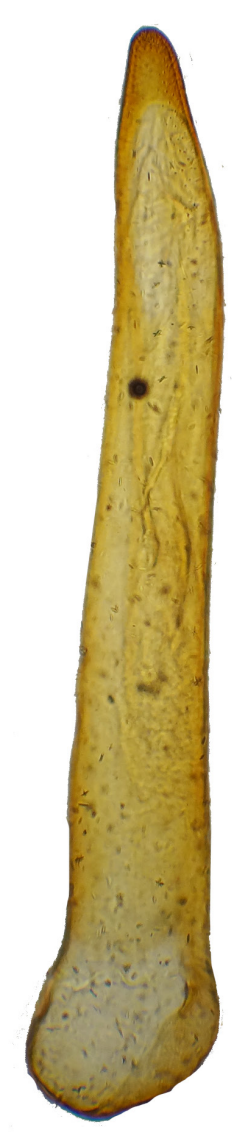

A

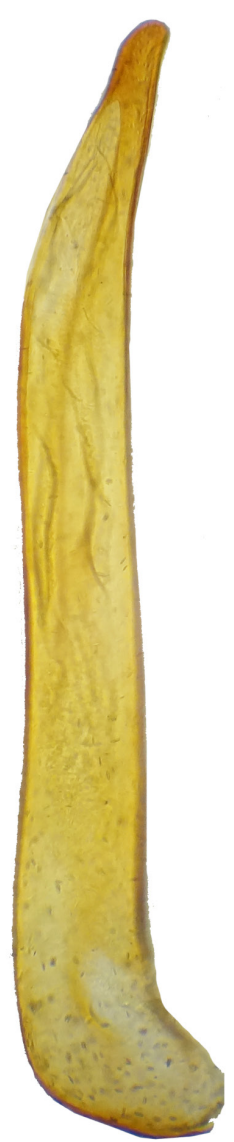

B

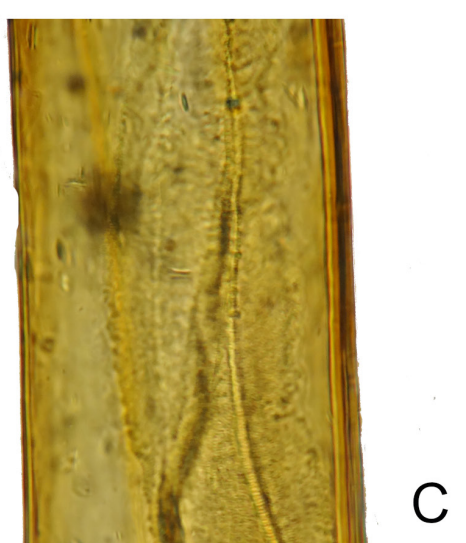

C
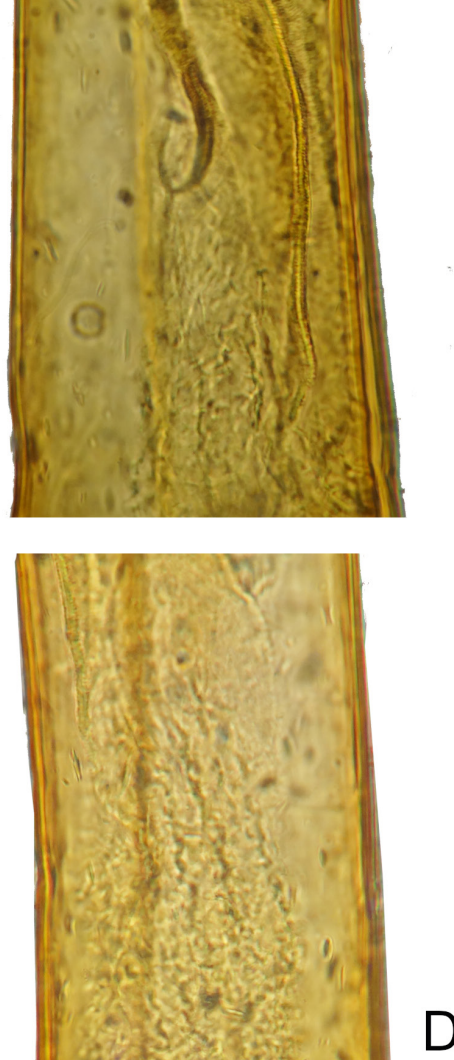

$\mathrm{D}$

\section{2}

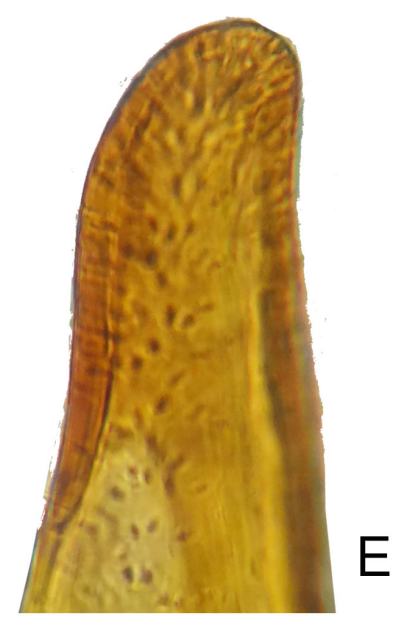

Fig. 2. Macrotomoderus angelinii sp. nov., holotype, $\widehat{\jmath}(\mathrm{ZIN})$, aedeagus. A-B. General view, different positions. C. Gonopore armature in median portion of aedeagus. D. Ditto, basal portion of apicale. E. Apical portion. Not to scale. 
TELNOV D., New species of Macrotomoderus, with a key to the Palaearctic taxa

\section{Macrotomoderus belousovi sp. nov. urn:1sid:zoobank.org:act:DCEEB63C-21C5-41DF-8518-840EC0D47632}

Fig. 3

\section{Differential diagnosis}

Most similar to Macrotomoderus kabaki sp. nov. (described below), differs primarily in the less strongly transverse antennomeres 9-10 (the antennomeres 8-10 strongly transverse in $M$. kabaki sp. nov.), the convex lateral outline of the anterior pronotal lobe (flattened in M. kabaki sp. nov.), the clypeus broadly emarginate anterodorsally (truncate in $M$. kabaki sp. nov.), and the comparatively longer, apically rounded elytra (the elytra comparatively shorter and subtruncate in $M$. kabaki sp. nov.). Also see key to species below.

\section{Etymology}

Patronymic. Named in honour of one of the first collectors, Igor' A. Belousov (All-Russian Institute of Plant Protection, St Petersburg, Russia).

\section{Type material}

\section{Holotype}

CHINA - $\widehat{o}$ (abdomen and aedeagus lost during dissection); "CHINA, W Yunnan, SSW Liuku, $25^{\circ} 41^{\prime} 34^{\prime \prime} \mathrm{N} 98^{\circ} 47^{\prime 2} 29^{\prime \prime} \mathrm{E} 2950$ m, traps, 22.v.2006 Belousov \& Kabak"; ZIN.

\section{Description}

MeAsurements. Holotype, total body length $4.4 \mathrm{~mm}$; head $0.8 \mathrm{~mm}$ long, across eyes $0.88 \mathrm{~mm}$ broad, pronotum $1.2 \mathrm{~mm}$ long, maximum width $0.85 \mathrm{~mm}$, minimum width $0.35 \mathrm{~mm}$, elytra $2.4 \mathrm{~mm}$ long, $1.5 \mathrm{~mm}$ combined wide.

Dorsum and venter uniformly brown, pronotum inconspicuously paler. Mouthparts, antennae, palps and legs yellowish-brown. Head ovoid with moderately large, ovoid compound eyes, which are not protruding beyond head outline laterally. Head rounded in broad arc posterior to eyes. Clypeus broadly emarginate anterodorsally. Head dorsal punctures minute and inconspicuous. Head dorsal setae inconspicuous, sparse. Antennae extending towards base of pronotum. Antennomere three about $1.25 \times$ as long as antennomere two, antennomeres 9-10 semispherical, transverse (Fig. 3D). Terminal antennomere triangular with pointed apex, nearly twice as long as penultimate antennomere. Terminal maxillary palpomere slightly securiform. Pronotum with broad and medially deeply notched postmedian lateral constriction. Front margin of anterior lobe very broadly rounded, dorsally without anterior rim. Anterior lobe slightly convex in lateral view (Fig. 3C). Lateral constriction continues onto disc in lateral view, shallow (Fig. 3C). Lateral pronotal fovea moderately rather narrow at lower external margin of pronotum, not or almost not widens upwards towards pronotal disc in lateral view, external margins protruding into a pair of obtuse, long setose and narrowly separated denticles (in lateral view). Cavity in lateral wall of pronotum between lateral denticles moderately broad, elliptical. In dorsal view, lateral pronotal fovea broad, anterior and posterior pair of denticles appear obtusely angulate, glabrous, partially concealed dorsally by setae from adjoining portion of lateral constriction (Fig. 3B). Pronotal punctures minute on disc; lateral constriction in anterior part dorsally with acute, short, median longitudinal carina (only visible by sufficient light!) that is projecting nearly to midlength of anterior lobe of pronotum, and densely, coarsely, irregularly shaped punctured. Dorsal pronotal setae inconspicuous, moderately long. Scutellar shield minute, triangular. Elytra dorsally elongate elliptical, flattened in lateral view, slightly widened laterally prior to middle, shoulders obsolete (apterous species). Elytral apices rounded. Elytral punctures small but rather dense, not becoming conspicuously smaller or sparser towards apices. Elytral 


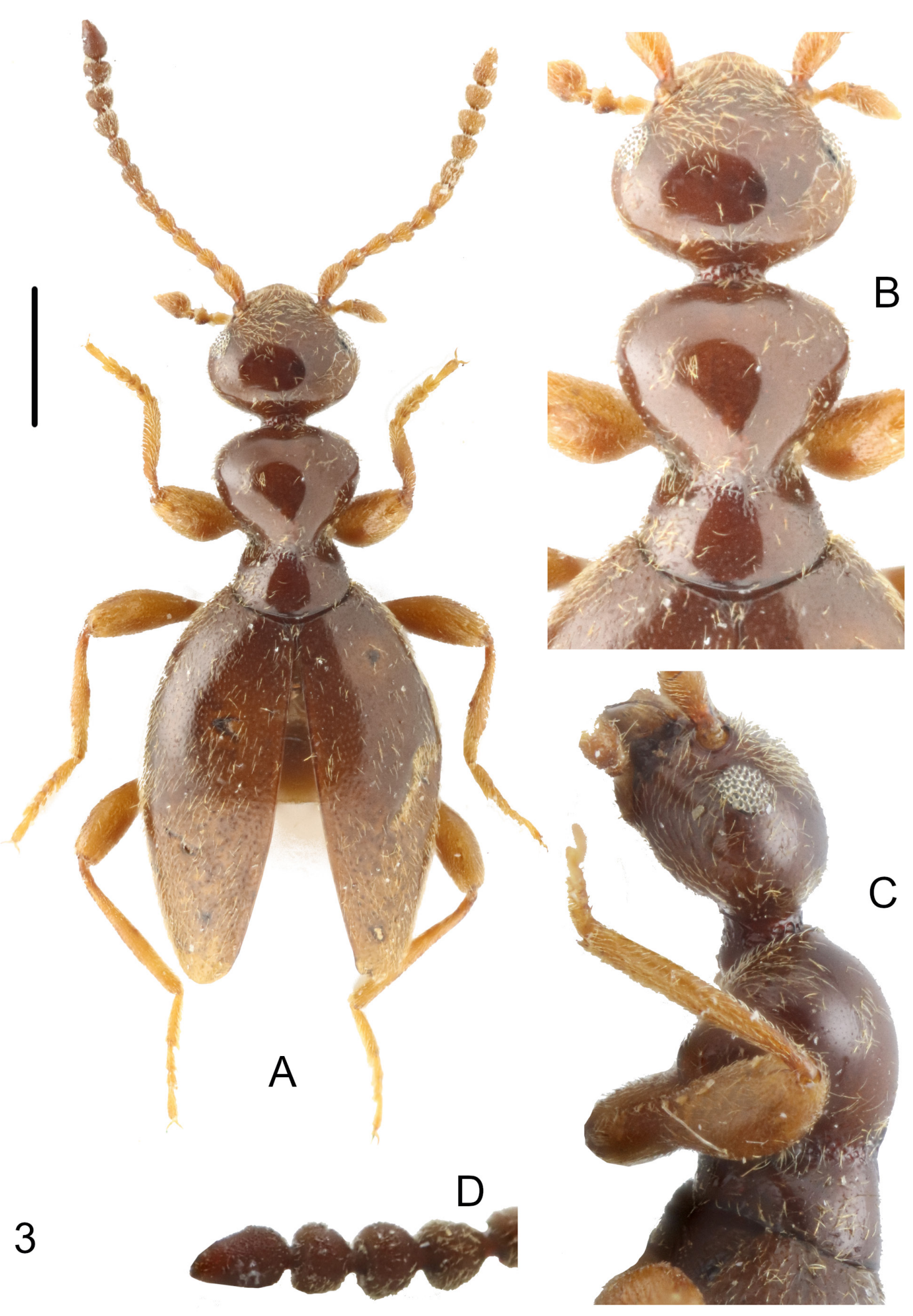

Fig. 3. Macrotomoderus belousovi sp. nov., holotype, ô (ZIN). A. Habitus, dorsal view. B. Forebody, dorsal view. C. Ditto, lateral view. D. Antennomeres 8-11 of the left antenna. Scale bar: A=1 mm; $\mathrm{B}-\mathrm{D}=$ not to scale. 
setae long and sparse, suberect. Male tergite and morphological sternite VII broadly rounded at posterior margin. Aedeagus lost during dissection.

\title{
Sexual dimorphism
}

Female is unknown.

\section{Ecology}

Collected in pitfall traps at $2950 \mathrm{~m}$ elevation.

\section{Distribution}

Known only from the western part of Yunnan Province, SW China.

\author{
Macrotomoderus bicrispus sp. nov. \\ urn:lsid:zoobank.org:act:0746DE3F-1EAB-483C-AC83-7EE4D3505DBA
}

Figs 4-5

\section{Differential diagnosis}

This species readily differs from all congeners primarily due to the presence of the paired bunches of the curl-like golden setae on the median part of the anterior margin of pronotum and in the peculiar shape of the anterior pronotal projection. Most similar to Macrotomoderus chingpo Telnov, 2018 (China: Yunnan) that also possesses somewhat similar, D-like curved median setae at anterior margin of pronotum. However, head is comparatively wider in M. bicrispus sp. nov., the shape of the aedeagus is different, the lateral constriction of the pronotum is broader and deeper (in dorsal view), and the elytra are comparatively slenderer, more elongate in the new species.

\section{Etymology}

Named from the Latin 'bi' ('two') + 'crispum' ('curled') to point on paired bunches of curl-like setae on anterior margin of pronotum.

\section{Type material}

\section{Holotype}

CHINA - ${ }^{\top}$; “CHINA, Yunnan, SW of Guoditang, $6.4 \mathrm{~km}$ ENE of Weixi City $27^{\circ} 12^{\prime} 38^{\prime \prime} \mathrm{N} 99^{\circ} 21^{\prime 2} 22^{\prime \prime} \mathrm{E}$, 3225 m, 29.v.2016 Kabak \& Davidian leg."; ZIN.

\section{Description}

MEAsurements. Holotype, total body length $4.6 \mathrm{~mm}$; head $0.95 \mathrm{~mm}$ long, across eyes $0.95 \mathrm{~mm}$ broad, pronotum $1.25 \mathrm{~mm}$ long, maximum width $0.95 \mathrm{~mm}$, minimum width $0.35 \mathrm{~mm}$, elytra $2.4 \mathrm{~mm}$ long, $1.7 \mathrm{~mm}$ combined wide.

Dorsum and venter uniformly brown. Mouthparts, antennae, palps and legs yellowish-brown. Head ovoid with moderately large, ovoid compound eyes, which laterally are slightly protruding beyond head outline. Head rounded in broad arc posterior to eyes, head base shortly subtruncate medially. Occiput slightly declivous posterodorsally. Head dorsal punctures minute and inconspicuous. Head dorsal setae inconspicuous, sparse. Antennae extending towards base of pronotum. Antennomere three about $1.2 \times$ as long as antennomere two, antennomeres 7-10 transverse, of them 9-10 strongly transverse. Terminal antennomere triangular with rounded apex, $2-2.2 \times$ as long as penultimate antennomere. Terminal maxillary palpomere securiform. Pronotum broadly hourglass-shaped with anterior lobe strongly wider than posterior, about same width as head across eyes. Postmedian lateral constriction broad and medially deeply notched. Front margin of anterior lobe very broadly rounded, near subtruncate, dorsally without 

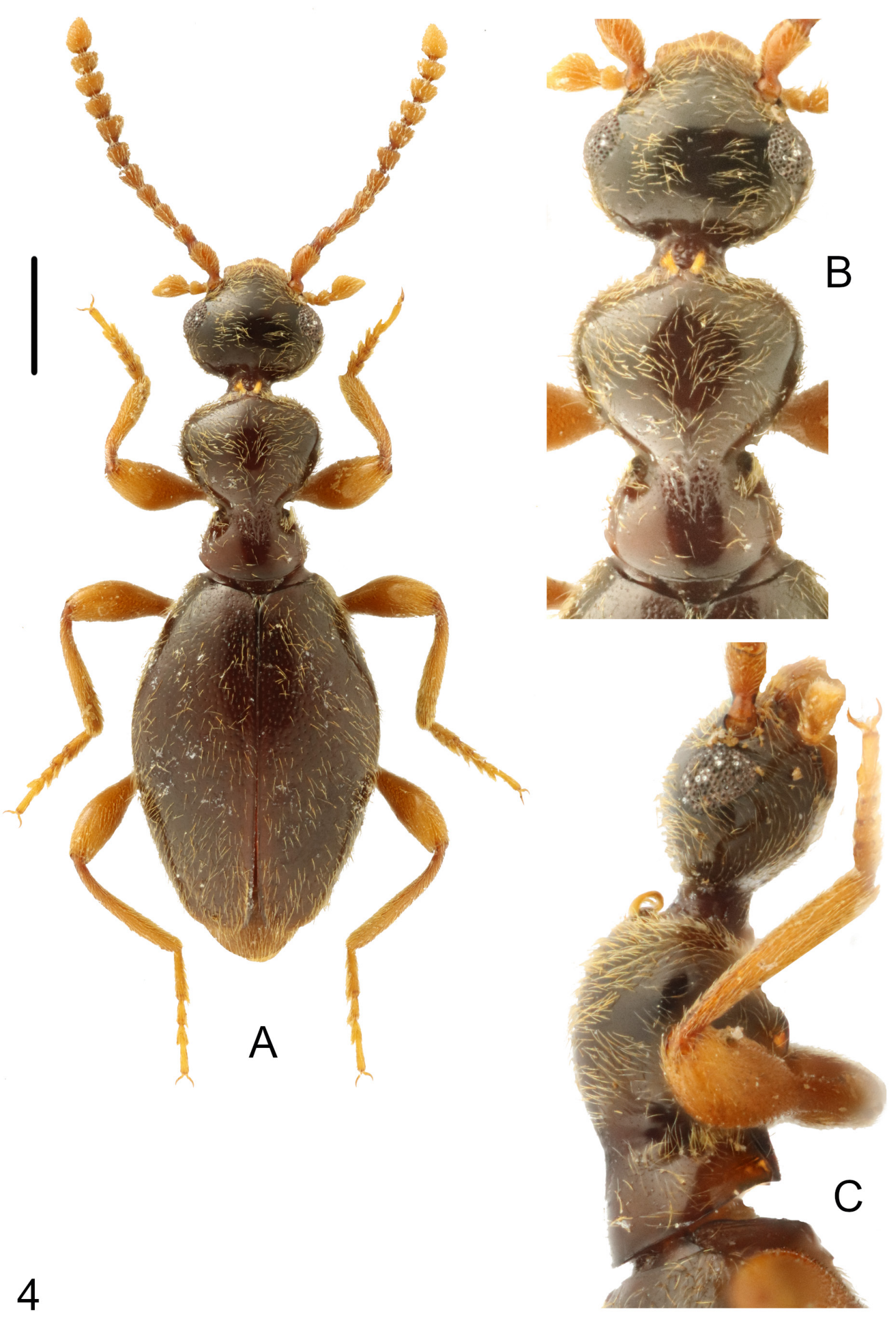

Fig. 4. Macrotomoderus bicrispus sp. nov., holotype, §̊ (ZIN). A. Habitus, dorsal view. B. Forebody, dorsal view. C. Ditto, lateral view. Scale bar: $A=1 \mathrm{~mm}$; $B-C=$ not to scale. 


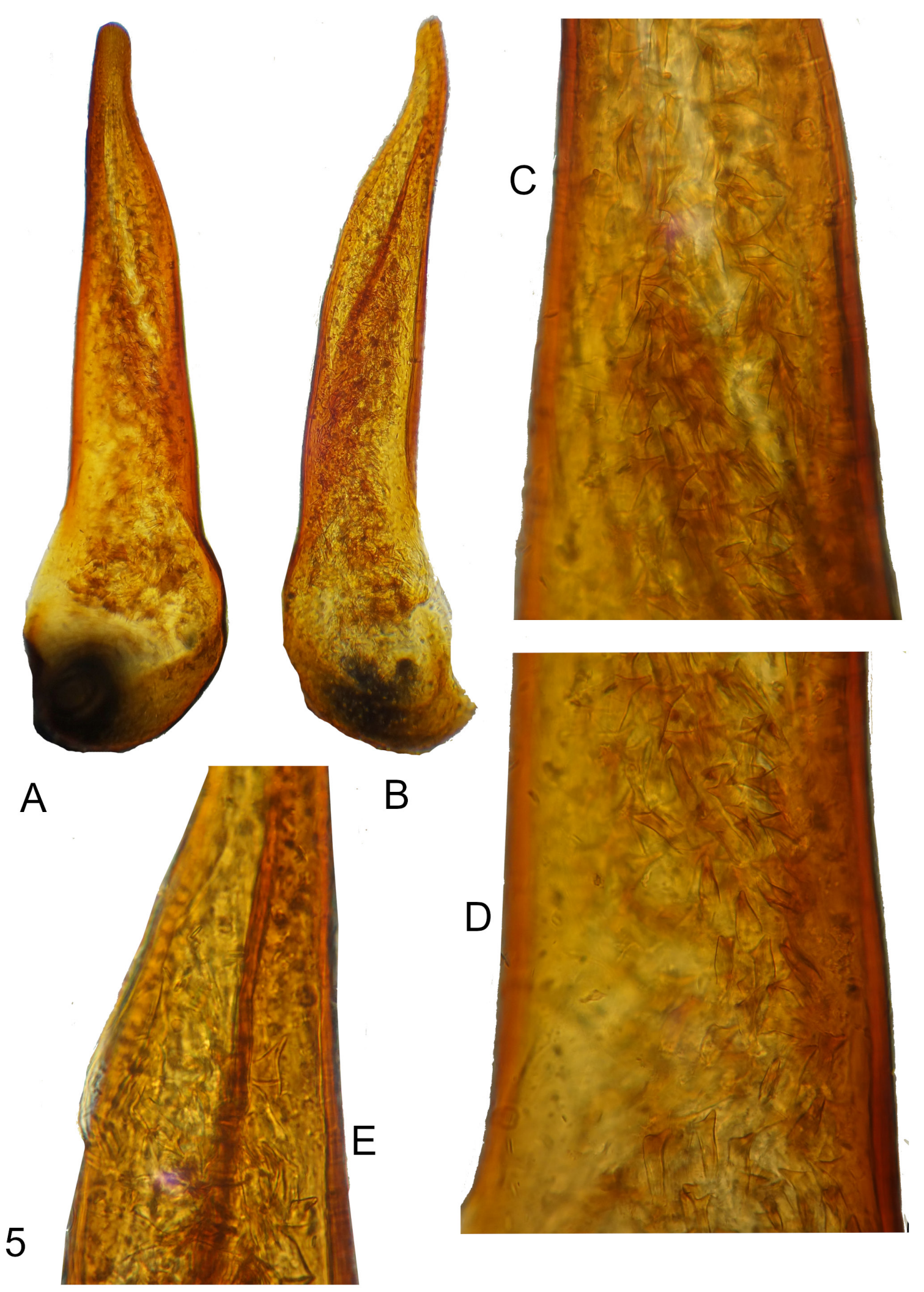

Fig. 5. Macrotomoderus bicrispus sp. nov., holotype, $\widehat{\jmath}(\mathrm{ZIN})$, aedeagus. A-B. General view, different positions. C. Gonopore armature in median portion of aedeagus. D. Ditto, basal portion of apicale. E. Ditto, apical portion, different position. Not to scale. 
anterior rim. Front margin of anterior lobe with two shallow impressions and very median part of front margin slightly projecting anteriad between these two impressions; this projection on both sides of its base is provided with a paired bunch of golden, long and strongly P-like curved setae touching neck and head base (Fig. 4B-C). Each of two bunches raises from one large pore. Anterior lobe convex in lateral view (Fig. 4C). Lateral constriction continues onto disc in lateral view, shallow (Fig. 4C). Lateral pronotal fovea moderately broad at lower external margin of pronotum, widens upwards towards pronotal disc in lateral view, external margins protruding into a pair of obtuse, short setose, moderately widely separated denticles (in lateral view). In lateral view anterior denticle is strongly obtuse, with few golden setae at base, posterior - subacute, glabrous. Cavity in lateral wall of pronotum between lateral denticles is large. In dorsal view, lateral pronotal fovea narrow, anterior and posterior pair of denticles appear obtusely angulate, glabrous (Fig. 4B). Posterior portion of pronotal fovea long and dense setose in dorsal view (Fig. 4B). Pronotal punctures minute on disc; lateral constriction dorsally with dense, irregularly shaped punctures, largest of which positioned longitudinally along midline. Dorsal pronotal setae inconspicuous, moderately long except dense and long setose area beyond to posterior pair of denticles. Scutellar shield minute, triangular. Elytra dorsally elongate elliptical, flattened in lateral view, widened laterally around midlength, lateral margins evenly broadly rounded, shoulders obsolete (apterous species). Elytral punctures rather small, moderately dense, becoming smaller and sparser towards apices. Elytral setae long and sparse, suberect. Male tergite and morphological sternite VII broadly rounded at posterior margin. Aedeagus as in Fig. 5, robust and large, most of apicale and median portion of basale filled with conspicuous, large and dense, irregularly shaped spine-like gonopore armature.

\section{Sexual dimorphism}

Female is unknown.

\section{Ecology}

Collected at 3225 m elevation.

\section{Distribution}

Known only from Hengduan Mountains, northern part of Yunnan Province, SW China.

$$
\begin{gathered}
\text { Macrotomoderus boops sp. nov. } \\
\text { urn:1sid:zoobank.org:act:417E7988-84CC-4F48-B177-778AB3339ACA }
\end{gathered}
$$

Figs 6-7

\section{Differential diagnosis}

This species falls in a group of species from continental China with pronotum wider than head across eyes. Among them, the males of M. mirabilis Telnov, 2018 and M. monstrificabilis Telnov, 2018 both have distinct triangular median projection at the head base (not present in M. boops sp. nov.), while the head base in the male M. monstratus Telnov, 2018 is slightly medially impressed (truncate in M. boops sp. nov.), the front margin of the anterior pronotal lobe in male with pointed, triangular mesal projection in $M$. hengduan sp. nov. (see description below) and M. monstratus (the anterior pronotal projection not present in M. boops sp. nov.). Macrotomoderus boops sp. nov. is also conspicuous due to its nonobsolete shoulders and in antennal asymmetry (in males only?).

\section{Etymology}

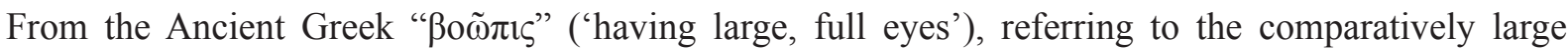
compound eyes of this species. 


\section{Type material}

Holotype

CHINA • O'; "CHINA, Sichuan Prov., Emeishan Mt., 9.VI. 2014, Leidongping env., 2410 m, 29³2'49"N $103^{\circ} 20^{\prime} 22^{\prime \prime} \mathrm{E}$, // sift \#9, bamboo groove, debris under rock abyss, near steep track to temples below, J. Hájek \& J. Růžička leg.”; NMP.

\section{Description}

MeAsurements. Holotype, total body length $3.76 \mathrm{~mm}$; head $0.75 \mathrm{~mm}$ long, across eyes $0.8 \mathrm{~mm}$ broad, pronotum $1 \mathrm{~mm}$ long, maximum width $0.9 \mathrm{~mm}$, minimum width $0.23 \mathrm{~mm}$, elytra $2 \mathrm{~mm}$ long, $1.1 \mathrm{~mm}$ combined wide.

Dorsum and venter uniformly pale brown, head slightly darker. Mouthparts, antennae, palps and legs yellowish-brown. Head subtriangular with large, ovoid compound eyes, which are protruding beyond head outline laterally. Tempora slightly converging towards head base, distinctly shorter than eye length. Temporal angles broadly rounded, head base truncate. Head dorsal punctures minute and inconspicuous. Head dorsal setae inconspicuous and sparse, denser on head base. Antennae long, extending towards anterior third of elytra. Antennomere three about $1.3 \times$ as long as antennomere two, in male somewhat slightly bulged distally at one edge, insertion of male antennomere four is therefore not exactly medial and male antennomere four positioned slightly asymmetrical with regard to antennal axis. Male antennomere four shortened and near spherical, shorter than antennomere three. Antennomeres 9-10 slightly transverse. Terminal antennomere elongate triangular with pointed apex, about twice as long as penultimate antennomere. Terminal maxillary palpomere slightly securiform. Pronotum broadly hourglass-shaped with anterior lobe significantly wider than posterior and wider than head across eyes. Postmedian lateral constriction broad and medially broadly and deeply notched. Front margin of anterior lobe very broadly rounded, slightly impressed mesally, dorsally without anterior rim. Anterior lobe large and broad, inverted triangular; posterior lobe about one third length of anterior lobe, much narrower. Front margin of anterior lobe at place of mesal impression with a group of golden, curved, very dense, anterolaterally directed setae touching head base (Fig. 6B-C). Anterior lobe convex in lateral view (Fig. 6C). Lateral constriction continues onto disc in lateral view, shallow (Fig. 6C). Lateral pronotal fovea broad at lower external margin of pronotum, widens upwards towards pronotal disc in lateral view, external margins protruding into a pair of strongly obtuse (in lateral view), widely separated denticles (in lateral view). Cavity in lateral wall of pronotum between lateral denticles large, elliptical. In dorsal view, lateral pronotal fovea broad and deep, anterior and posterior pair of denticles appear rectangular to obtuse angulate, fully concealed by dense appressed setae of adjacent portions of fovea (Fig. 6B). Pronotal punctures minute on disc; lateral constriction dorsally with inconspicuous, median longitudinal carina and few sparse, moderately large punctures around it (Fig. 6B). Dorsal pronotal setae inconspicuous, moderately long. Scutellar shield minute, rounded apically. Elytra dorsally elliptical, slightly convex in lateral view, widened laterally around midlength, lateral margins evenly broadly rounded. Shoulders rounded but prominent (metathoracic wings present). Elytral punctures moderately large, rather dense, becoming slightly smaller and sparser towards apices. Elytral setae long and sparse, suberect. Male tergite and morphological sternite VII broadly rounded at posterior margin. Aedeagus as in Fig. 7, large and rather slender, apicale and median portion of basale filled with elongate, dense spineshaped gonopore armature. Armature spines closely attached to one another in basal half of aedeagus, arranged into 'garland', becoming irregularly directed in apical half of aedeagus. Armature spines significantly smaller at apex of aedeagus compared to those in median and basal parts of it.

\section{Sexual dimorphism}

Female is unknown. 


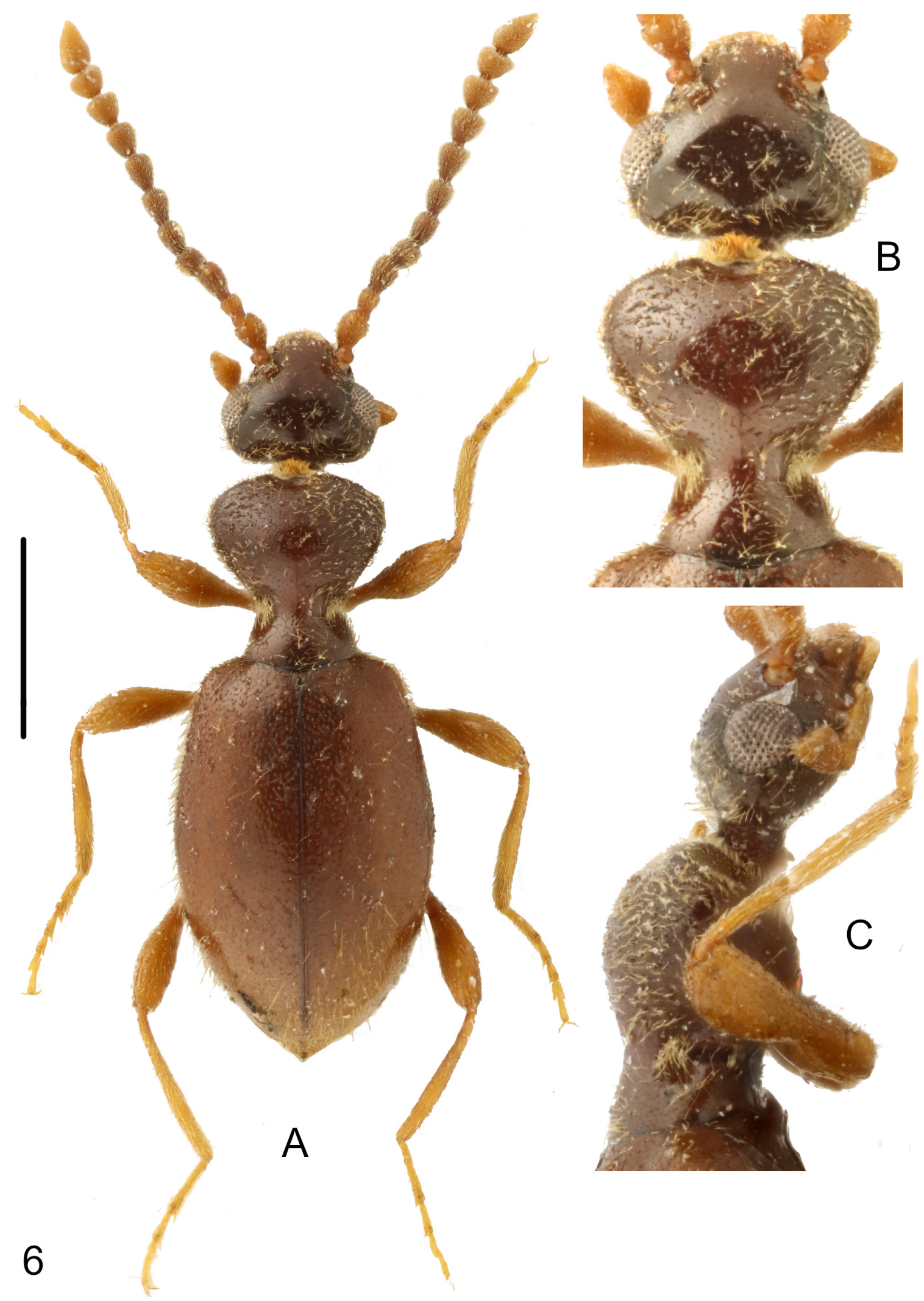

Fig. 6. Macrotomoderus boops sp. nov., holotype, $\widehat{\overbrace{}}$ (NMP). A. Habitus, dorsal view. B. Forebody, dorsal view. C. Ditto, lateral view. Scale bar: $A=1 \mathrm{~mm} ; \mathrm{B}-\mathrm{C}=$ not to scale. 


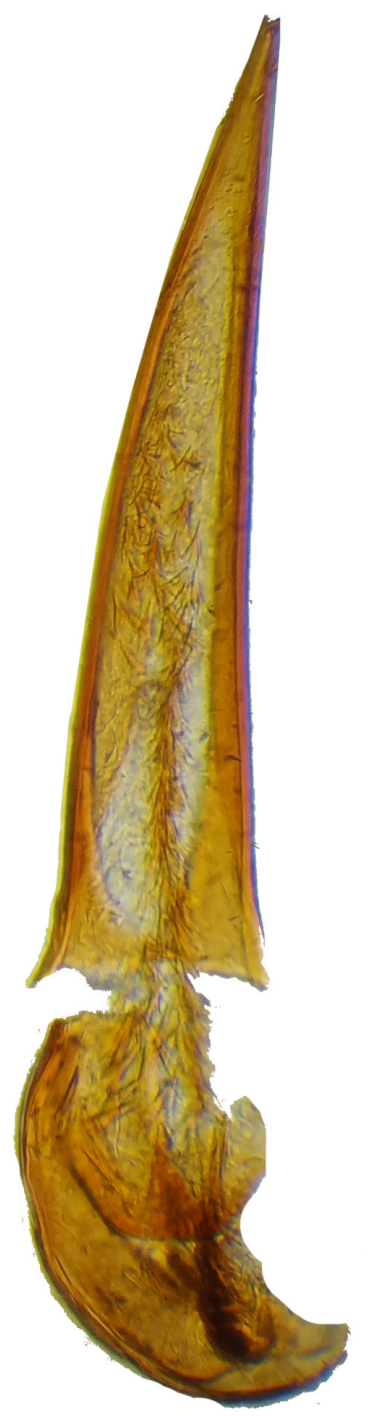

A

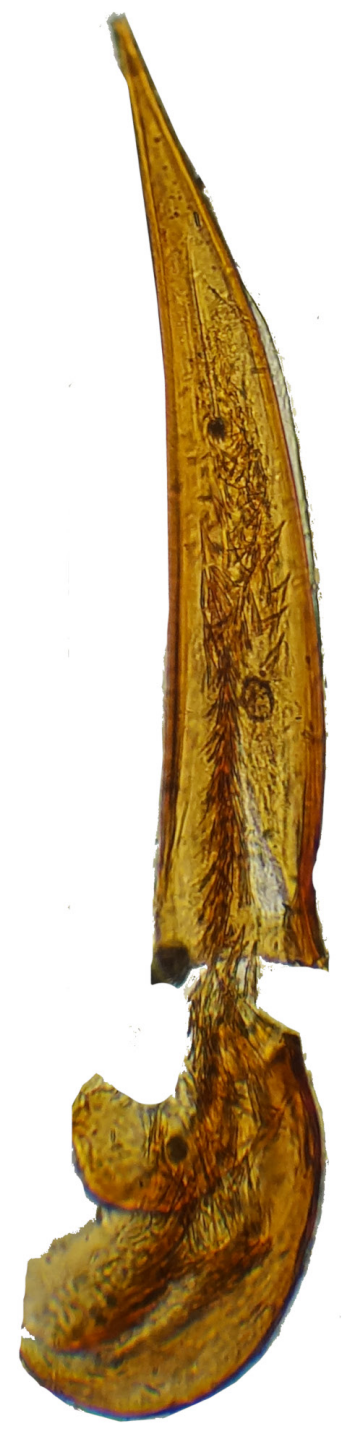

B

\section{7}
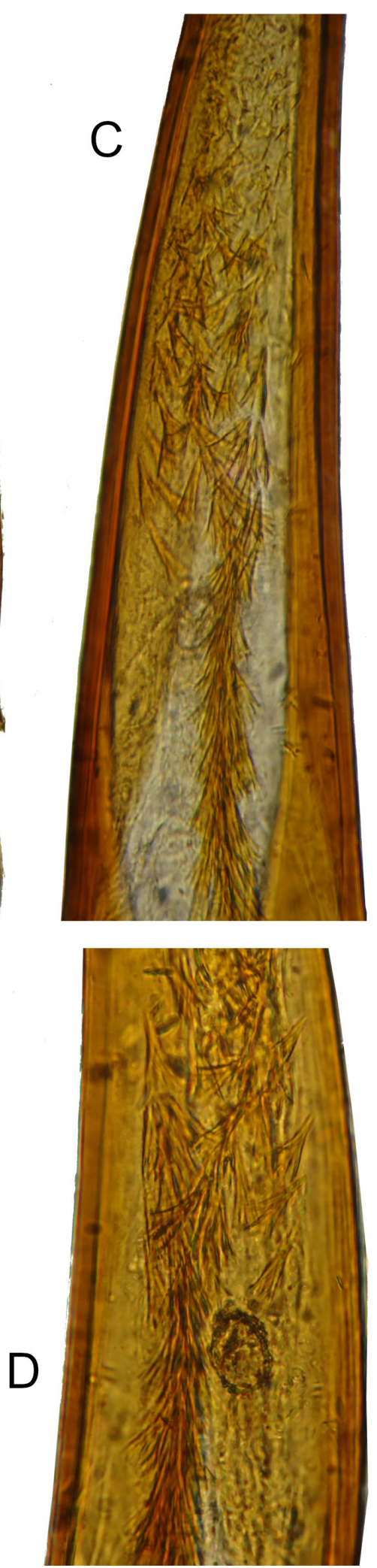

Fig. 7. Macrotomoderus boops sp. nov., holotype, $\widehat{\jmath}$ (NMP), aedeagus. A-B. General view, different positions. C. Gonopore armature in median portion of aedeagus. D. Ditto, different position. Not to scale. 


\section{Ecology}

Collected by sifting leaf litter in a bamboo grove at $2410 \mathrm{~m}$ elevation.

\section{Distribution}

Known only from Mount Emei in Sichuan Province, central China.

Macrotomoderus bordonii sp. nov.

urn:lsid:zoobank.org:act:AB3A3E8C-1CEA-4C77-A8AF-BF99B6A42383

Figs 8-9

\section{Differential diagnosis}

This species appears similar to Indo-Chinese congeners with anteriorly excavate and medially longitudinally carinate pronotum, like Macrotomoderus humerifer (Uhmann, 1994) (N Vietnam), M. perforatus Telnov, 2019 (China: Yunnan), M. transitans sp. nov. (China: Yunnan) (see description below), and M. yunnanus (Telnov, 1998) (China: Yunnan). The new species has the obsolete humeri (the humeri angulate in $M$. humerifer, this species is macropterous) and the aedeagus is significantly slenderer than that of $M$. perforatus and $M$. transitans sp. nov. (not conspicuously bulb-shaped widened in basal half) and is significantly shorter than the slender aedeagus of M. yunnanus.

\section{Etymology}

Patronymic. Named in honour of Arnaldo Bordoni (Florence, Italy), an outstanding staphylinid beetles specialist and my good friend.

\section{Type material}

\section{Holotype}

CHINA • $0^{\lambda}$; “CHINA, YUNNAN Prov. 5.9 km W Tongbiguan, 24³6.78’N, 97³5.48’E, J. Hájek \& J. J. Růžička leg. // (Ch12) 25.vi. 2016; 1290 m, sift \#08, secondary broad-leaved forest, valley near stream”; NMP.

\section{Description}

Measurements. Holotype, total body length $3.5 \mathrm{~mm}$; head $0.7 \mathrm{~mm}$ long, across eyes $0.7 \mathrm{~mm}$ broad, pronotum $0.8 \mathrm{~mm}$ long, maximum width $0.6 \mathrm{~mm}$, minimum width $0.3 \mathrm{~mm}$, elytra $2 \mathrm{~mm}$ long, $1.25 \mathrm{~mm}$ combined wide.

Dorsum and venter uniformly brown, pronotum dark reddish brown. Mouthparts, antennae, palps and legs yellowish-brown. Head subtriangular with moderately large, ovoid compound eyes, which are protruding beyond head outline laterally. Tempora slightly converging towards head base, as long as dorsal eye length. Temporal angles broadly rounded. Head base subtruncate. Head dorsal punctures minute and sparse. Intervening spaces glossy and glabrous, much wider than punctures. Head dorsal setae long, sparse. Antennae extending towards base of pronotum. Antennomere slightly longer than antennomere two, antennomeres 4-6 shortened and thickened, ovoid, antennomeres 7-10 transverse, of them 8-10 strongly transverse. Terminal antennomere broadly triangular with rounded apex, twice as long as penultimate antennomere. Terminal maxillary palpomere securiform. Pronotum with short, medially deeply and broadly notched postmedian lateral constriction. Front margin of anterior lobe very broadly rounded (subtruncate), in male moderately deeply and broadly impressed mesally opposite median part of head base; anterolateral margins of this impression raised in dorsal aspect, produced into subacute denticles (Fig. 8B-C). Anterior edge of pronotum in male in front of anterior impression with thin, rather low median wall that is provided with several stout, in part anteriad-pointed, erect setae (Fig. 8C). Pronotum dorsally without anterior rim. Anterior and posterior lobe convex in lateral view 


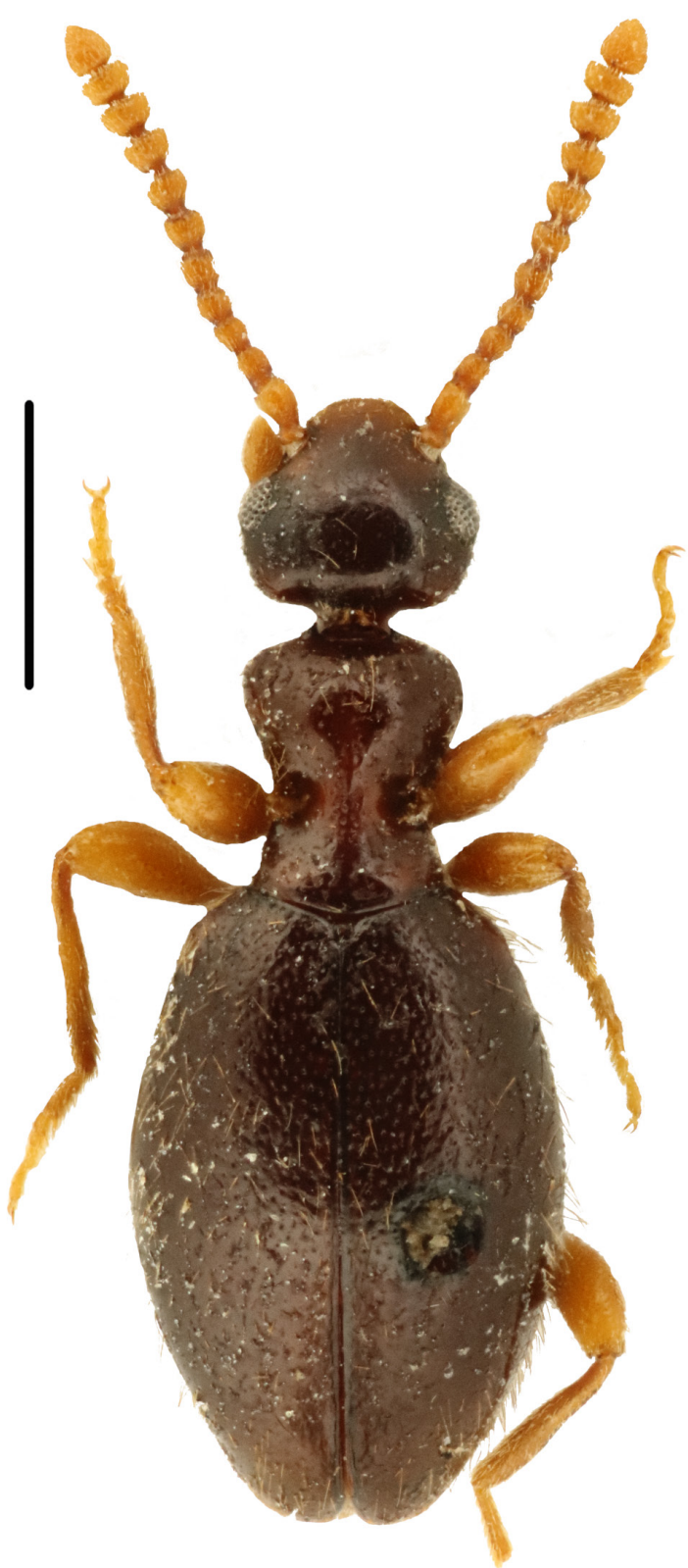

A

\section{8}

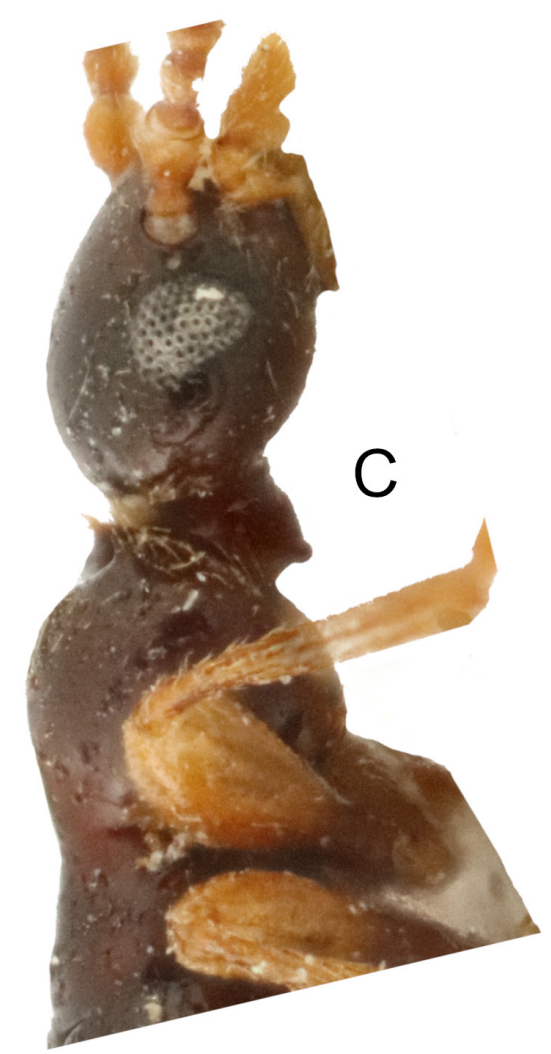

Fig. 8. Macrotomoderus bordonii sp. nov., holotype, $\widehat{\jmath}$ (NMP). A. Habitus, dorsal view. B. Forebody, dorsal view. C. Ditto, lateral view. Scale bar: A $=1 \mathrm{~mm}$; $\mathrm{B}-\mathrm{C}=$ not to scale. 


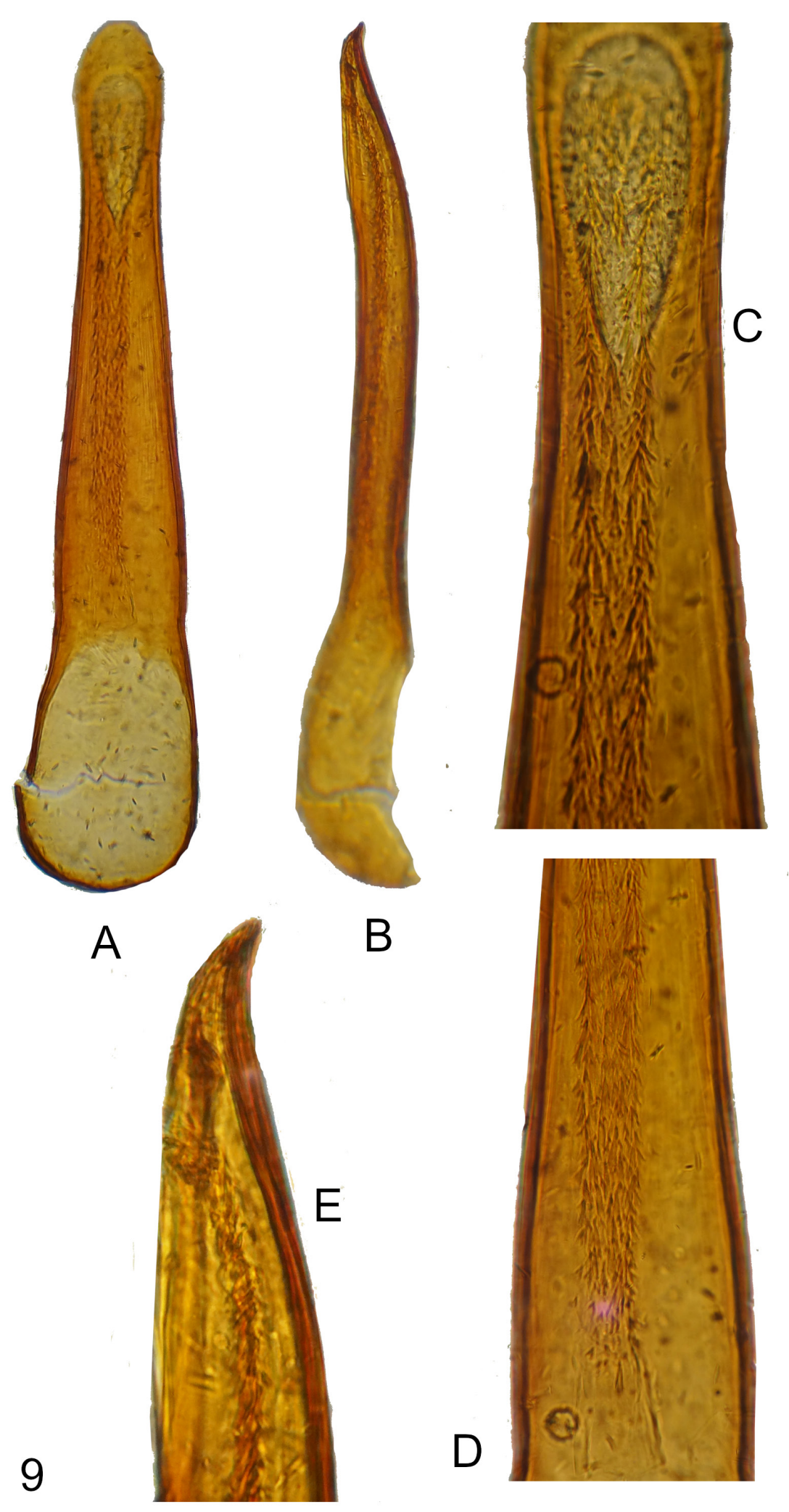

Fig. 9. Macrotomoderus bordonii sp. nov., holotype, $\widehat{\curlywedge}$ (NMP), aedeagus. A-B. General view, different positions. C. Gonopore armature in apical and median portions of aedeagus. D. Ditto, basal portion of apicale. E. Apical portion. Not to scale. 
(Fig. 8C). Lateral constriction continues onto disc in lateral view, shallow (Fig. 8C). Lateral pronotal fovea moderately broad at lower external margin of pronotum, widens upwards towards pronotal disc in lateral view, external margins protruding into a pair of obtuse (in lateral view), moderately widely separated denticles (in lateral view). Both denticles dorsolaterally with a brush of dense, short, golden setae. In dorsal view, lateral pronotal fovea deep and broad, anterior and posterior pair of denticles appear obtusely angulate, each with a brush of short, dense setae (Fig. 8B). Anterior lobe and lateral constriction dorsally medially longitudinally carinate. Pronotal punctures minute on disc; lateral constriction dorsally dense and coarse, irregularly punctured. Dorsal pronotal setae as those on head. Scutellar shield very small, apically pointed. Elytra dorsally elongate elliptical, flattened in lateral view, slightly widened laterally around midlength and broadly rounded at lateral margins, shoulders obsolete (apterous species). Elytral punctures moderately large and deep, moderately dense on basal half of elytra, becoming smaller and shallower towards apices. Intervening spaces on basal half of elytra about as large as punctures. Elytral setae long and rather dense, suberect. Male tergite and morphological sternite VII broadly rounded at posterior margin. Aedeagus as in Fig. 9, elongate, narrow and slender, rounded apically, apicale with delicate, long and spine-shaped gonopore armature that is arranged into 'garland' with multiple (3-4) rows. Armature spines becoming smaller and more delicate at apex of aedeagus.

\section{Sexual dimorphism}

Female is unknown.

\section{Ecology}

Collected from leaf litter in a secondary broad-leaved forest at $1290 \mathrm{~m}$ elevation.

\section{Distribution}

Known only from western part of Yunnan Province, SW China.

Macrotomoderus chingpo Telnov, 2018

\section{New material}

CHINA • 1 specimen; "CHINA, W Yunnan, SSW Liuku, 2543'35"N 9846"20"E 2860 m, 17.v.2006 Belousov \& Kabak leg.”; DTC 11 specimen; same label data as for preceding; ZIN.

\section{Note}

Previously only known from Diancang and Gaoligong mountains of Yunnan Province, SW China.

Macrotomoderus dali sp. nov. urn:1sid:zoobank.org:act:F4C22B7A-9A8F-4FAE-B190-B28C99E6AB17

Figs 10-11

\section{Differential diagnosis}

This species falls in a group of species from continental China with pronotum wider than head across eyes. Among them, the males of M. mirabilis Telnov, 2018 and M. monstrificabilis Telnov, 2018 have distinct triangular median projection at the head base (not present in $M$. dali sp. nov.). The median, dorsal longitudinal carina of pronotal constriction not present in $M$. dali sp. nov., weakly present in M. boops sp. nov. (see description above), the eyes are comparatively smaller in $M$. dali sp. nov., the head base either only medially subtruncate (broadly subtruncate in M. boops sp. nov.). In M. hengduan sp. nov. (see description below) the shape of the aedeagus is different, the head base is broadly rounded (truncate medially in $M$. dali sp. nov.), the compound eyes are comparatively smaller and not protruding 
from the lateral outline of the head (the eyes are larger and stronger protruding beyond head outline laterally in $M$. dali sp. nov.).

\section{Etymology}

Named after the ancient Dali Kingdom, situated in modern Yunnan Province from 937 until 1382 in the area where this new species occurs.

\section{Type material}

Holotype

CHINA • ^’ "CHINA, Yunnan, W Dali City, SW Yangbi, 1km N Laoheshang Mt, 2620 m, 20.v.2019

Belousov, Davidian \& Kabak leg. // 25³6'33"N 9955'12"E"; ZIN.

\section{Description}

Measurements. Holotype, total body length $4.5 \mathrm{~mm}$; head $0.9 \mathrm{~mm}$ long, across eyes $0.96 \mathrm{~mm}$ broad, pronotum $1.35 \mathrm{~mm}$ long, maximum width $1.05 \mathrm{~mm}$, minimum width $0.4 \mathrm{~mm}$, elytra $2.25 \mathrm{~mm}$ long, $1.5 \mathrm{~mm}$ combined wide.

Dorsum and venter uniformly brown. Mouthparts, antennae, palps and legs yellowish-brown. Head subtriangular with moderately large, ovoid compound eyes, which are protruding beyond head outline laterally. Tempora converging towards head base, about one third shorter of eye length. Temporal angles broadly rounded, head base broadly rounded, occiput declivous posterodorsally. Head dorsal punctures minute and inconspicuous. Head dorsal setae inconspicuous, distinctly denser posterior to eyes than on frons. Antennae long, extending towards anterior third of elytra. Antennomere three about $1.25 \times$ as long as antennomere two, antennomeres 9-10 transverse, of which penultimate antennomere strongly transverse. Terminal antennomere broadly triangular with rounded apex, twice as long as penultimate antennomere. Terminal maxillary palpomere securiform. Pronotum broad, anterior lobe significantly wider than posterior and slightly wider than head across eyes. Postmedian lateral constriction broad and medially deeply notched. Front margin of anterior lobe broadly rounded, truncate medially, dorsally without anterior rim. Anterior lobe large and broad, inverted triangular, almost twice as long as much narrower posterior lobe. Front margin of anterior lobe medially somewhat flattened and with a group of golden, very dense setae; some (central-positioned) setae are significantly longer than other, stronger curved and touching head base (Fig. 10B-C). Anterior lobe slightly convex in lateral view (Fig. 10C). Lateral constriction continues onto disc in lateral view, shallow (Fig. 10C). Lateral pronotal fovea moderately broad at lower external margin of pronotum, widens upwards towards pronotal disc in lateral view, external margins protruding into a pair of strongly obtuse (in lateral view), moderately widely separated denticles (in lateral view). Cavity in lateral wall of pronotum between lateral denticles broad, elliptical. In dorsal view, lateral pronotal fovea broad and deep, anterior and posterior pair of denticles appear acute angulate, partially concealed by dense appressed setae from adjacent portions of fovea (Fig. 10B). Pronotal punctures minute on disc; lateral constriction dorsally with irregularly sized, dense punctures (Fig. 10B). Dorsal pronotal setae rather long and dense. Scutellar shield minute, triangular. Elytra dorsally elongate elliptical, flattened in lateral view, widened laterally around midlength, lateral margins evenly broadly rounded; shoulders obsolete (apterous species). Elytral punctures inconspicuous, sparse, not becoming much smaller and sparser towards apices. Elytral setae long and sparse, suberect. Male tergite and morphological sternite VII broadly rounded at posterior margin. Aedeagus as in Fig. 11, large and robust, with rounded apex and peculiar, double gonopore armature consists of numerous irregularly shaped constituting pieces intermixed with very delicate, foam-like constituting pieces. Large constituting pieces of armature becoming distinctly smaller in apical and basal portions of aedeagus. 


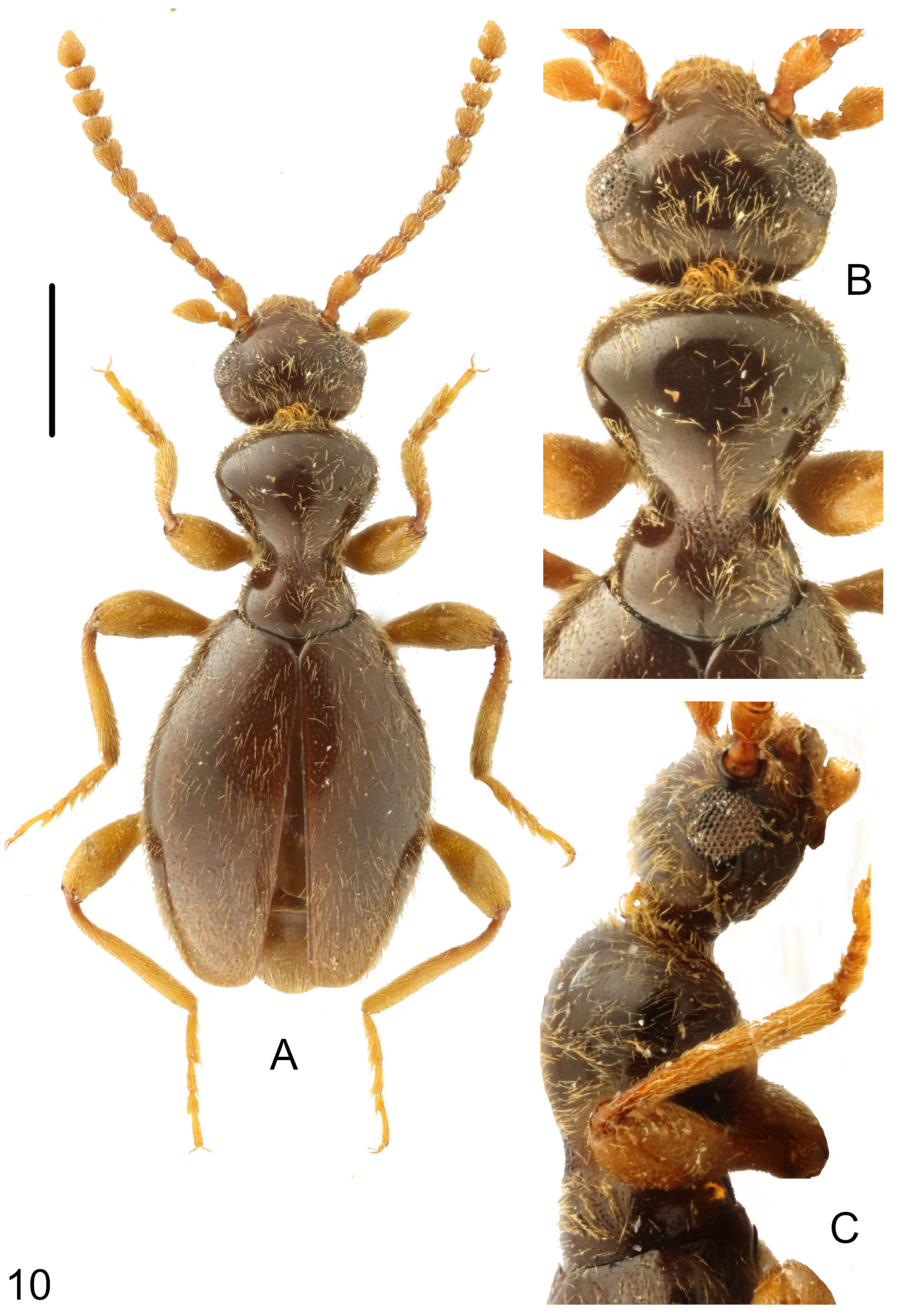

Fig. 10. Macrotomoderus dali sp. nov., holotype, $\widehat{\jmath}(\mathrm{ZIN})$. A. Habitus, dorsal view. B. Forebody, dorsal view. C. Ditto, lateral view. Scale bar: $A=1 \mathrm{~mm} ; \mathrm{B}-\mathrm{C}=$ not to scale. 

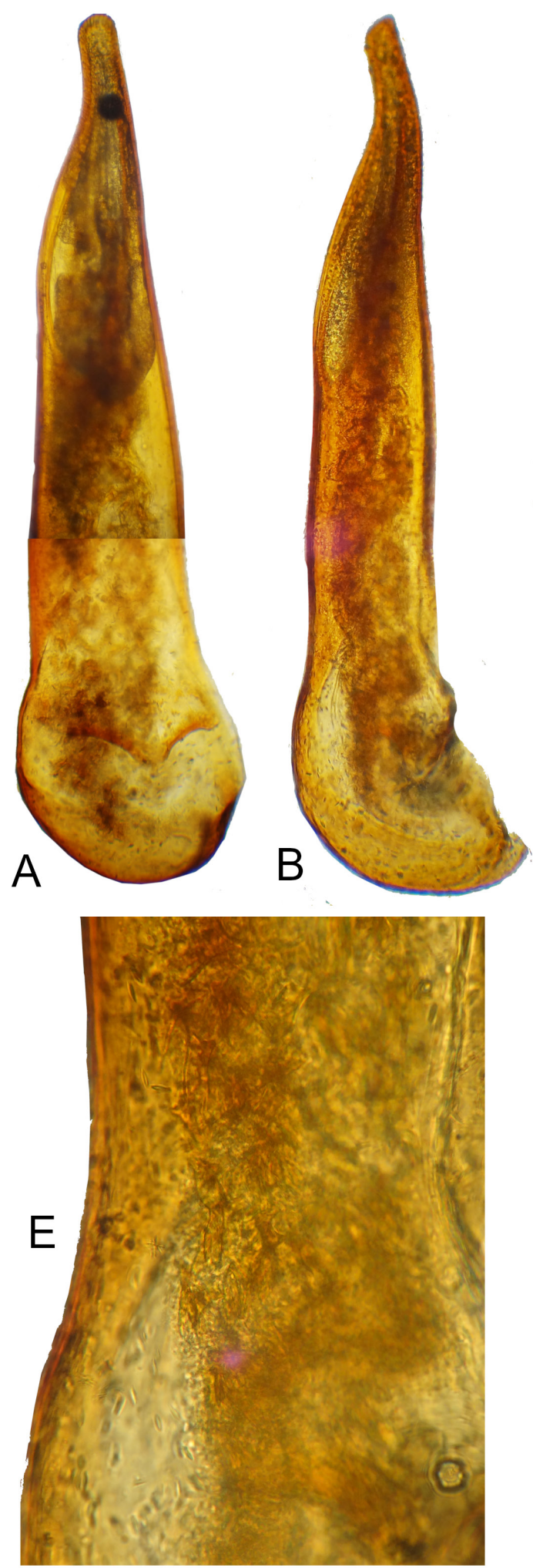

11
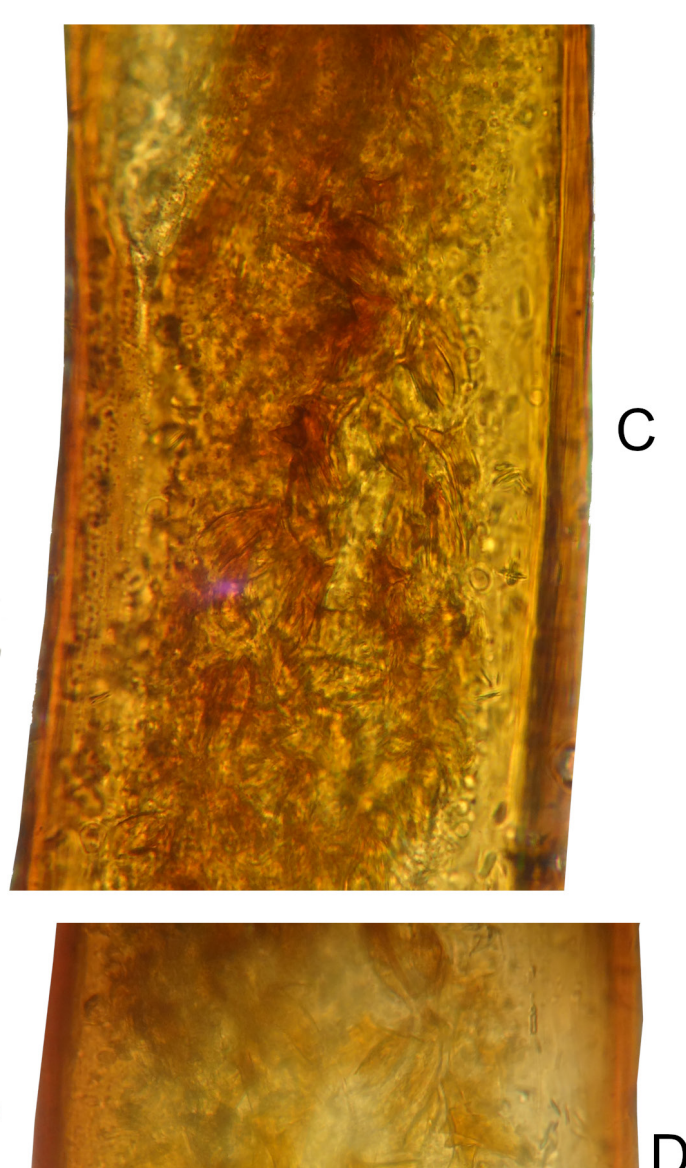

D
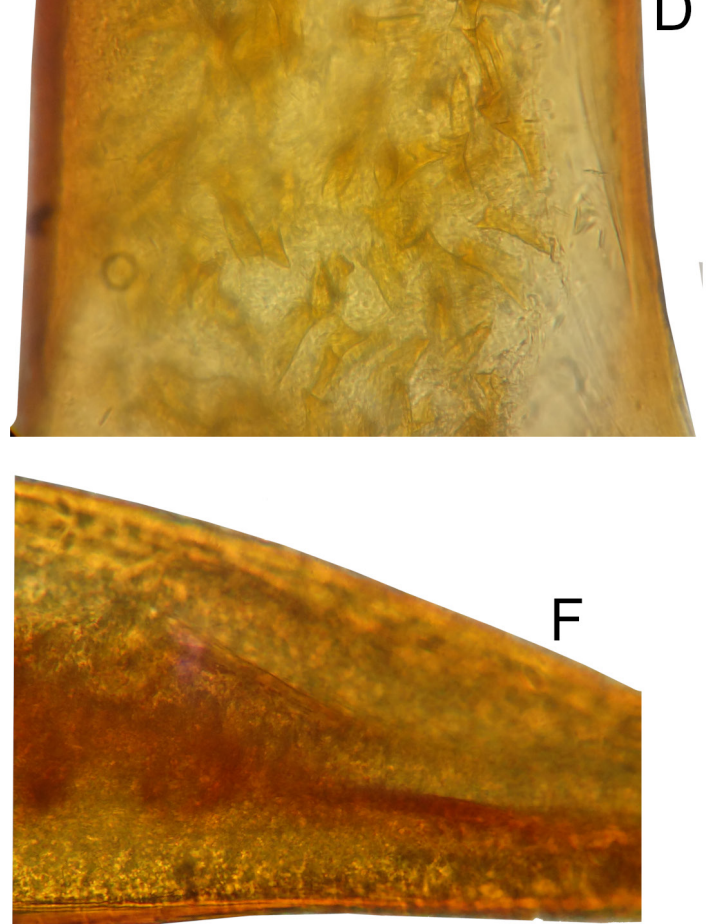

Fig. 11. Macrotomoderus dali sp. nov., holotype, $\widehat{\partial}(\mathrm{ZIN})$, aedeagus. A-B. General view, different positions (A combined from two images). C. Gonopore armature in median portion of aedeagus. D. Ditto, stronger magnification. E. Basal portion of apicale. F. Apical portion. Not to scale. 


\section{Sexual dimorphism}

Female is unknown.

\section{Ecology}

Collected at $2620 \mathrm{~m}$ elevation.

\section{Distribution}

Known only from Yunnan Province, SW China.

Macrotomoderus daxiangling sp. nov. urn:1sid:zoobank.org:act:E2523A73-13E9-405A-BEA2-A37E9DA709ED

Figs $12-13$

\section{Differential diagnosis}

This taxon, that falls in a group of species with the denticles of the lateral pronotal constriction not exposed in dorsal view, is primarily recognizable among its congeners by the shape of the male aedeagus in the combination with the gently sculptured dorsal area of the pronotal constriction (the area is slightly, irregularly, longitudinally rugulose with finely punctured intervening spaces). Also see key to species below.

\section{Etymology}

Toponymic. This species named after the Daxiangling Mountains, a small montane range located at the western rim of the Sichuan Basin, where this species was first collected. Noun in apposition.

\section{Type material}

\section{Holotype}

CHINA • ${ }^{\top}$; "CHINA, Sichuan, Emeishan Cl., ENE Longchizhen Village 2900 m, 4.v.2010 Belousov \& Kabak leg. // 29²4'51"N 103¹1'29"E”; ZIN.

\section{Description}

MeAsuREMENTs. Holotype, total body length $3.75 \mathrm{~mm}$; head $0.75 \mathrm{~mm}$ long, across eyes $0.7 \mathrm{~mm}$ broad, pronotum $0.9 \mathrm{~mm}$ long, maximum width $0.7 \mathrm{~mm}$, minimum width $0.3 \mathrm{~mm}$, elytra $2.1 \mathrm{~mm}$ long, $1.7 \mathrm{~mm}$ combined wide.

Dorsum and venter uniformly brown. Mouthparts, antennae, palps and legs yellow. Head ovoid with small, ovoid compound eyes, which are slightly protruding beyond head outline laterally. Head rounded in broad arc posterior to eyes. Head dorsal punctures minute and inconspicuous. Head dorsal setae inconspicuous, sparse. Antennae comparatively short, extending slightly over lateral constriction of pronotum. Antennomere three about $1.1-1.2 \times$ as long as antennomere two, antennomeres 8-10 transverse, of them 9-10 strongly transverse. Terminal antennomere short, asymmetrically triangular with rounded apex, about $1.2-1.25 \times$ as long as penultimate antennomere. Terminal maxillary palpomere slightly securiform. Pronotum with broad, medially not notched (in dorsal view) postmedian lateral constriction. Front margin of anterior lobe very broadly rounded dorsally, medially subtruncate, with narrow dorsal anterior rim (Fig. 12B). Anterior lobe slightly convex in lateral view (Fig. 12C). Lateral constriction slightly continues onto disc in lateral view, very shallow (Fig. 12C). Lateral pronotal fovea moderately broad at lower external margin of pronotum, widens upwards and deepens towards pronotal disc in lateral view, external margins protruding into small, strongly obtuse (in lateral view), moderately widely separated denticles (in lateral view). Cavity in lateral wall of pronotum between lateral denticles not observed. In dorsal view anterior and posterior pair of lateral constriction deeply notched, no 


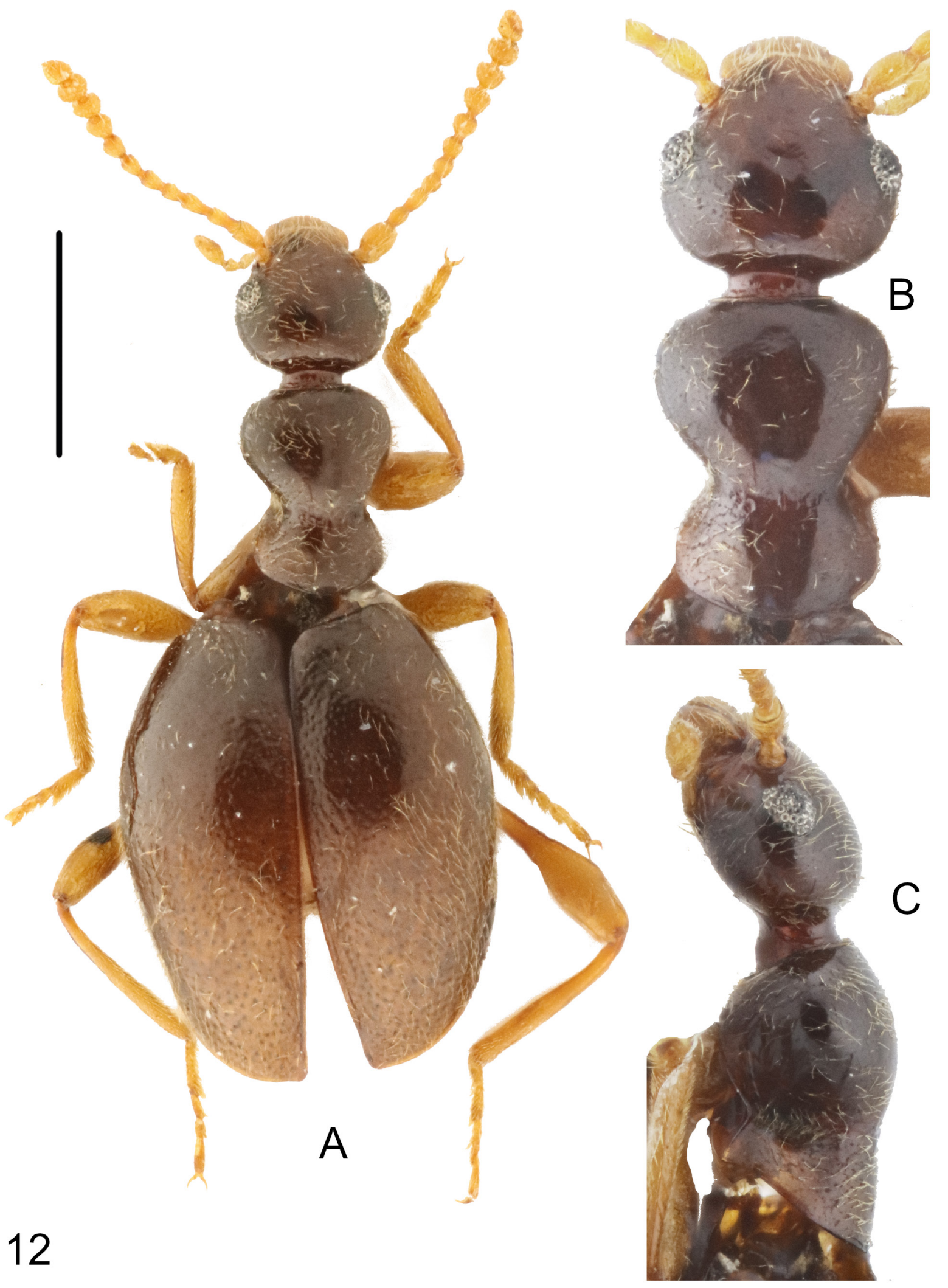

Fig. 12. Macrotomoderus daxiangling sp. nov., holotype, $\widehat{\partial}(\mathrm{ZIN})$. A. Habitus, dorsal view. B. Forebody, dorsal view. C. Ditto, lateral view. Scale bar: $A=1 \mathrm{~mm} ; \mathrm{B}-\mathrm{C}=$ not to scale. 


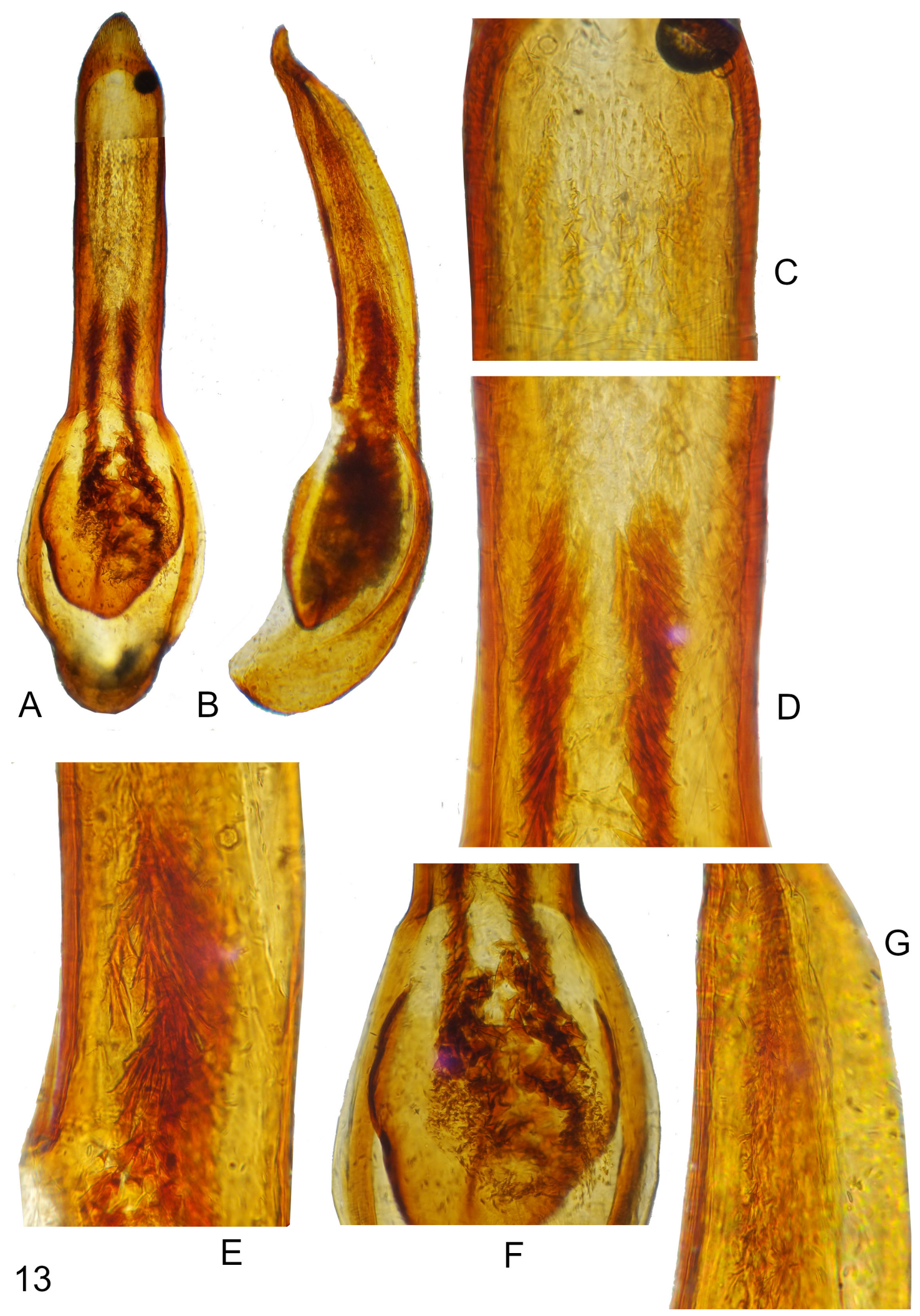

Fig. 13. Macrotomoderus daxiangling sp. nov., holotype, ô (ZIN), aedeagus. A-B. General view, different positions. C. Gonopore armature in apical portion of aedeagus. D. Ditto, median portion. E. Ditto, stronger magnification. F. Basale. G. Apical portion. Not to scale. 
denticles visible (Fig. 12B). Pronotal punctures minute on disc; lateral constriction dorsally with few irregular, glabrous, longitudinal rugules and small, irregularly shaped punctures between them. Dorsal pronotal setae inconspicuous, moderately long. Scutellar shield minute, triangular. Elytra dorsally elliptical, flattened in lateral view, widened laterally around midlength, lateral margins evenly broadly rounded, shoulders obsolete (apterous species). Elytral punctures much stronger and larger than those on dorsal forebody, becoming smaller and less deep in apical third of elytra. Elytral setae moderately long and sparse, suberect. Male tergite and morphological sternite VII broadly rounded at posterior margin. Aedeagus as in Fig. 13, large and robust, with large, bubble-like basale and peculiar gonopore armature. Gonopore armature double in basale, consists of dense, irregularly shaped and positioned, small and very large constituting pieces. Apicale in basal half with two 'garlands' of dense, spineshaped, closed attached to one another gonopore armature. 'Garlands' fuse together in apical half of apicale, constituting pieces of armature becoming distinctly smaller and almost perfectly spine-shaped near apex of aedeagus.

\section{Sexual dimorphism}

Female is unknown.

\section{Ecology}

Collected at 2900 m elevation.

\section{Distribution}

Known only from Daxiangling Mountains in Sichuan Province, central China.

Macrotomoderus femoridens sp. nov. urn:1sid:zoobank.org:act:5042B54D-6150-40D4-BA04-44A170958275

Figs 14-15

\section{Differential diagnosis}

Readily different from all congeners due to the strongly dentate male metafemora, the comparatively small body and the dorsally non-carinate and non-sulcate pronotum.

\section{Etymology}

From the Latin 'femur' + 'dens', to point on the strongly dentate male metafemora.

\section{Type material}

\section{Holotype}

CHINA - ; "CHINA, Guangdong prov. Nanling National Nature Reserve Dadongshan NP, 21.iv.2013 $24^{\circ} 54.62^{\prime} \mathrm{N}, 112^{\circ} 43.11^{\prime} \mathrm{E}, 770 \mathrm{~m}$, J. Hájek \& J. Růžička leg. // Sift \#19 bamboo forest on right slope of valley above small dam, close to former field station, sifting of leaves in deeper, wet depressions and close to large stones"; NMP.

\section{Description}

MeAsurements. Holotype, total body length $2.75 \mathrm{~mm}$; head $0.65 \mathrm{~mm}$ long, across eyes $0.55 \mathrm{~mm}$ broad, pronotum $0.7 \mathrm{~mm}$ long, maximum width $0.52 \mathrm{~mm}$, minimum width $0.22 \mathrm{~mm}$, elytra $1.4 \mathrm{~mm}$ long, $1.1 \mathrm{~mm}$ combined wide.

Dorsum and venter uniformly pale brown, pronotum inconspicuously paler. Mouthparts, antennae, palps and legs yellow. Head ovoid with moderately large, ovoid compound eyes, which are not protruding beyond head outline laterally. Head rounded in broad arc posterior to eyes. Head dorsal punctures minute 


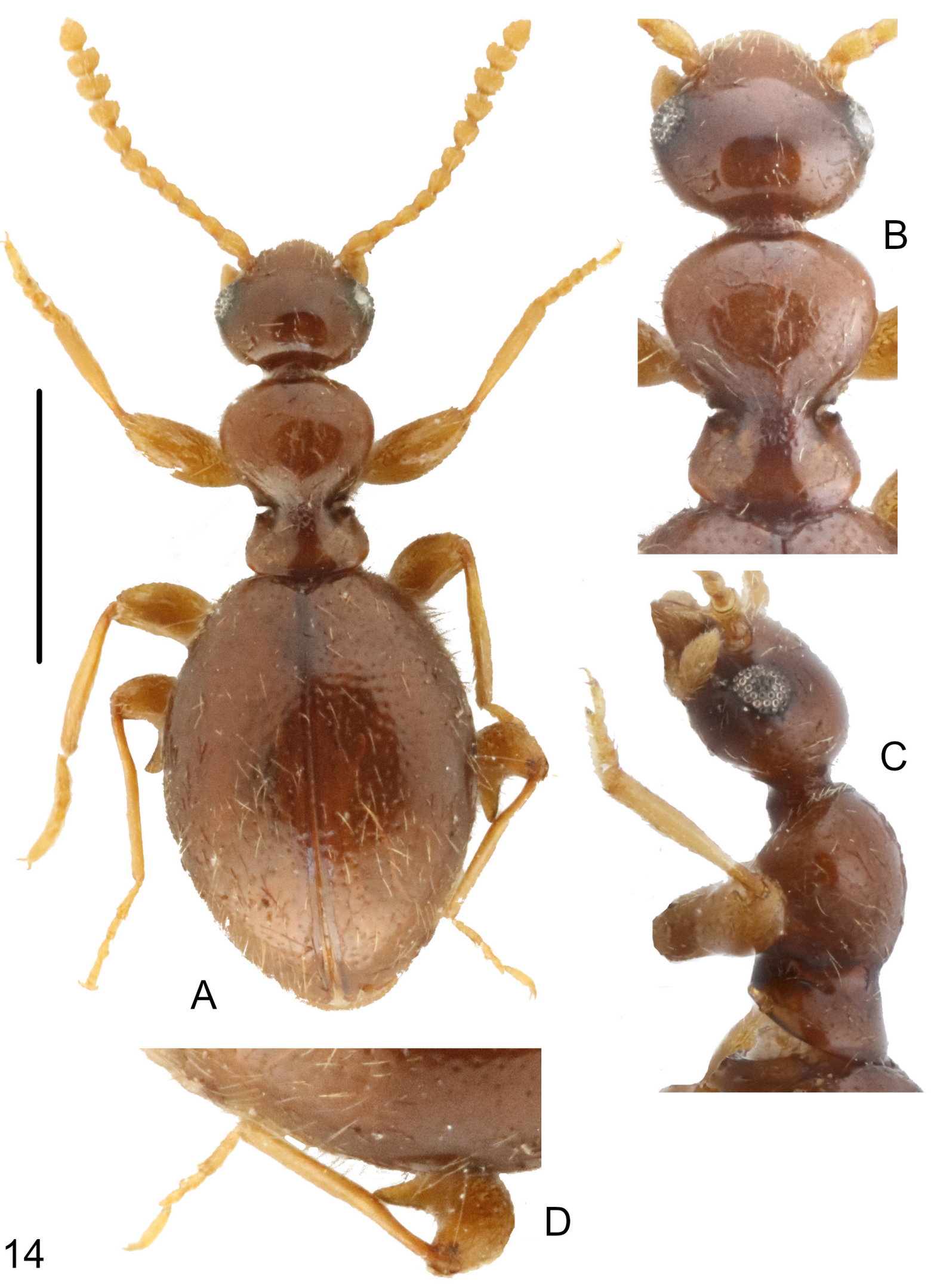

Fig. 14. Macrotomoderus femoridens sp. nov., holotype, $\widehat{\jmath}$ (NMP). A. Habitus, dorsal view. B. Forebody, dorsal view. C. Ditto, lateral view. D. Right posterior leg. Scale bar: A $=1 \mathrm{~mm}$; B-D = not to scale. 
and inconspicuous. Head dorsal setae inconspicuous, sparse. Antennae extending or nearly extending towards base of pronotum. Antennomere three nearly as long as antennomere two, antennomeres 8-10 transverse, of them 9-10 strongly transverse. Terminal antennomere broadly triangular with rounded apex, one third longer than penultimate antennomere. Terminal maxillary palpomere slightly

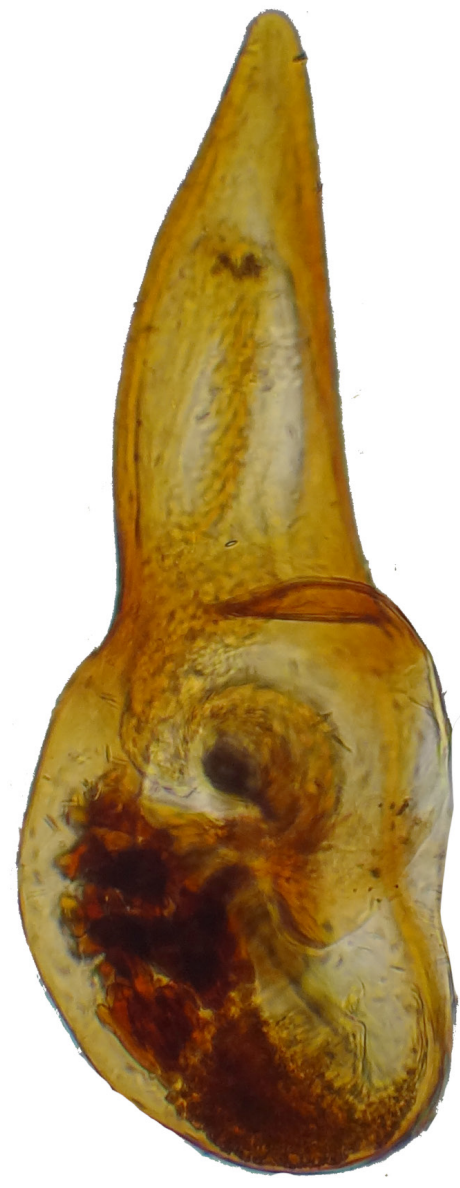

A

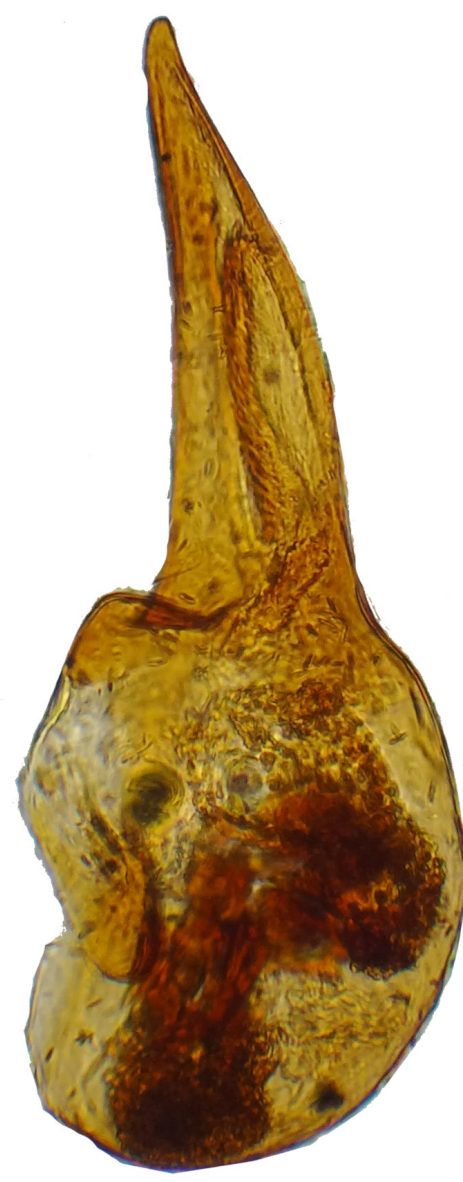

$\mathrm{B}$

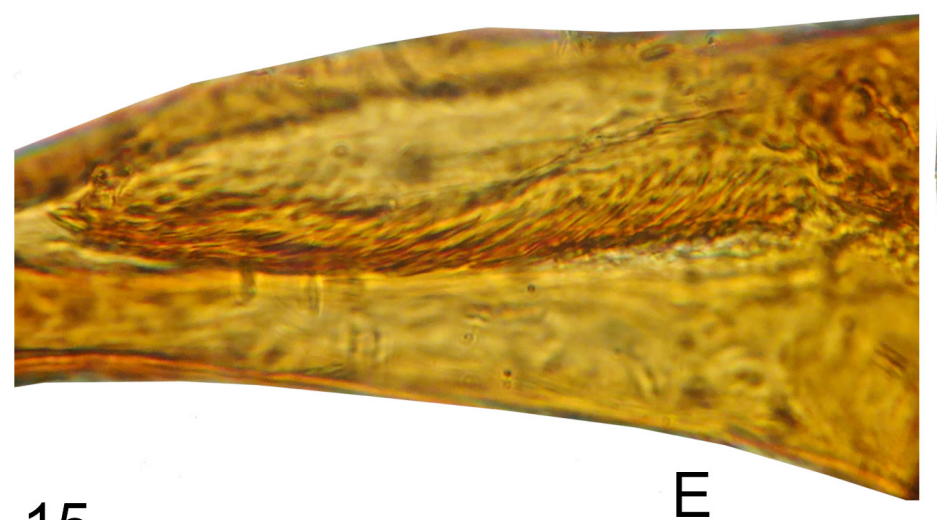

15

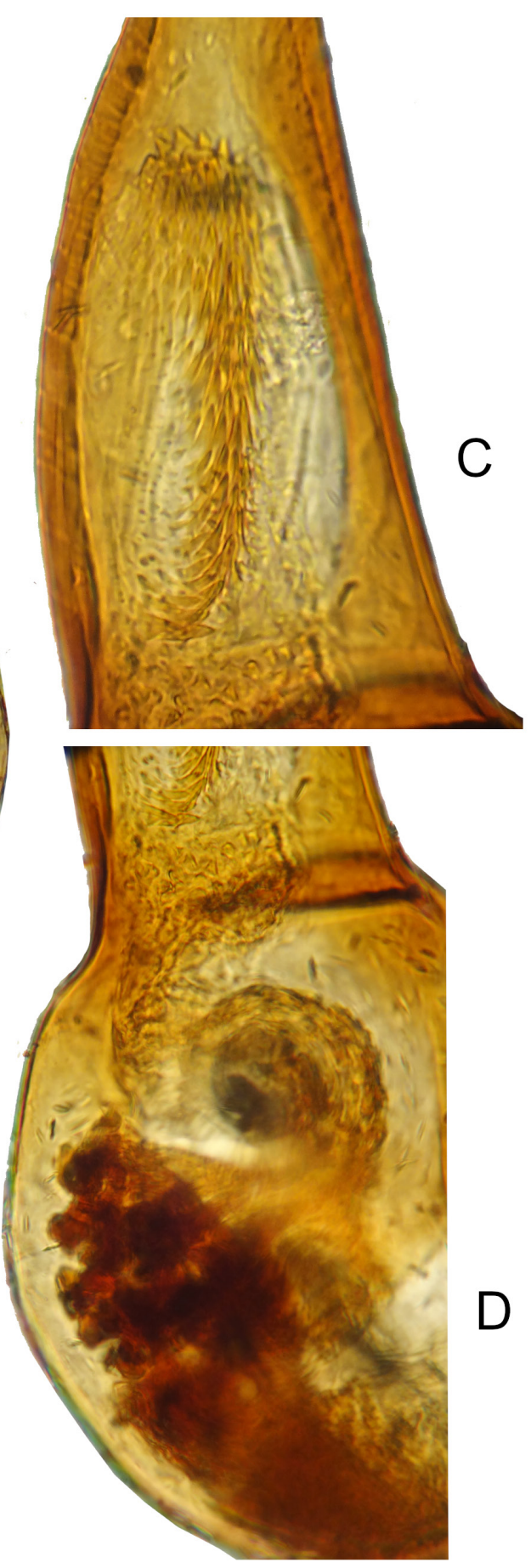

D

Fig. 15. Macrotomoderus femoridens sp. nov., holotype, đิ (NMP), aedeagus. A-B. General view, different positions. C. Gonopore armature in median portion of aedeagus. D. Ditto, basale and basal portion of apicale. E. Median portion, different position. Not to scale. 
securiform, nearly triangular. Pronotum with broad and medially deeply notched postmedian lateral constriction. Front margin of anterior lobe broadly rounded, dorsally without anterior rim. Anterior lobe convex in lateral view (Fig. 14C). Lateral constriction continues onto disc in lateral view, shallow (Fig. 14C). Lateral pronotal fovea rather moderately broad at lower external margin of pronotum, slightly widens upwards towards pronotal disc in lateral view, external margins protruding into pair of obtuse (in lateral view), moderately widely separated denticles (in lateral view). Cavity in lateral wall of pronotum between lateral denticles large. In dorsal view lateral pronotal fovea broad and deep, anterior and posterior pair of denticles appear right-angled or slightly obtuse, glabrous (Fig. 14B). Posterior pair of denticles dorsally with a brush of dense, moderately long, golden setae. Pronotal punctures minute on disc; lateral constriction dorsally with irregular, large and dense punctures. Dorsal pronotal setae inconspicuous, moderately long. Scutellar shield minute, triangular. Elytra dorsally elliptical, convex in lateral view, strongly widened laterally around midlength, lateral margins evenly broadly rounded, shoulders obsolete (apterous species). Elytral punctures much stronger and larger than those on dorsal forebody, becoming much smaller and sparser on posterior third of elytra. Elytral setae long and sparse, suberect. Metafemora (only in males?) on posterior margin with large, subacutely pointed median tooth that is slightly arched at its anterior but nearly straight at posterior margin (Fig. 14A, D). Male tergite VII broadly rounded at posterior margin. Male morphological sternite VII medially emarginate at posterior margin. Aedeagus as in Fig. 15, short and robust, with large, bubble-like basale and peculiar gonopore armature. Basale with double gonopore armature consisting of small to very large, pebble-like constituting pieces (grouped by size classes). Apicale with 'garland' of elongate, large spines closely attached to one another, becoming distinctly less elongate and more obtuse at apex of aedeagus.

\section{Sexual dimorphism}

Female is unknown.

\section{Ecology}

Collected at $770 \mathrm{~m}$ elevation in bamboo forest.

\section{Distribution}

Known only from Dadongshan Mountain in Guangdong Province, SW China.

Macrotomoderus hajeki sp. nov. urn:1sid:zoobank.org:act:9445FADE-9561-412D-B434-DA1D0699ACC4

Figs 16-17

\section{Differential diagnosis}

See key to species below.

\section{Etymology}

Patronymic. Named in honour of one of the first collectors and my good colleague, Jiří Hájek (NMP).

\section{Type material}

\section{Holotype}

CHINA - ${ }^{\lambda}$; "CHINA, Guangdong prov (MF 16) W of Qixing, 1-3.v.2011 Heishiding nature reserve $23^{\circ} 27.9^{\prime} \mathrm{N}, 111^{\circ} 54.3^{\prime} \mathrm{E} 190-260 \mathrm{~m}$, Fikáček \& Hájek // sifting of moist leaf litter in the dried-up streambeds and along the streams in the primary lowland forest"; NMP.

Paratypes (3 specimens)

CHINA • 2 + $\bigcirc$; same labels as for holotype; NMP • 1 \% ; same labels as for holotype; DTC. 


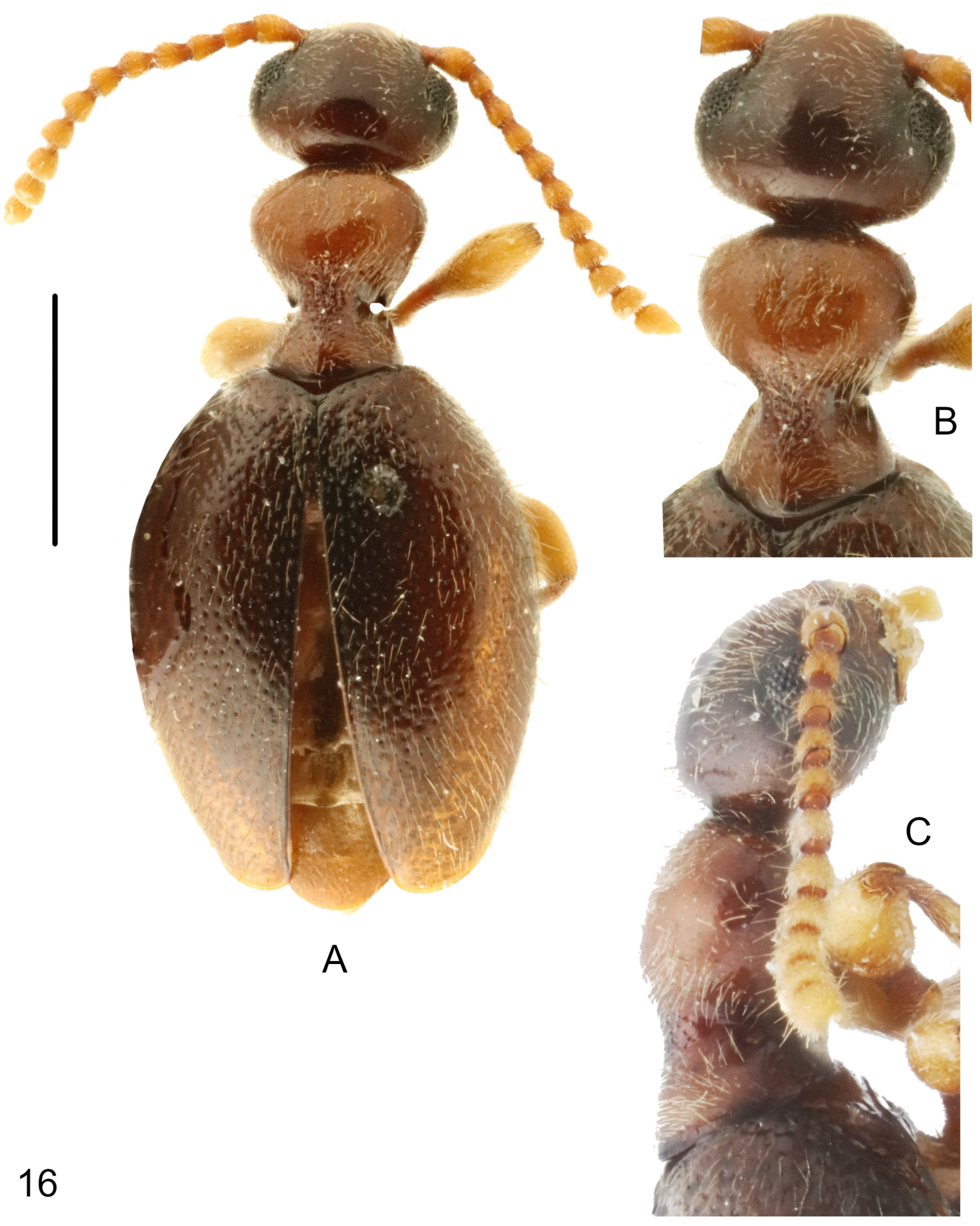

Fig. 16. Macrotomoderus hajeki sp. nov., holotype, ${ }^{\Uparrow}$ (NMP). A. Habitus, dorsal view. B. Forebody, dorsal view. C. Ditto, lateral view. Scale bar: $A=1 \mathrm{~mm} ; \mathrm{B}-\mathrm{C}=$ not to scale. 


\section{Description}

Measurements. Holotype, total body length $3.55 \mathrm{~mm}$; head $0.7 \mathrm{~mm}$ long, across eyes $0.8 \mathrm{~mm}$ broad, pronotum $0.85 \mathrm{~mm}$ long, maximum width $0.7 \mathrm{~mm}$, minimum width $0.3 \mathrm{~mm}$, elytra $2 \mathrm{~mm}$ long, $1.5 \mathrm{~mm}$ combined wide. Selected female paratypes are $3.5 \mathrm{~mm}$ and $3.6 \mathrm{~mm}$ long.

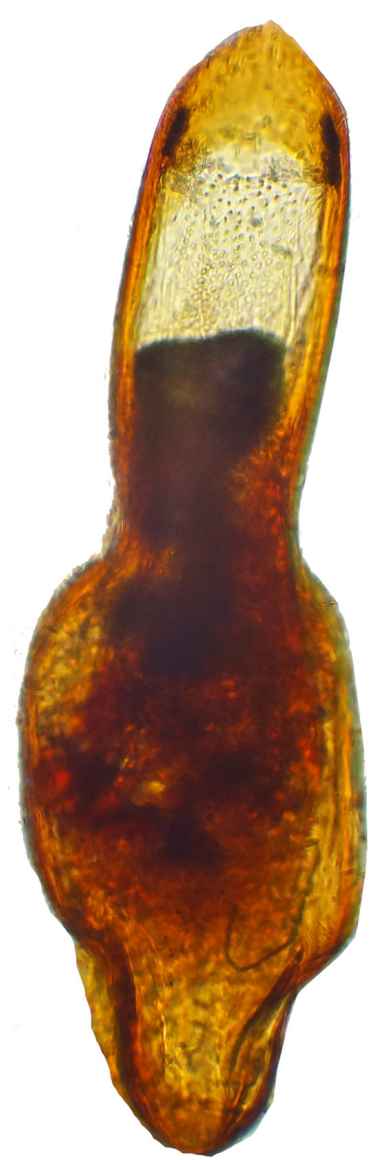

A

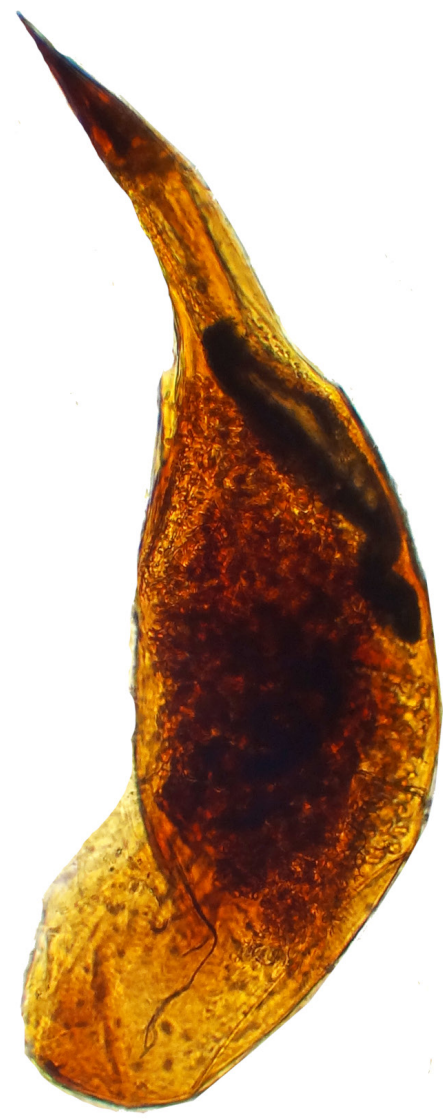

B
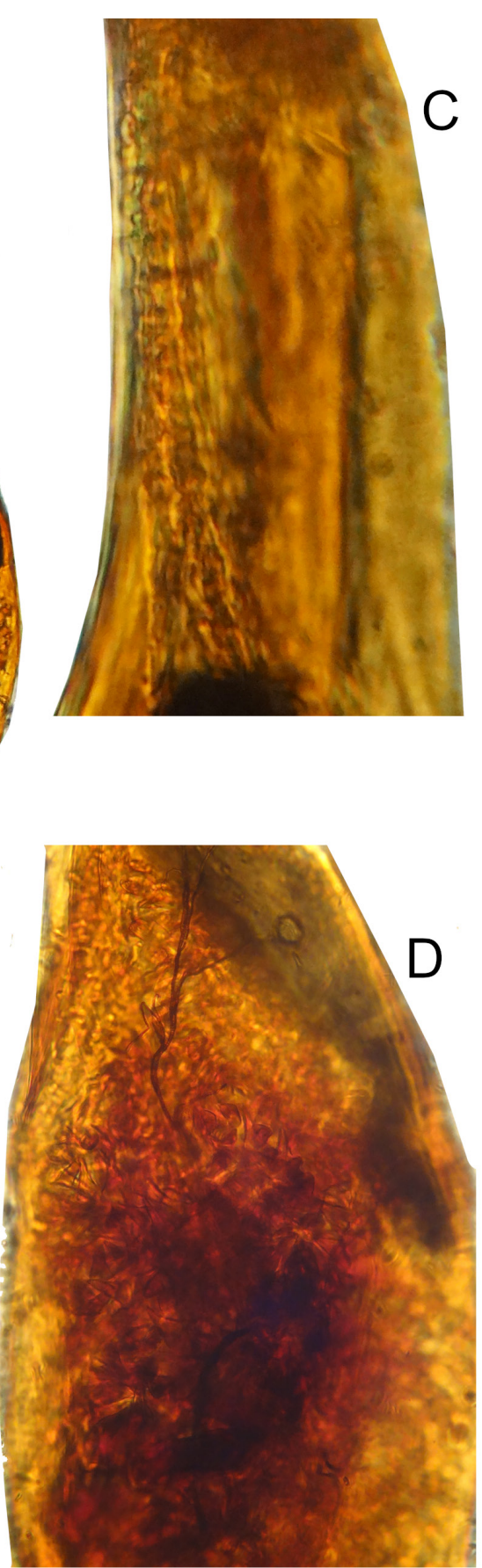

Fig. 17. Macrotomoderus hajeki sp. nov., holotype, $\widehat{\partial}$ (NMP), aedeagus. A-B. General view, different positions. C. Gonopore armature in median portion of aedeagus. D. Ditto, apical portion of basale. Not to scale. 
Dorsum and venter uniformly brown, pronotum contrastingly paler. Mouthparts, antennae, palps and legs yellow. Head broadly ovoid with moderately large, ovoid compound eyes, which are slightly protruding beyond head outline laterally. Head rounded in very broad arc posterior to eyes. Head dorsal punctures minute and inconspicuous. Head dorsal setae inconspicuous, sparse. Antennae extending towards base of pronotum. Antennomere three slightly longer than antennomere two, antennomeres 8-10 transverse, of them 9-10 strongly transverse. Terminal antennomere asymmetrically triangular with pointed apex, $2-2.2 \times$ as long as penultimate antennomere. Terminal maxillary palpomere securiform. Pronotum with broad and medially deeply notched postmedian lateral constriction. Front margin of anterior lobe broadly rounded, dorsally without anterior rim (Fig. 16B). Anterior lobe very slightly convex, near flattened in lateral view (Fig. 16C). Lateral constriction slightly continues onto disc in lateral view, very shallow (Fig. 16C). Lateral pronotal fovea moderately broad and deep at lower external margin of pronotum, widens upwards towards pronotal disc in lateral view, external margins protruding into obtuse (in lateral view), moderately widely separated denticles (in lateral view). Cavity in lateral wall of pronotum between lateral denticles small, elliptical. In dorsal view, lateral pronotal fovea moderately broad, anterior and posterior pair of denticles appear obtusely angulate, anterior pair glabrous, posterior dorsally with a brush of dense, short setae (Fig. 16B). Pronotal punctures minute on disc; lateral constriction dorsally with dense, irregularly shaped punctures. Dorsal pronotal setae inconspicuous, moderately long. Scutellar shield small, apically rounded. Elytra dorsally elliptical, flattened in lateral view, widened laterally around midlength, shoulders obsolete (apterous species). Elytral punctures moderately large, dense, becoming smaller and sparser towards apices. Elytral setae long and sparse, suberect. Male tergite and morphological sternite VII broadly rounded at posterior margin. Aedeagus as in Fig. 17, rather large and robust, with large, balloon-like basale and large, irregularly-shaped, apically tapered, gonopore armature.

\section{Sexual dimorphism}

Not indicated.

\section{Ecology}

Collected from leaf litter in the streambeds in the primary lowland forest at 190-260 m elevation.

\section{Distribution}

Known only from Heishiding nature reserve, Guangdong Province, SE China.

Macrotomoderus hartmanni sp. nov. urn:lsid:zoobank.org:act:C69A07A9-DE1E-468E-BCFD-F720BE621D2D

Figs 18-19

\section{Differential diagnosis}

See key to species below.

\section{Etymology}

Patronymic. This species is named after the famous coleopterist, explorer of the Himalayas and my good friend Matthias Hartmann, Director of the Naturkundemuseum Erfurt (Germany) to celebrate his $60^{\text {th }}$ birthday in 2021.

\section{Type material}

Holotype

CHINA • O’; "CHINA, Yunnan, S Pungchuan, 1.65 km E Mahuacun Vill. 2835 m, 2.vi.2019 Belousov, Davidian \& Kabak leg. // 2554'26"N 100'46'35"E”; ZIN. 

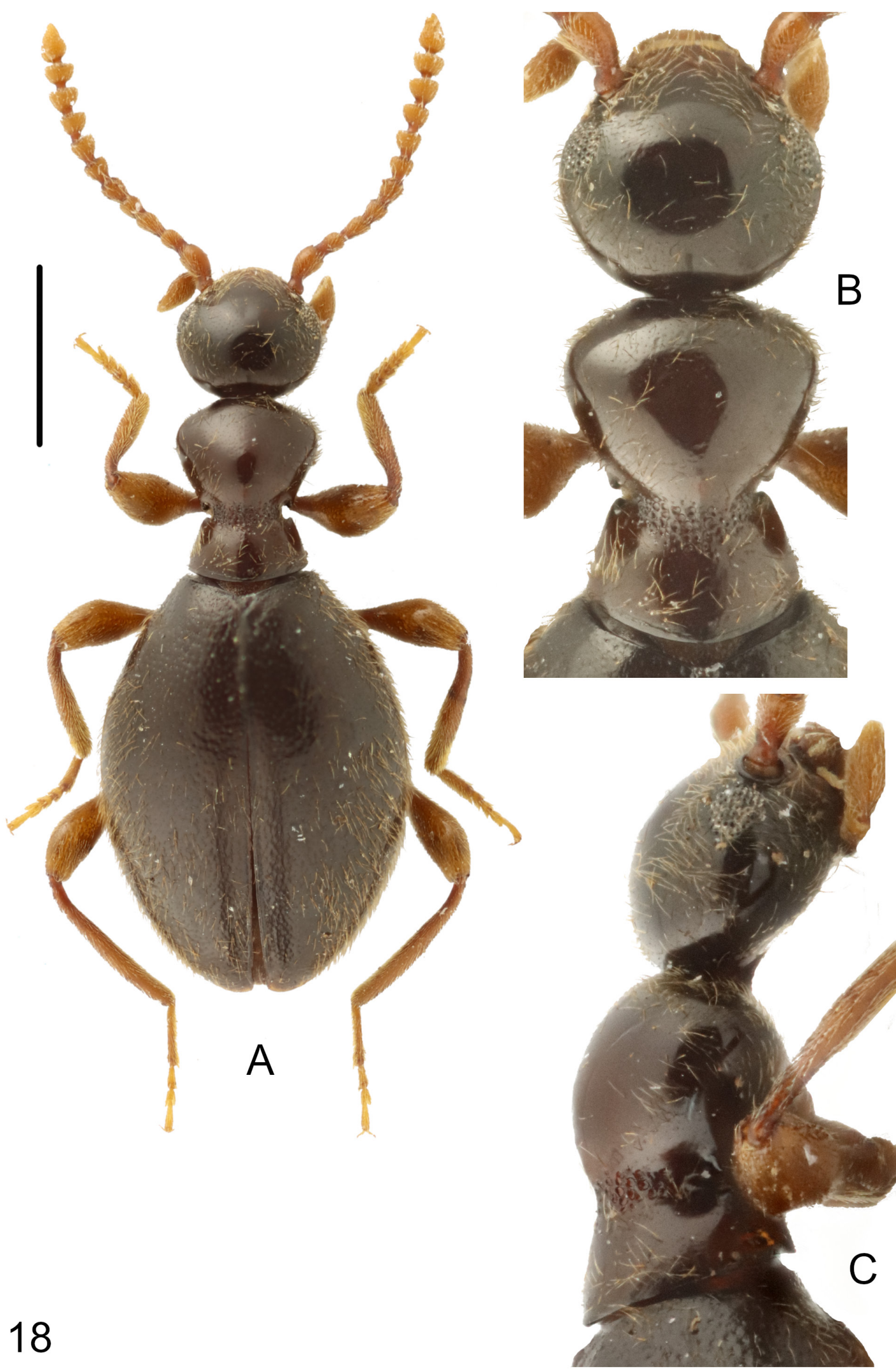

Fig. 18. Macrotomoderus hartmanni sp. nov., holotype, ठ̊ (ZIN). A. Habitus, dorsal view. B. Forebody, dorsal view. C. Ditto, lateral view. Scale bar: A $=1 \mathrm{~mm}$; $B-C=$ not to scale. 

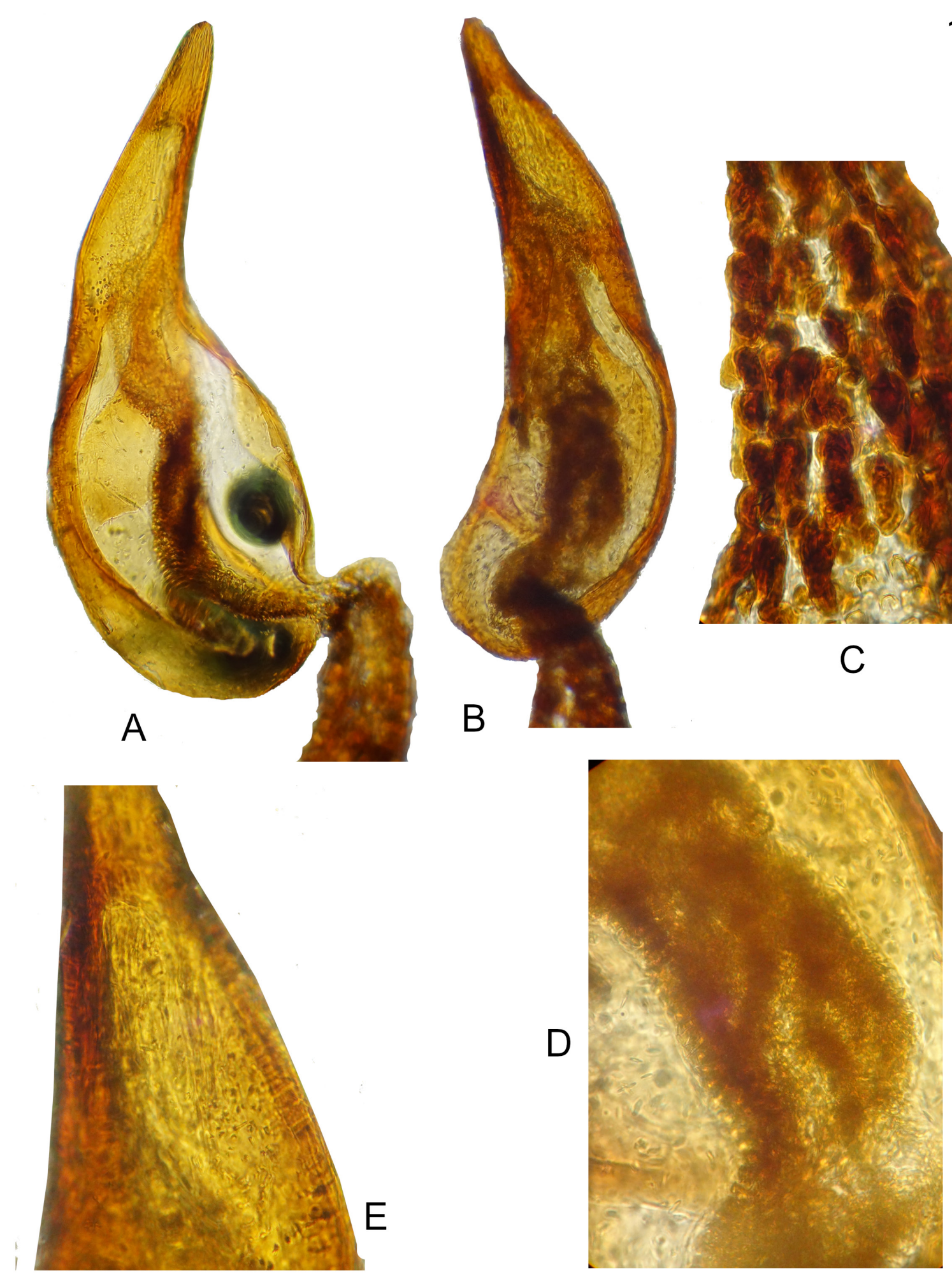

Fig. 19. Macrotomoderus hartmanni sp. nov., holotype, $\widehat{\partial}(\mathrm{ZIN})$, aedeagus. A-B. General view, different positions. C. Gonopore armature, extracted from basale. D. Ditto, apical portion of basale. E. Apical portion of apicale. Not to scale. 


\section{Description}

Measurements. Holotype, total body length $4.7 \mathrm{~mm}$; head $0.95 \mathrm{~mm}$ long, across eyes $0.85 \mathrm{~mm}$ broad, pronotum $1.1 \mathrm{~mm}$ long, maximum width $0.85 \mathrm{~mm}$, minimum width $0.4 \mathrm{~mm}$, elytra $2.65 \mathrm{~mm}$ long, $1.8 \mathrm{~mm}$ combined wide.

Dorsum and venter uniformly brown, pronotum inconspicuously paler. Mouthparts, antennae, palps and legs yellowish-brown. Head ovoid with moderately large, ovoid compound eyes, which are not protruding beyond head outline laterally. Head rounded in broad arc posterior to eyes. Head dorsal punctures minute and inconspicuous. Head dorsal setae inconspicuous, sparse. Antennae extending slightly over base of pronotum. Antennomere three about $1.25 \times$ as long as antennomere two, antennomeres 7-10 transverse, of them 8-10 strongly transverse. Terminal antennomere triangular with pointed apex, twice as long as penultimate antennomere. Terminal maxillary palpomere securiform. Pronotum with broad and medially deeply notched postmedian lateral constriction. Front margin of anterior lobe broadly rounded, dorsally without anterior rim (Fig. 18B). Anterior and posterior lobe convex in lateral view (Fig. 18C). Lateral constriction continues onto disc in lateral view, shallow (Fig. 18C). Lateral pronotal fovea rather narrow at lower external margin of pronotum, widens upwards towards pronotal disc in lateral view, external margins protruding into a pair of subacute (in lateral view), glabrous, narrowly separated denticles (in lateral view). Cavity in lateral wall of pronotum between lateral denticles small, elliptical. In dorsal view, lateral pronotal fovea broad, anterior and posterior pair of denticles appear obtusely angulate, glabrous (Fig. 18B). Pronotal punctures minute on disc; lateral constriction dorsally with numerous dense, variably sized punctures. Dorsal pronotal setae inconspicuous, moderately long. Scutellar shield minute, triangular. Elytra dorsally elliptical, convex in lateral view, strongly widened laterally around midlength, lateral margins evenly broadly rounded, shoulders obsolete (apterous species). Elytral punctures much stronger and larger than those on dorsal forebody, becoming less prominent on posterior third of elytra. Elytral setae long and sparse, suberect. Male tergite and morphological sternite VII broadly rounded at posterior margin. Aedeagus as in Fig. 19, short, broadly hook-shaped, with peculiar gonopore armature. Basale with a broad multi-row 'garland' of pebble-like constituting pieces. Gonopore armature of apicale of very dense, irregularly shaped and positioned constituting pieces.

\section{Sexual dimorphism}

Female is unknown.

\section{Ecology}

Collected at 2835 m elevation.

\section{Distribution}

Known only from east of Erhai Lake, northern part of Yunnan Province, SW China.

Macrotomoderus hengduan sp. nov. urn:1sid:zoobank.org:act:3C10F9ED-7C43-410B-9E6F-99197F75ABE8

Figs 20-21

\section{Differential diagnosis}

This species falls in a group of species from continental China with pronotum wider than head across eyes. Among them, males of M. mirabilis Telnov, 2018 and M. monstrificabilis Telnov, 2018 have distinct triangular median projection at the head base (not present in M. hengduan sp. nov.), while the head base in male M. monstratus Telnov, 2018 is slightly medially impressed (evenly rounded in $M$. hengduan sp. nov.), the anterior lobe of the pronotum more than twice as long as the posterior lobe (about twice as long in M. hengduan sp. nov.), the front margin of anterior lobe in male with the pointed, 
triangular mesal projection that is densely setose ventrally and touching the head base at the place of the basal impression (the anterior pronotal projection different in M. hengduan sp. nov. - see Fig. 20B-C, not setose ventrally and with few conspicuous dorsal setae). Also see diagnoses of $M$. boops and $M$. dali spp. nov. above and of $M$. imitator sp. nov. below.

\section{Etymology}

Toponymic. Named after Yunnan's Hengduan Mountains, a group of mountain ranges in southwest China that connect the southeast portions of the Tibetan Plateau with the Yunnan-Guizhou Plateau, where this species occurs. Noun in apposition.

\section{Type material}

\section{Holotype}

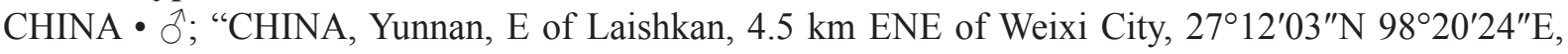
2580 m, 29.v.2016 Kabak \& Davidian leg."; $\widehat{o}$ ZIN [The coordinates on the original label are referring to Myanmar, not Yunnan, but Laishkan and Weixi both are towns in northern Yunnan, not Myanmar].

Paratype (1 specimen)

CHINA $\bullet 1$ ${ }^{\lambda}$; same label as for holotype; DTC.

\section{Description}

Measurements. Holotype, total body length $4.15 \mathrm{~mm}$; head $0.85 \mathrm{~mm}$ long, across eyes $0.8 \mathrm{~mm}$ broad, pronotum $1.05 \mathrm{~mm}$ long, maximum width $1.15 \mathrm{~mm}$, minimum width $0.35 \mathrm{~mm}$, elytra $2.25 \mathrm{~mm}$ long, $1.4 \mathrm{~mm}$ combined wide. Paratype is $4.1 \mathrm{~mm}$ long.

Dorsum and venter uniformly brown, sutural area of elytra slightly paler. Mouthparts, antennae, palps and legs yellowish-brown. Head elongate ovoid with moderately large, ovoid compound eyes, which are not protruding beyond head outline laterally. Head rounded in broad arc posterior to eyes. Head dorsal punctures minute and inconspicuous. Head dorsal setae inconspicuous, sparse. Antennae conspicuously robust and long, extending towards anterior third of elytra. Antennomere three about $1.3 \times$ as long as antennomere two, antennomeres 8-10 transverse, of them 9-10 strongly transverse. Terminal antennomere asymmetrically triangular with rounded apex, twice as long as penultimate antennomere. Terminal maxillary palpomere securiform. Pronotum with anterior lobe significantly wider than posterior and wider than head across eyes. Postmedian lateral constriction broad and medially shortly notched. Front margin of anterior lobe subtruncate, dorsally with narrow anterior rim. Anterior lobe large and broad, inverted triangular; posterior lobe shorter and much narrower. Front margin of anterior lobe with short, median, anteriad-directed projection and shallow antero-dorsal impression posterior to it; projection is dorsally provided with two erect (straight) and two 7 -shaped (bent), anteriad-directed setae (Fig. 20B-C). Anterior and posterior lobe convex in lateral view (Fig. 20C). Lateral constriction continues onto disc in lateral view, shallow (Fig. 20C). Lateral pronotal fovea broad and deep at lower external margin of pronotum, strongly widens upwards towards pronotal disc in lateral view, external margins protruding into a pair of obtuse (in lateral view), widely separated denticles (in lateral view), which are provided with long, sparse setae. Cavity in lateral wall of pronotum between lateral denticles large, elliptical. In dorsal view, lateral pronotal fovea narrow, anterior and posterior pair of denticles appear obtusely angulate, glabrous (Fig. 20B). Pronotal punctures minute on disc; lateral constriction dorsally with sparse, rather small punctures. Dorsal pronotal setae inconspicuous, moderately long. Scutellar shield minute, triangular. Elytra dorsally elliptical, slightly convex in lateral view, widened laterally around midlength, lateral margins evenly broadly rounded, shoulders obsolete (apterous species). Elytral punctures rather small and moderately dense, becoming slightly smaller and sparser towards apices. Elytral setae long and sparse, suberect. Male tergite and morphological sternite VII 


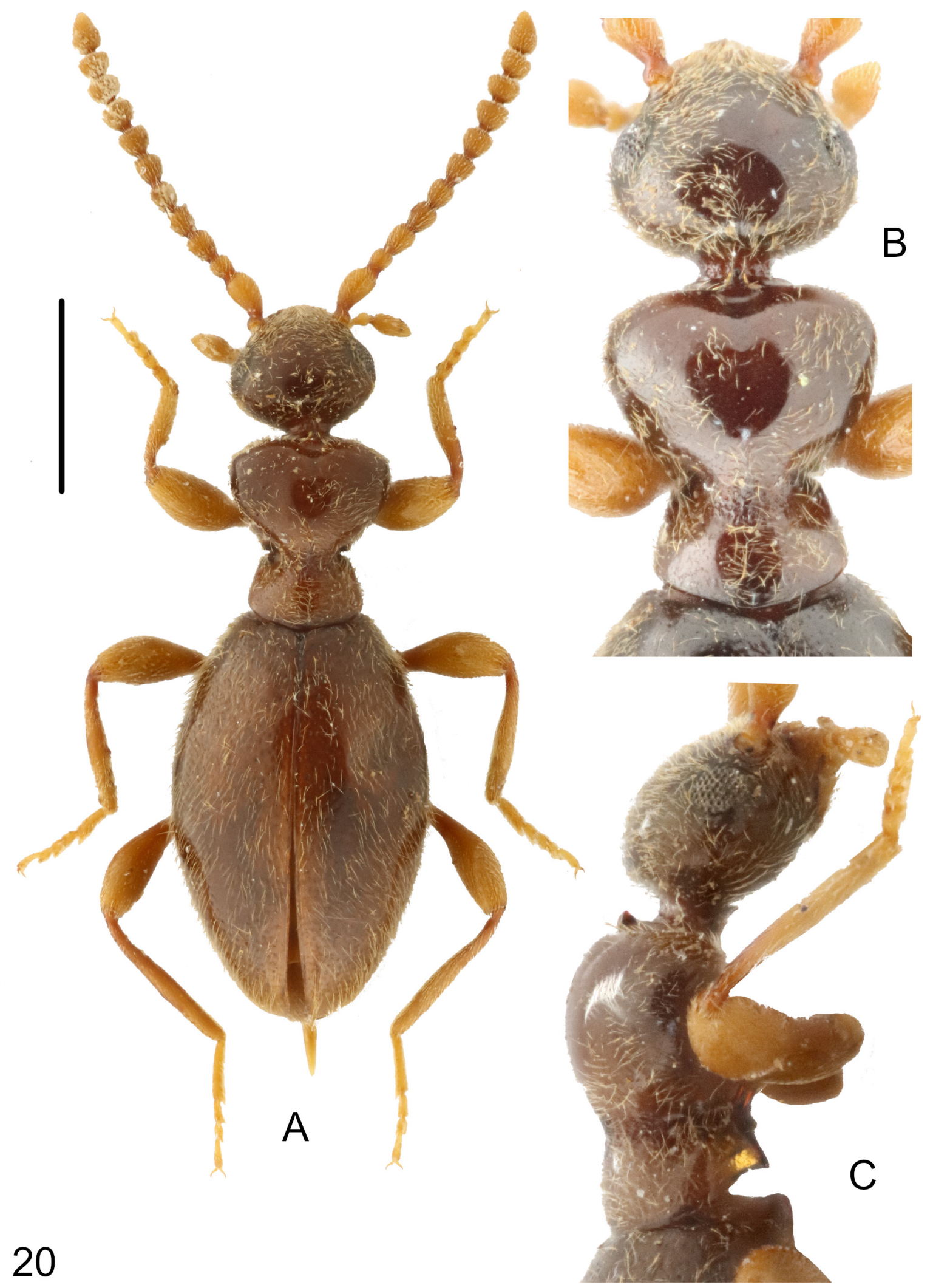

Fig. 20. Macrotomoderus hengduan sp. nov., holotype, $\widehat{\jmath}(\mathrm{ZIN})$. A. Habitus, dorsal view. B. Forebody, dorsal view. C. Ditto, lateral view. Scale bar: A $=1 \mathrm{~mm}$; $B-C=$ not to scale. 


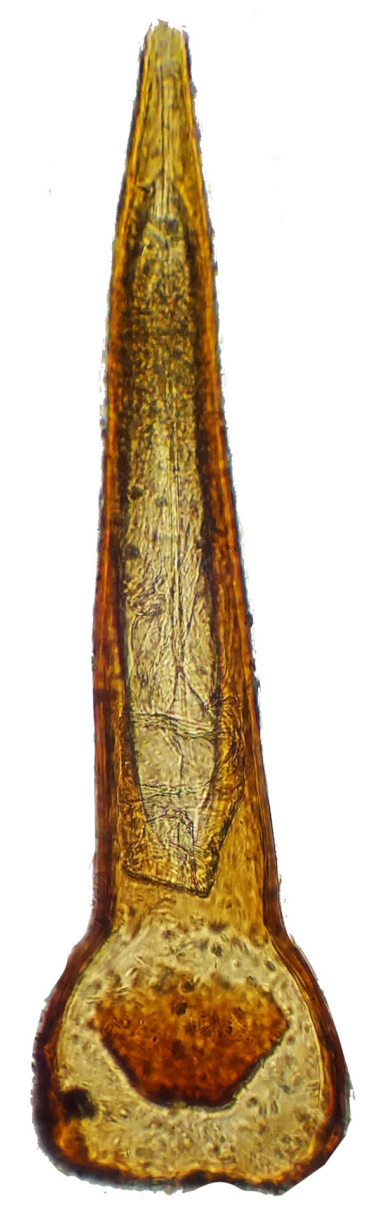

A

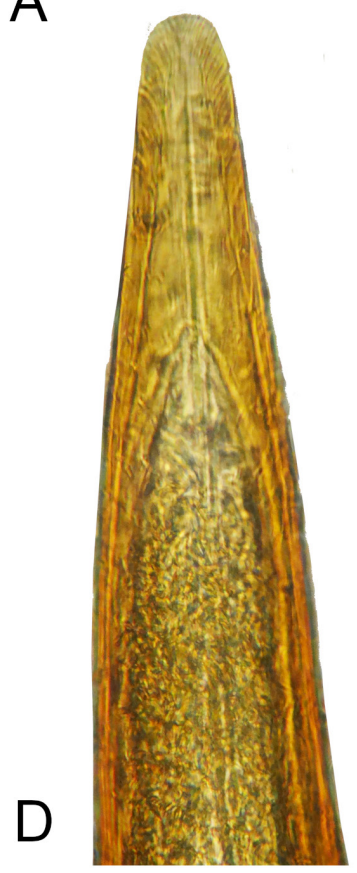

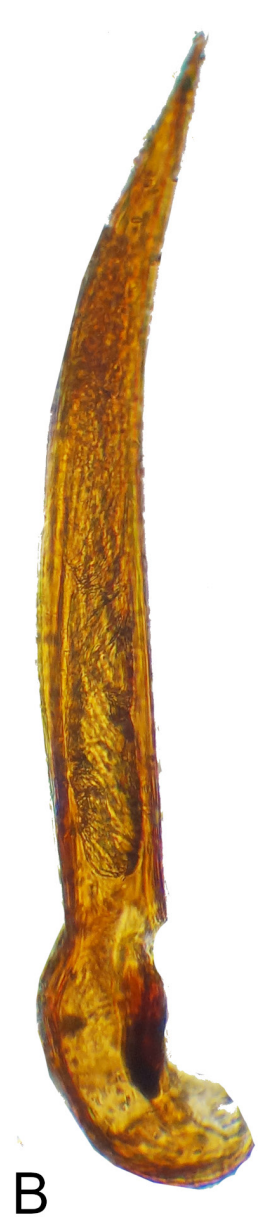

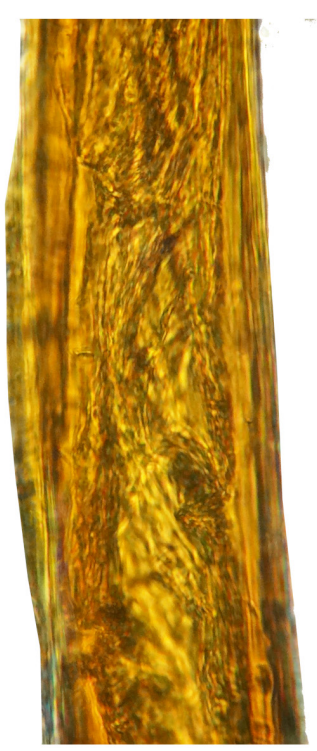

$\mathrm{E}$

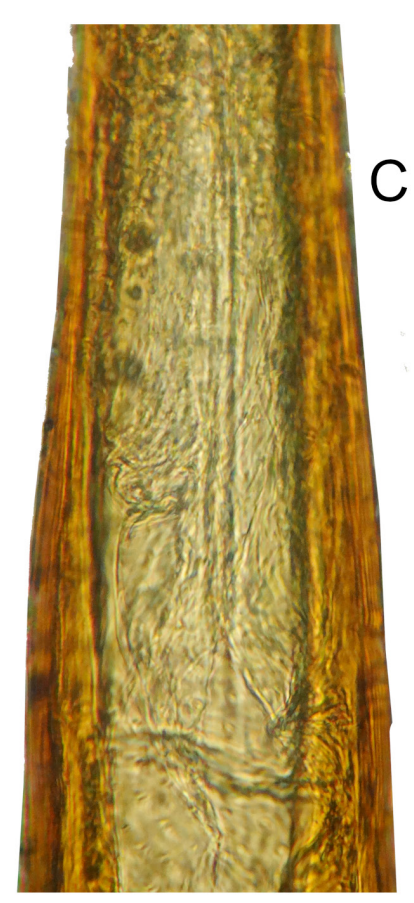

C

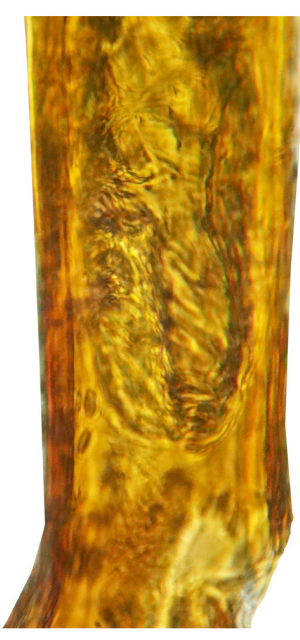

$\mathrm{F}$

Fig. 21. Macrotomoderus hengduan sp. nov., holotype, $\widehat{\partial}(\mathrm{ZIN})$, aedeagus. A-B. General view, different positions. C. Gonopore armature, median portion of apicale. D. Ditto, apical portion of apicale. E. Basal portion of apicale. F. Ditto, stronger magnification. Not to scale. 
broadly rounded at posterior margin. Aedeagus as in Fig. 21, large and dagger-shaped, with short, spherical basale and inconspicuous, delicate, irregularly filamentous gonopore armature.

\title{
Sexual dimorphism
}

Female is unknown.

\section{Ecology}

Collected at $2580 \mathrm{~m}$ elevation.

\section{Distribution}

Known only from Hengduan Mountains, northern part of Yunnan Province, SW China.

\author{
Macrotomoderus imitator sp. nov. \\ urn:1sid:zoobank.org:act:A37A44DE-B2B6-409B-891B-45DC6F1DABCF
}

Figs 22-23

\section{Differential diagnosis}

This species falls in a group of species from continental China with pronotum wider than head across eyes. Most similar to Macrotomoderus hengduan sp. nov. (see description above) and M. monstratus Telnov, 2018 (China: Yunnan). The new species differs from M. hengduan sp. nov. in the head impressed posteroventrally opposite the anterior pronotal projection, in the presence of the rather broad anterior rim of the pronotum in dorsal view (rim very narrow in M. hengduan sp. nov.), the comparatively longer and heavier antenna (the antenna not extending towards the median third of the elytra in M. hengduan sp. nov.), and in the absence of the anteromedian impression on pronotum (present in M. hengduan sp. nov.). The new species resembles M. monstratus also in the shape of the aedeagus, differs in the truncate anterior pronotal margin (subtruncate in M. monstratus), presence of inconspicuous, dorsal, median, longitudinal carina in the pronotal constriction (not present in M. monstratus), the denser and coarser dorsal punctures on the pronotal constriction, without broad, glossy, intervening spaces (the pronotal constriction area dorsally with two irregular, transverse rows of punctures, smooth and glossy intervened between them), and the generally slightly larger body (3.37-3.5 mm for M. imitator vs $2.47 \mathrm{~mm}$ for $M$. monstratus). Also see descriptions of the similarly looking M. boops and $M$. dali spp. nov. above and the key to species.

\section{Etymology}

From the Latin 'imitator' ('an imitator') to point on extreme similarity to Macrotomoderus hengduan sp. nov. and M. monstratus Telnov, 2018 (see description above).

\section{Type material}

\section{Holotype}

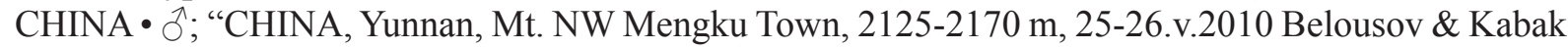
leg. // $23^{\circ} 40^{\prime} 28^{\prime \prime} \mathrm{N} 98^{\circ} 48^{\prime} 11^{\prime \prime} \mathrm{E} 23^{\circ} 40^{\prime} 29^{\prime \prime} \mathrm{N} 98^{\circ} 46^{\prime} 53^{\prime \prime} \mathrm{E}^{\prime \prime}$; ${ }^{\top} \mathrm{ZIN}$. [The coordinates on the original labels are referring to Myanmar, not Yunnan, but Mengku is definitively a town in western Yunnan, not Myanmar].

Paratype (1 specimen)

CHINA $\bullet 1 \stackrel{1}{ }$; ; same labels as for holotype; DTC. 

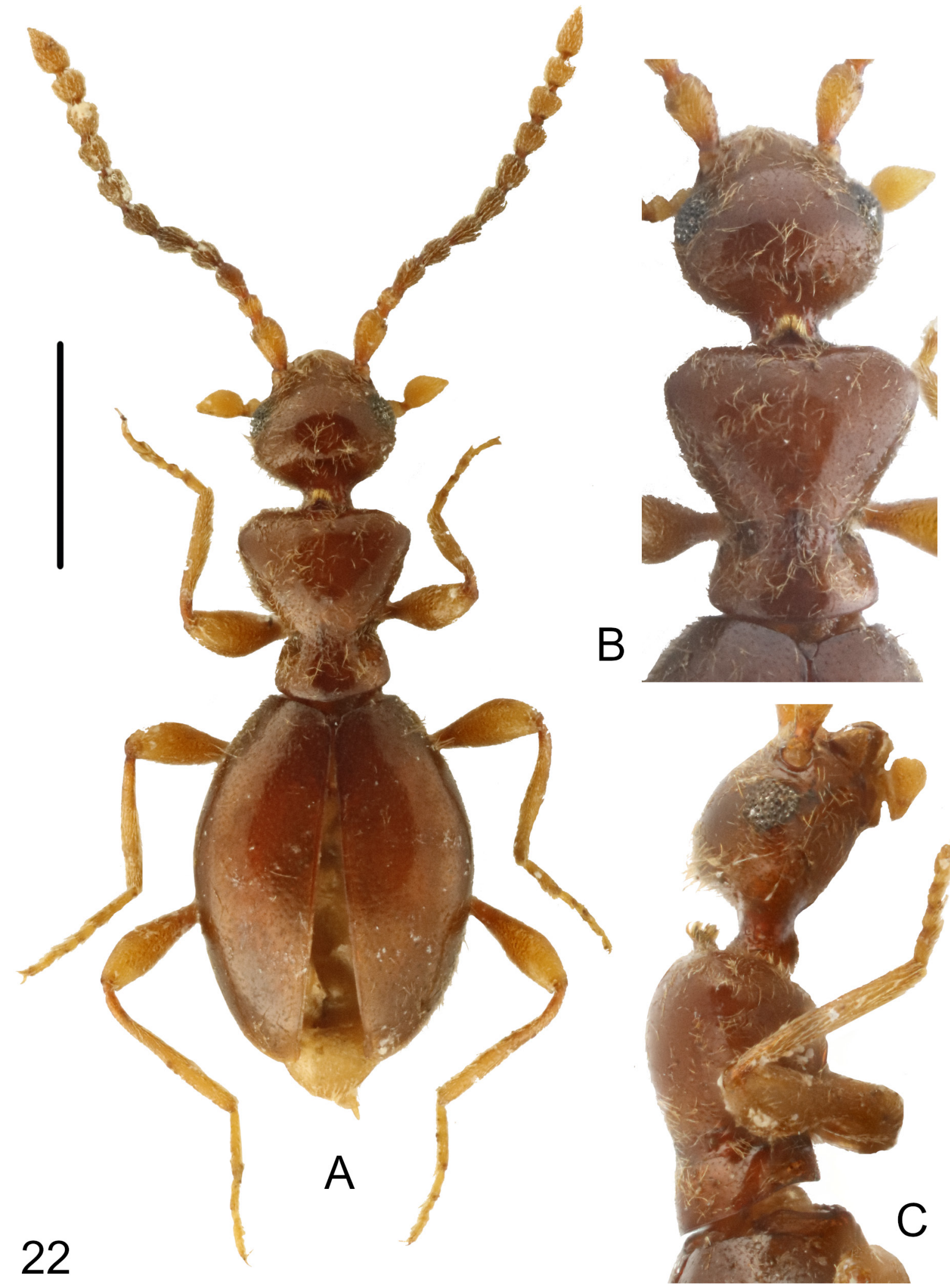

Fig. 22. Macrotomoderus imitator sp. nov., holotype, ô (ZIN). A. Habitus, dorsal view. B. Forebody, dorsal view. C. Ditto, lateral view. Scale bar: $A=1 \mathrm{~mm} ; \mathrm{B}-\mathrm{C}=$ not to scale. 


\section{Description}

Measurements. Holotype, total body length $3.37 \mathrm{~mm}$; head $0.75 \mathrm{~mm}$ long, across eyes $0.7 \mathrm{~mm}$ broad, pronotum $0.9 \mathrm{~mm}$ long, maximum width $0.8 \mathrm{~mm}$, minimum width $0.3 \mathrm{~mm}$, elytra $1.7 \mathrm{~mm}$ long, $1.3 \mathrm{~mm}$ combined wide. Male paratype is $3.5 \mathrm{~mm}$ long.

Dorsum and venter uniformly reddish-brown. Mouthparts, palps and legs yellowish-brown, antennae yellowish-brown with somewhat darkened antennomeres 3-8. Head elongate ovoid with small, ovoid compound eyes, which are not protruding beyond head outline laterally. Head rounded in broad arc posterior to eyes. Occiput at posteroventral side (above insertion of cranial neck and opposing triangular projection of pronotum) subtruncate or with shallow impression. Head dorsal punctures minute and inconspicuous. Head dorsal setae inconspicuous, sparse. Antennae conspicuously long and thickened, extending or nearly so towards median third of elytra. Antennomere three about $1.6-1.7 \times$ as long as antennomere two, antennomere four shortened, about as same length as antennomere two. Antennomeres

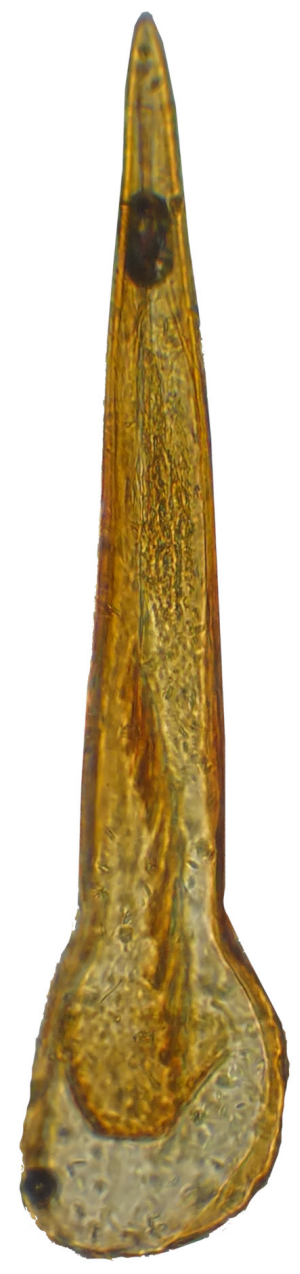

A

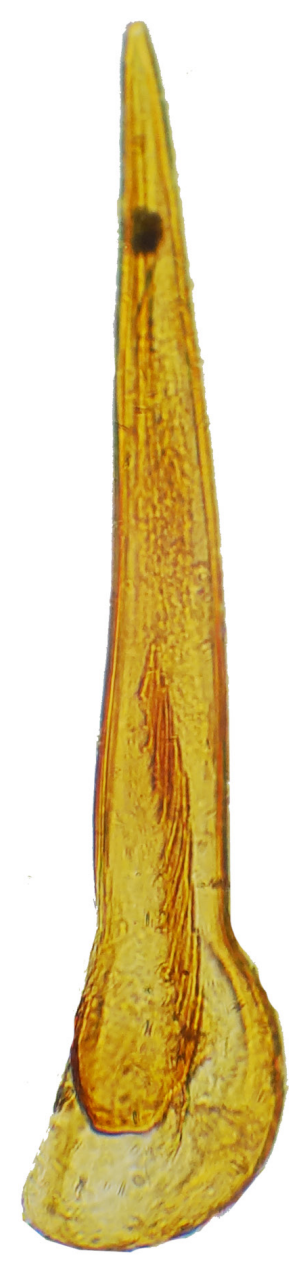

B

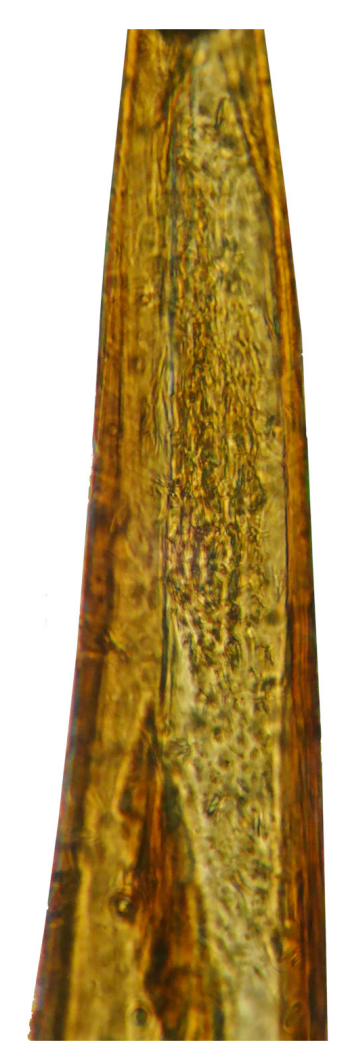

C

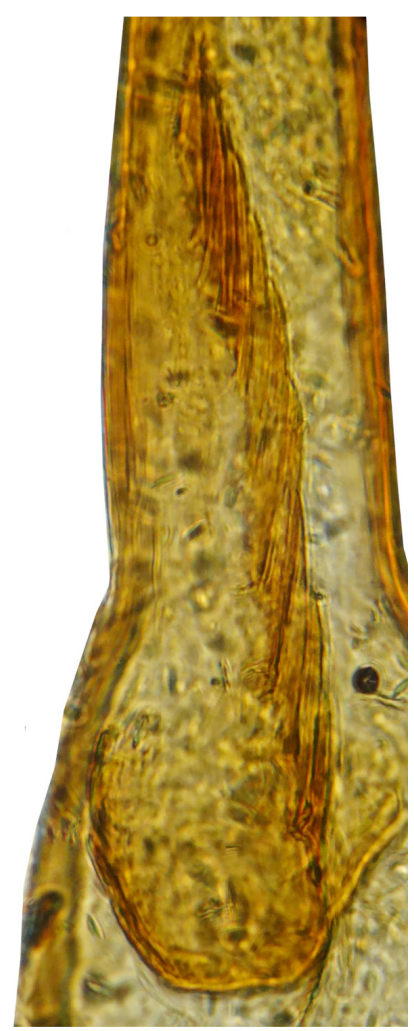

$\mathrm{D}$

\section{3}

Fig. 23. Macrotomoderus imitator sp. nov., holotype, $\widehat{\partial}(\mathrm{ZIN})$, aedeagus. A-B. General view, different positions. C. Gonopore armature, median portion of apicale. D. Ditto, basal portion of apicale. Not to scale. 
9-10 transverse. Terminal antennomere elongate triangular with pointed apex, nearly twice as long as penultimate antennomere. Terminal maxillary palpomere securiform. Pronotum with anterior lobe significantly wider than posterior and wider than head across eyes. Postmedian lateral constriction broad and medially deeply notched. Front margin of anterior lobe truncate, dorsally with rather broad anterior rim. Anterior lobe large and broad, inverted triangular; posterior lobe shorter and much narrower. Front margin of anterior lobe with short, median, anteriad-directed projection; projection is dorsally provided with a bunch of golden, dense, anteriad-pointed setae (Fig. 22B-C). Anterior lobe slightly convex in lateral view (Fig. 22C). Lateral constriction not or barely continues onto disc in lateral view (Fig. 22C). Lateral pronotal fovea broad and deep at lower external margin of pronotum, slightly widens upwards towards pronotal disc in lateral view, external margins protruding into a pair of strongly obtuse (in lateral view), widely separated denticles (in lateral view), which are provided with long, sparse setae. Cavity in lateral wall of pronotum between lateral denticles large, elliptical. In dorsal view, lateral pronotal fovea broad and deep, anterior and posterior pair of denticles appear obtusely angulate (Fig. 22B). Pronotal punctures minute on disc; lateral constriction dorsally with dense and moderately coarse, variably sized punctures and with inconspicuous, short, median longitudinal carina. Dorsal pronotal setae inconspicuous, moderately long. Scutellar shield minute, triangular. Elytra dorsally elliptical, flattened in lateral view, widened laterally around midlength, lateral margins evenly broadly rounded, shoulders obsolete (apterous species). Elytral punctures shallow, moderately dense, becoming slightly smaller and sparser towards apices. Intervening spaces about as large as to $3 \times$ as large as punctures on anterior half of elytra. Elytral setae long and sparse, suberect. Male tergite and morphological sternite VII broadly rounded at posterior margin. Aedeagus as in Fig. 23, large and dagger-shaped, with short, spherical basale and peculiar gonopore armature. Armature in basal portion consists of a row of large, strongly elongate, closely attached to one another, brush-like constituting pieces. Apical portion of apicale, in contrast, with delicate, irregularly shaped constituting pieces.

\section{Sexual dimorphism}

Female is unknown.

\section{Ecology}

Collected at 2125-2170 m elevation.

\section{Distribution}

Known only from the western part of Yunnan Province, SW China.

Macrotomoderus kabaki sp. nov. urn:1sid:zoobank.org:act:1902038B-5421-46BB-940A-D0E1BD9D92D0

Figs 24-25

\section{Differential diagnosis}

See above for diagnosis of $M$. belousovi sp. nov. and below for key to species.

\section{Etymology}

Patronymic. Named in honour of one of the first collectors, Ilya I. Kabak (All-Russian Institute of Plant Protection, St Petersburg, Russia).

\section{Type material}

\section{Holotype}

CHINA • ${ }^{\top}$; “CHINA, Yunnan, W of Lugu Lake, 2742'53"N 100³4'54"E 3460 m, 27.v.2012 Belousov, Davidian, Kabak \& Korolev"; ZIN. 

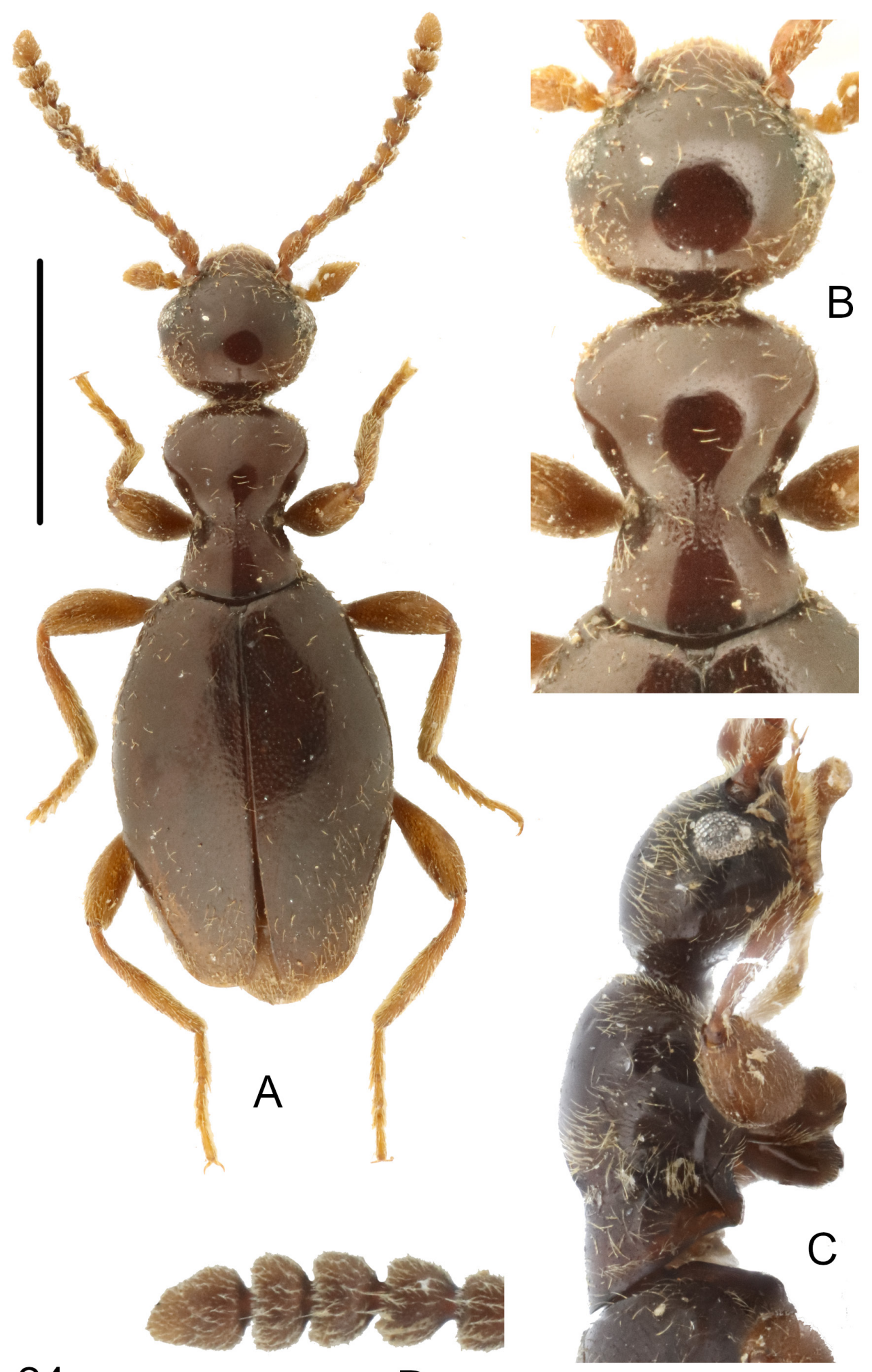

24

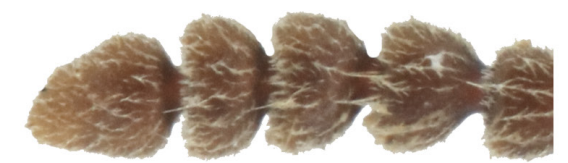

$\mathrm{D}$

Fig. 24. Macrotomoderus kabaki sp. nov., holotype, §ิ (ZIN). A. Habitus, dorsal view. B. Forebody, dorsal view. C. Ditto, lateral view. D. Antennomeres $8-11$ of the left antenna. Scale bar: A = $1 \mathrm{~mm}$; B-D not to scale. 
Paratypes (4 specimens)

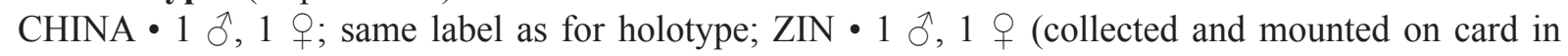
copula); same label as for holotype; DTC.
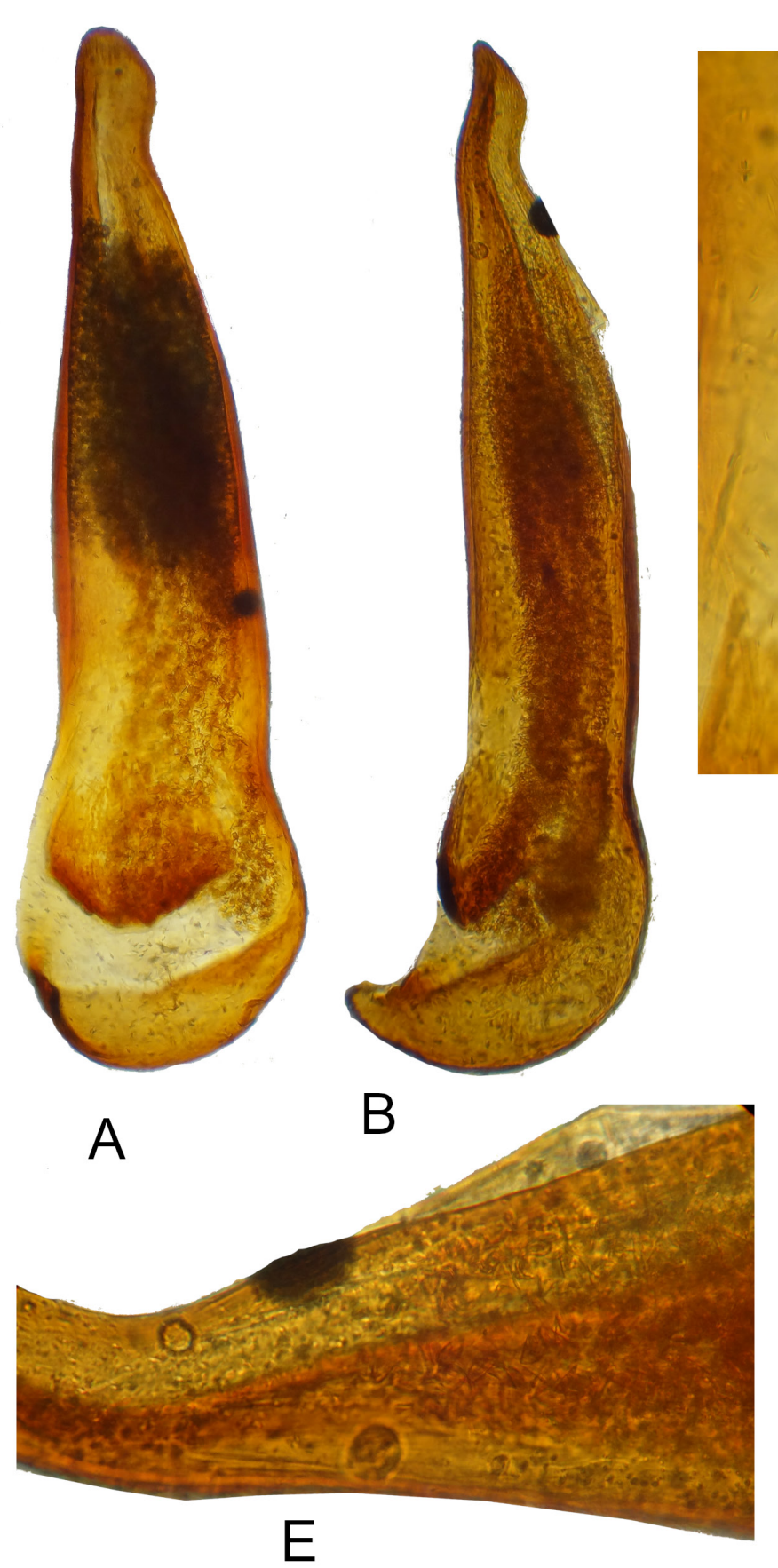
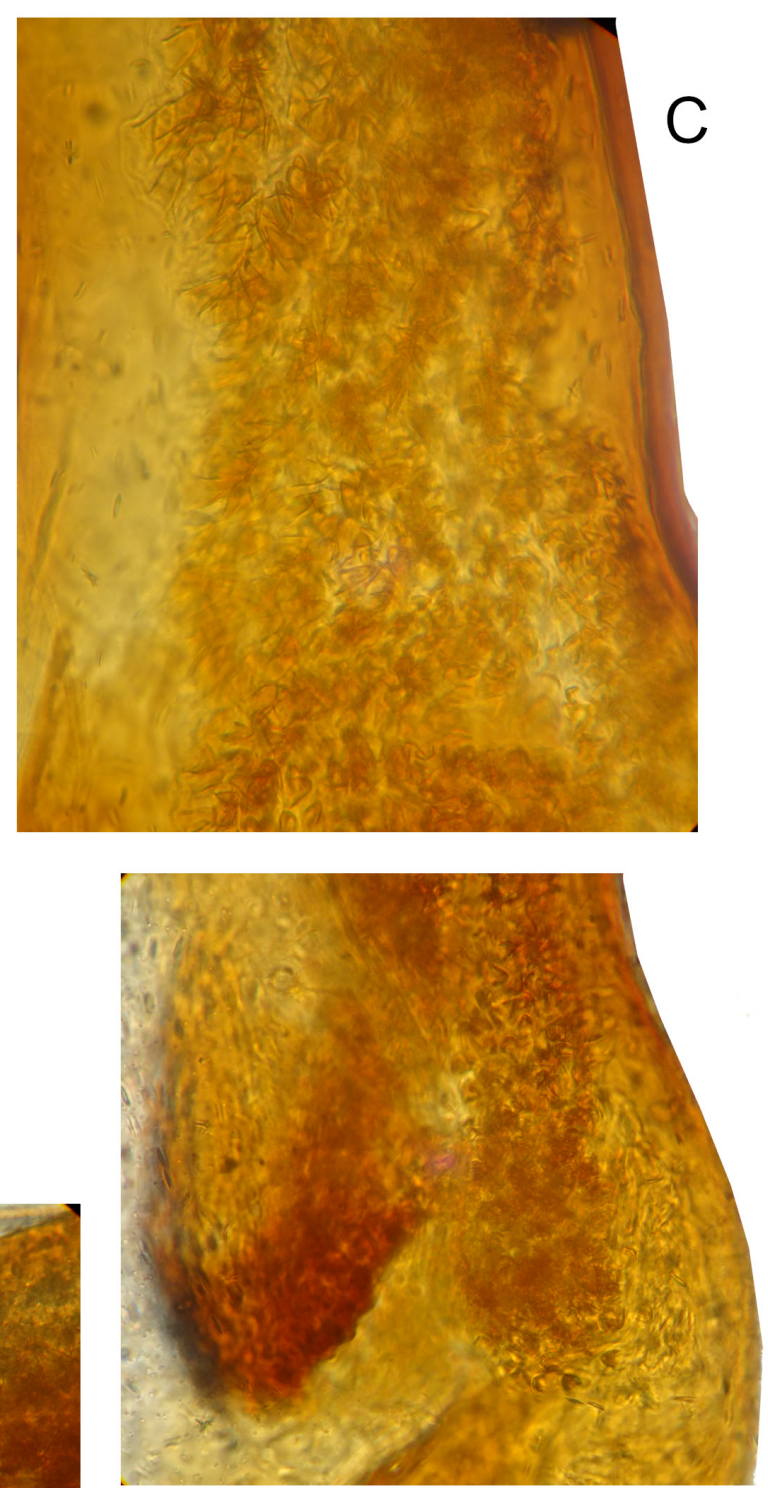

D

Fig. 25. Macrotomoderus kabaki sp. nov., holotype, $\widehat{\jmath}(\mathrm{ZIN})$, aedeagus. A-B. General view, different positions. C. Gonopore armature, median portion of apicale. D. Ditto, basal portion of apicale. E. Apical portion. Not to scale. 


\section{Description}

Measurements. Holotype, total body length $4 \mathrm{~mm}$; head $0.85 \mathrm{~mm}$ long, across eyes $0.8 \mathrm{~mm}$ broad, pronotum $1.05 \mathrm{~mm}$ long, maximum width $0.75 \mathrm{~mm}$, minimum width $0.35 \mathrm{~mm}$, elytra $2.1 \mathrm{~mm}$ long, $1.5 \mathrm{~mm}$ combined wide. Selected paratypes $4.25-4.5 \mathrm{~mm}$ long.

Dorsum and venter uniformly brown. Mouthparts, antennae, palps and legs yellowish-brown. Head ovoid with moderately large, ovoid compound eyes, which are slightly protruding beyond head outline laterally. Head rounded in broad arc posterior to eyes. Clypeus truncate at anterior margin. Head dorsal punctures minute and inconspicuous. Head dorsal setae inconspicuous, sparse. Antennae nearly touching base of pronotum. Antennomere three about $1.25 \times$ as long as antennomere two, antennomeres 8-10 transverse, of them 9-10 strongly transverse (Fig. 24D). Terminal antennomere triangular with rounded apex, twice as long as penultimate antennomere. Terminal maxillary palpomere securiform. Pronotum with broad and medially deeply notched postmedian lateral constriction. Front margin of anterior lobe broadly rounded, dorsally without anterior rim (Fig. 24B). Both lobes flattened in lateral view (Fig. 24C). Lateral constriction slightly continues onto disc in lateral view, shallow (Fig. 24C). Lateral pronotal fovea moderately broad at lower external margin of pronotum, widens upwards towards pronotal disc in lateral view, external margins protruding into a pair of moderately widely separated denticles (in lateral view), of which anterior denticle strongly obtuse and posterior subacute (in lateral view). Cavity in lateral wall of pronotum between lateral denticles not observed since the area laterally concealed by dense, whitish setae. In dorsal view, lateral pronotal fovea broad, anterior and posterior pair of denticles appear near rectangular to obtusely angulate, glabrous (Fig. 24B). Pronotal punctures minute on disc; lateral constriction dorsally with dense, irregularly shaped, moderately large punctures and median longitudinal carina that is projected to approximately midlength of anterior pronotal lobe. Dorsal pronotal setae inconspicuous, moderately long. Scutellar shield small, apically rounded. Elytra dorsally elongate elliptical, flattened in lateral view, widened laterally around midlength, shoulders obsolete (apterous species). Elytral apices subtruncate. Elytral punctures moderately large, rather dense, not becoming smaller and sparser towards apices. Elytral setae long and sparse, suberect. Male tergite and morphological sternite VII broadly rounded at posterior margin. Aedeagus as in Fig. 25, robust, elongate, apicale filled with dense, moderately strong, irregularly shaped and positioned, in part obtusely spinose gonopore armature.

\section{Sexual dimorphism}

Poorly indicated. Female antenna comparatively shorter than male.

\section{Ecology}

Collected at 3460 m elevation.

\section{Distribution}

Known only from surrounding of Lugu Lake, northern part of Yunnan Province, SW China.

Macrotomoderus korolevi sp. nov. urn:1sid:zoobank.org:act:DA8234A8-A2A7-4A17-89CA-687732FD6668

Figs 26-27

\section{Differential diagnosis}

Most similar to Macrotomoderus usitatus sp. nov. (described below). Differs primarily in the shape of the male aedeagus, the evenly rounded head base (the head base is medially subtruncate in M. usitatus sp. nov.), the dorsally comparatively denser and rougher punctured area on the lateral constriction (punctures on the area generally smaller and less rough in M. usitatus sp. nov.), and the absence of 
the large, strongly ovoid, median longitudinal notch on the lateral constriction (present in M. usitatus sp. nov.). Also see key to species below.

\section{Etymology}

Patronymic. Named in honour of one of the first collectors, Alexander Korolev (Russian Federal Research Institute of Fisheries and Oceanography, St Petersburg branch, St Petersburg, Russia).

\section{Type material}

\section{Holotype}

CHINA • $0^{\top}$ : “CHINA, Yunnan, W Yunxian Town, 2528'29"N 9958'23"E 2965 m, 17.vi.2011 Belousov, Kabak, Korolev leg.”; ZIN.

\section{Description}

Measurements. Holotype, total body length $4.2 \mathrm{~mm}$; head $0.95 \mathrm{~mm}$ long, across eyes $0.9 \mathrm{~mm}$ broad, pronotum $1 \mathrm{~mm}$ long, maximum width $0.85 \mathrm{~mm}$, minimum width $0.4 \mathrm{~mm}$, elytra $2.55 \mathrm{~mm}$ long, $1.75 \mathrm{~mm}$ combined wide.

Dorsum and venter uniformly brown, pronotum paler reddish-brown. Mouthparts, antennae, palps and legs yellowish-brown. Head ovoid with small, ovoid compound eyes, which are not protruding beyond head outline laterally. Head rounded in broad arc posterior to eyes. Head dorsal punctures minute and inconspicuous. Head dorsal setae inconspicuous, sparse. Antennae extending slightly over base of pronotum. Antennomere three about 1.1-1.2 $\times$ as long as antennomere two, antennomeres 8-10 transverse, of them 9-10 strongly transverse. Terminal antennomere triangular with pointed apex, about $1.6-1.7 \times$ as long as penultimate antennomere. Terminal maxillary palpomere securiform. Pronotum with broad and medially deeply notched postmedian lateral constriction. Front margin of anterior lobe subtruncate, dorsally without anterior rim (Fig. 26B). Anterior lobe slightly convex in lateral view (Fig. 26C). Lateral constriction continues onto disc in lateral view, shallow (Fig. 26C). Lateral pronotal fovea broad at lower external margin of pronotum, slightly widens upwards towards pronotal disc in lateral view, external margins protruding into a pair of obtuse (in lateral view), dorsally glabrous, moderately widely separated denticles (in lateral view). Cavity in lateral wall of pronotum between lateral denticles moderately large, elliptical. In dorsal view, lateral pronotal fovea broad, anterior and posterior pair of denticles appear obtusely angulate, glabrous (Fig. 26B). Pronotal punctures minute on disc; lateral constriction dorsally with dense and coarse, variably sized punctures. Dorsal pronotal setae inconspicuous, moderately long. Scutellar shield minute, triangular. Elytra dorsally elliptical, slightly convex in lateral view, strongly widened laterally around midlength, lateral margins evenly broadly rounded, shoulders obsolete (apterous species). Elytral punctures much stronger and larger than those on dorsal forebody, becoming less prominent on posterior third of elytra. Intervening spaces about $2-3 \times$ as large as punctures on basal half of elytra. Elytral setae long and sparse, suberect. Male tergite and morphological sternite VII broadly rounded at posterior margin. Aedeagus as in Fig. 27, large and broad, with balloon-like basale and peculiar, 'garland'-arranged gonopore armature. Basal portion of armature consists of large, pebble-shaped constituting pieces while in apical portion these large, elliptical pieces intermixed with dense, elongate, irregularly shaped, spine-like pieces. Near apex of aedeagus armature constituting pieces becoming smaller, generally less elongate (with exceptions).

\section{Sexual dimorphism}

Female is unknown.

\section{Ecology}

Collected at $2965 \mathrm{~m}$ elevation. 

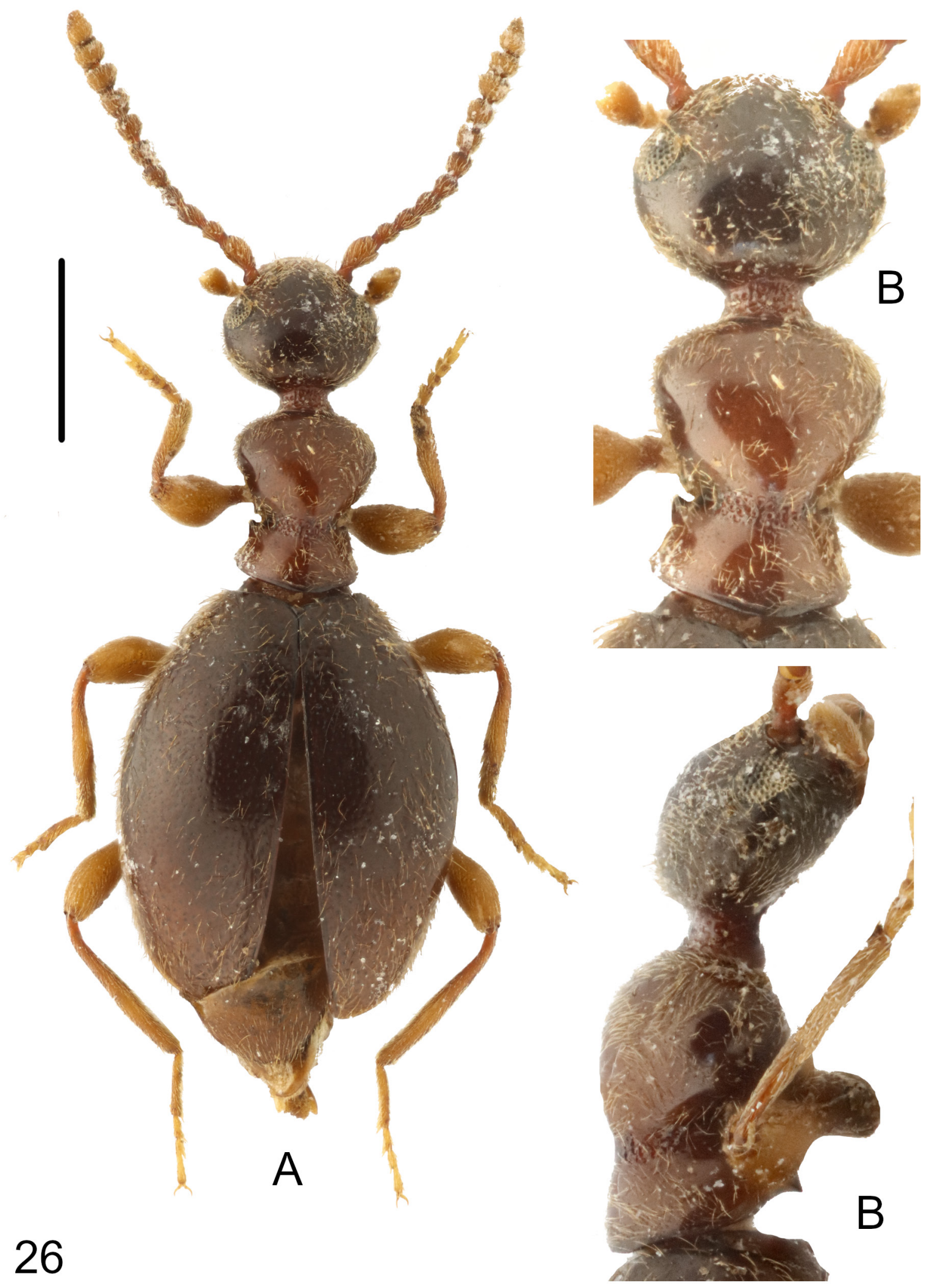

Fig. 26. Macrotomoderus korolevi sp. nov., holotype, $\widehat{\partial}(\mathrm{ZIN})$. A. Habitus, dorsal view. B. Forebody, dorsal view. C. Ditto, lateral view. Scale bar: $A=1 \mathrm{~mm}$; $B-C=$ not to scale. 


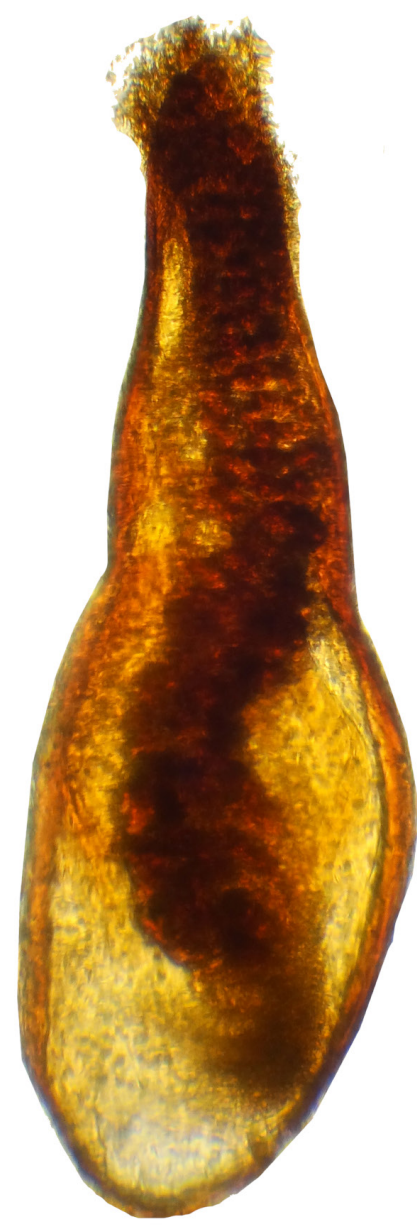

A

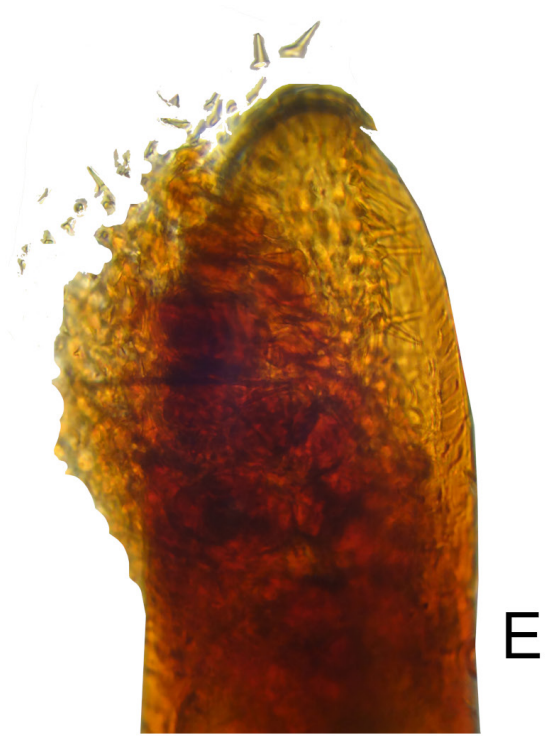

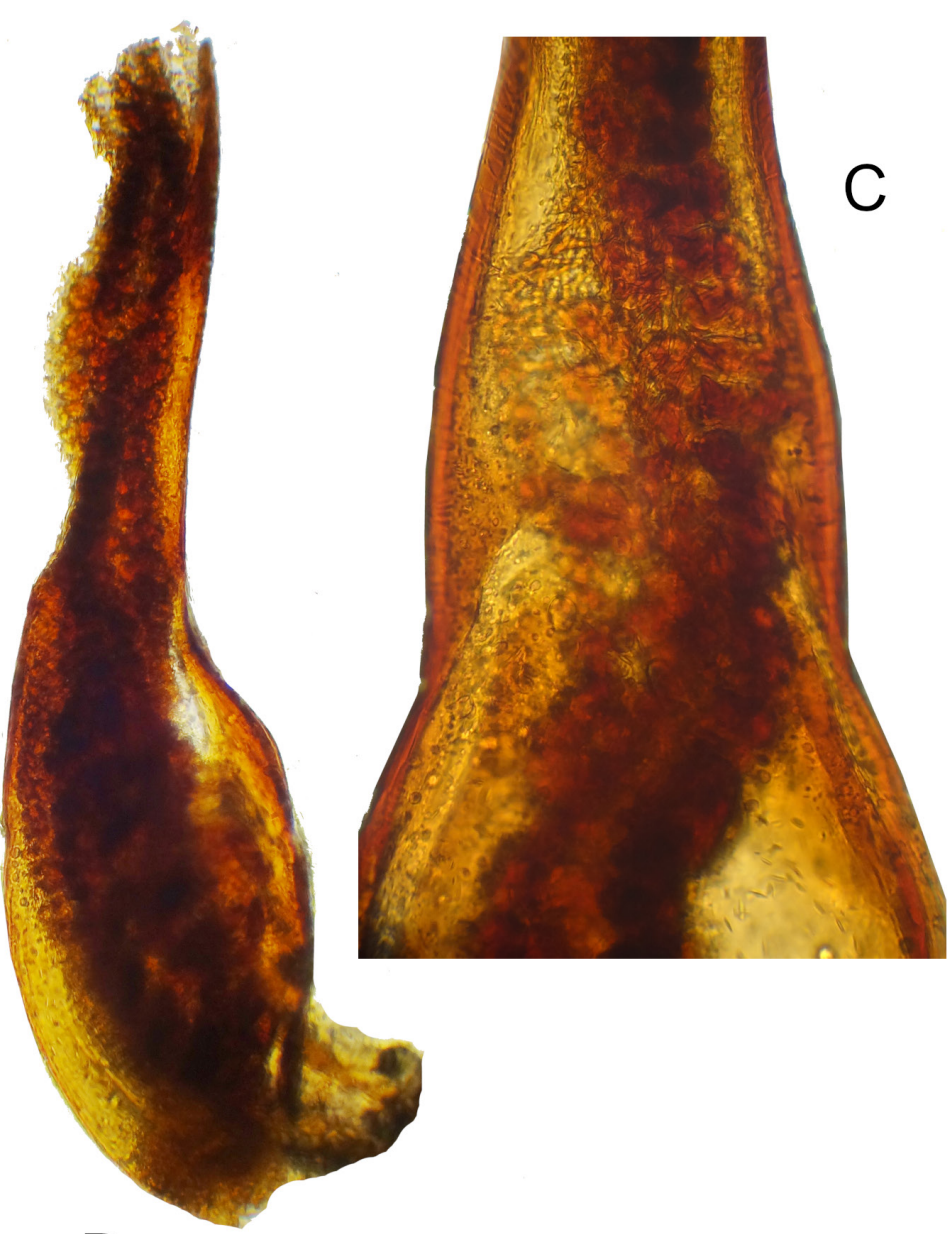

B

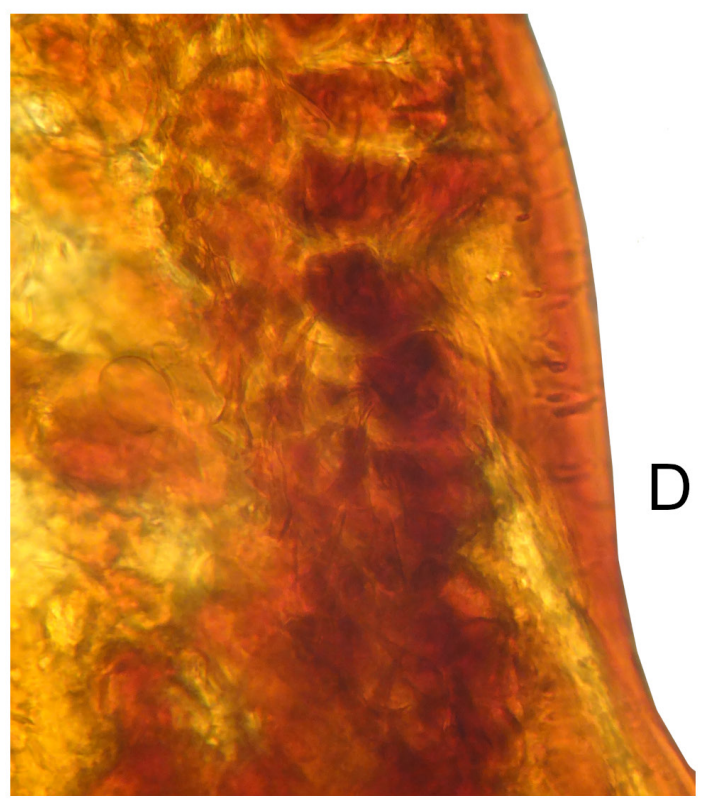

Fig. 27. Macrotomoderus korolevi sp. nov., holotype, $\widehat{\partial}(\mathrm{ZIN})$, aedeagus. A-B. General view, different positions. C. Gonopore armature, median portion of aedeagus. D. Ditto, basal portion of apicale, stronger magnification. E. Apical portion. Not to scale. 
TELNOV D., New species of Macrotomoderus, with a key to the Palaearctic taxa

\section{Distribution}

Known only from east of Erhai Lake, central part of Yunnan Province, SW China.

Macrotomoderus lapidarius sp. nov. urn:lsid:zoobank.org:act:9A75AB9B-80C4-4735-B09E-4BA38C365337

Figs $28-29$

\section{Differential diagnosis}

This species readily differs from all congeners due to the specifically modified head base and the anterior margin of pronotum (see details below) in the combination with the comparatively broad, robust pronotum and the specific shape of the male genitalia. The structure of the anterior margin of the pronotum similar as in M. truncatulus sp. nov. (see description below), consider diagnosis of this species.

\section{Etymology}

Since the city of Yujiacun near the type locality of this new species is widely known in China for its ancient stone houses, stone streets, wells and stone terraced fields, the new species is named from the Latin 'lapidarius' ('the practice of shaping stone and minerals, or gemstones into decorative items').

\section{Type material}

\section{Holotype}

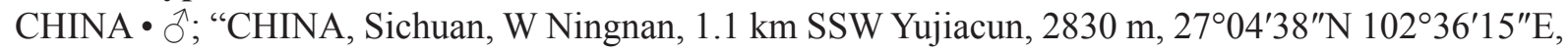
1.vii.2018 Belousov \& Kabak lg."; ZIN.

\section{Description}

Measurements. Holotype, total body length $4.08 \mathrm{~mm}$; head $0.83 \mathrm{~mm}$ long, across eyes $0.75 \mathrm{~mm}$ broad, pronotum $1 \mathrm{~mm}$ long, maximum width $0.8 \mathrm{~mm}$, minimum width $0.45 \mathrm{~mm}$, elytra $2.25 \mathrm{~mm}$ long, $1.55 \mathrm{~mm}$ combined wide.

Forebody dorsally and ventrally brown, elytra dark brown. Mouthparts, antennae, palps and legs yellowish-brown. Head ovoid with moderately large, ovoid compound eyes, which are not protruding beyond head outline laterally. Head rounded in broad arc posterior to eyes. Head base with conspicuous, short and broad, posteriad-pointed median triangular projection that is provided with a group of dense, thick, yellowish setae on both sides of this projection (Fig. 28B-C). Head dorsal punctures minute and inconspicuous. Head dorsal setae inconspicuous, sparse. Antennae extending slightly over base of pronotum. Antennomere three nearly same long as antennomere two, antennomeres 9-10 transverse. Terminal antennomere shortly triangular with rounded apex, 1.2-1.3 $\times$ as long as penultimate antennomere. Terminal maxillary palpomere securiform. Pronotum shortly cylindrical with very broad and medially shortly notched postmedian lateral constriction. Front margin of anterior lobe broadly rounded, in male deeply and broadly impressed mesally opposite median part of head base; anterolateral margins of this impression are moderately strongly raised in dorsal aspect, acutely denticulate (Fig. 28B). Anterior edge of pronotum in front of anterior impression in male forms thin and short median wall, at upper margin with a row of golden, long, in part curved and anteriad-pointing setae (Fig. 28B-C). Pronotum dorsally without anterior rim. Anterior and posterior lobe slightly convex in lateral view (Fig. 28C). Lateral constriction slightly continues onto disc in lateral view, broad and shallow (Fig. 28C). Lateral pronotal fovea broad at lower external margin of pronotum, slightly widens upwards towards pronotal disc in lateral view, external margins protruding into a pair of obtuse (in lateral view), moderately widely separated denticles (in lateral view). Cavity in lateral wall of pronotum between lateral denticles moderately large, elliptical. In dorsal view, lateral pronotal fovea moderately broad, anterior and posterior pair of denticles appear obtusely angulate, glabrous (Fig. 28B). Pronotal punctures minute 

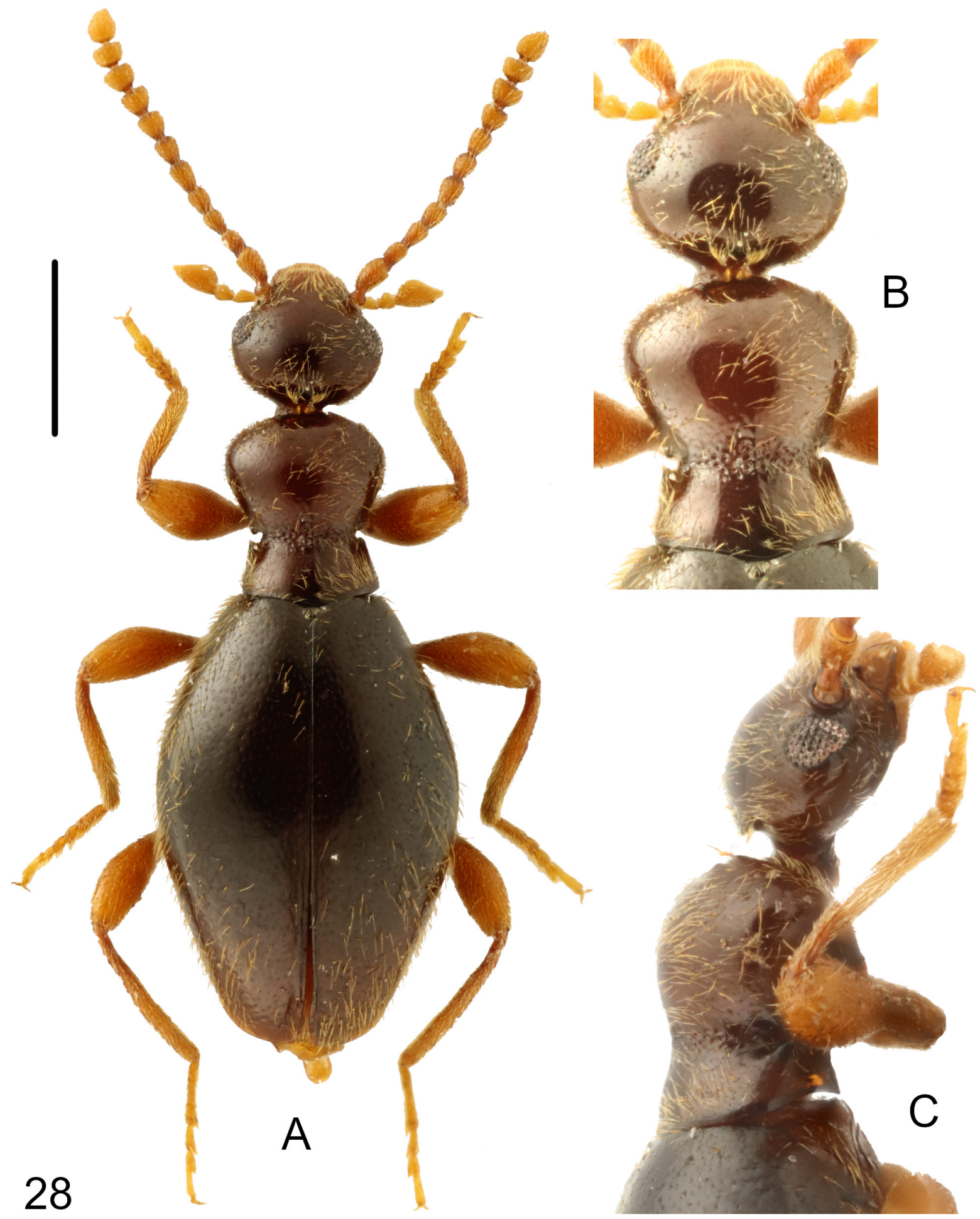

Fig. 28. Macrotomoderus lapidarius sp. nov., holotype, ô (ZIN). A. Habitus, dorsal view. B. Forebody, dorsal view. C. Ditto, lateral view. Scale bar: $A=1 \mathrm{~mm}$; $B-C=$ not to scale. 

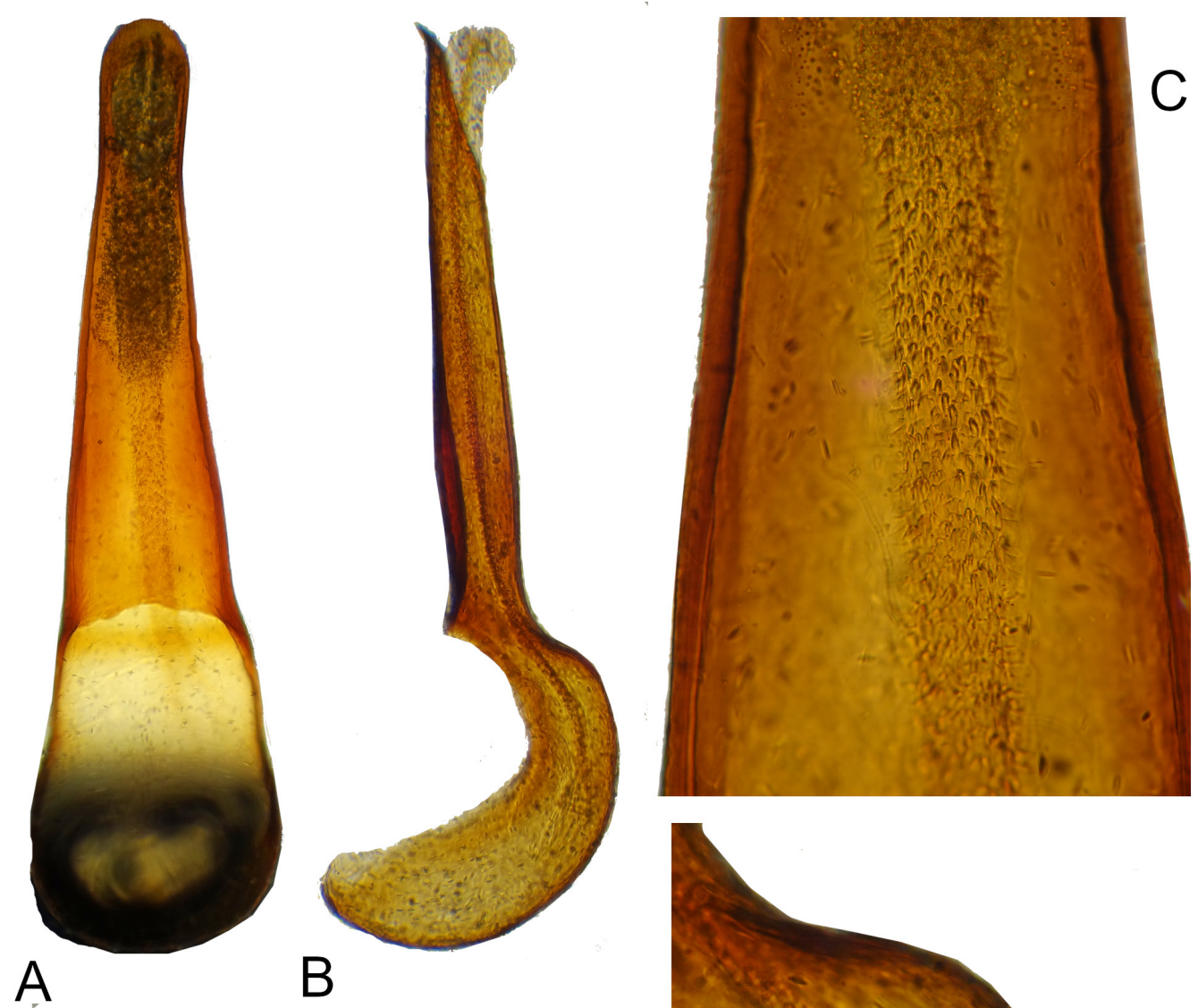

$\mathrm{B}$
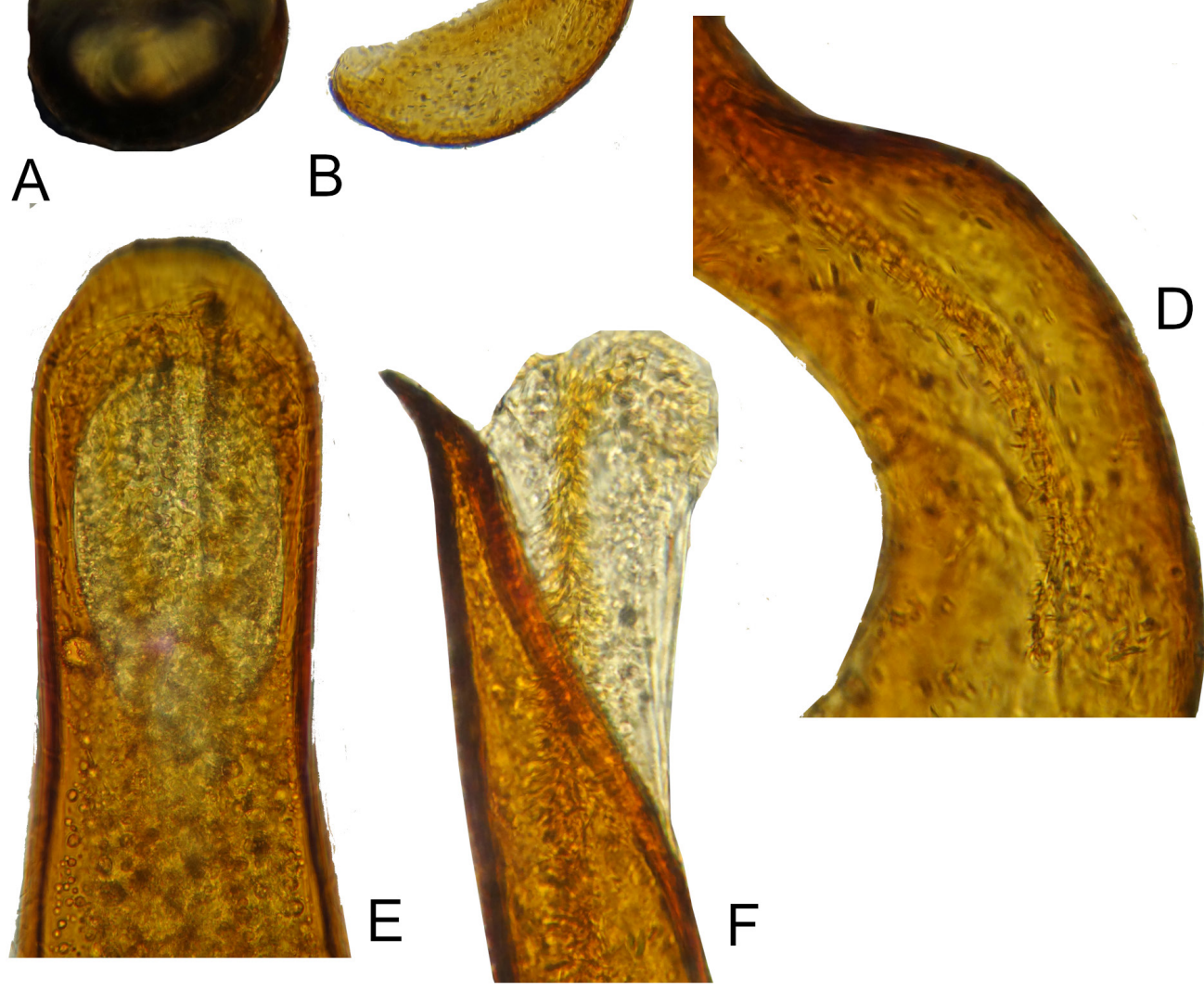

29

Fig. 29. Macrotomoderus lapidarius sp. nov., holotype, $\widehat{\jmath}(\mathrm{ZIN})$, aedeagus. A-B. General view, different positions. C. Gonopore armature, median portion of apicale. D. Ditto, apical portion of basale. E. Apical portion. F. Ditto, different position. Not to scale. 
on disc; lateral constriction dorsally with very dense, irregularly shaped and variably sized punctures, few largest of which positioned medially in constriction. Dorsal pronotal setae rather long, appressed, at least in part concealing surface of posterior pronotal lobe. Scutellar shield small, apically rounded. Elytra dorsally elongate elliptical, slightly convex in lateral view, widened laterally around midlength, shoulders obsolete (apterous species). Elytral punctures moderately large, very sparse, becoming smaller and sparser towards apices. Elytral setae long and sparse, suberect. Male tergite and morphological sternite VII broadly rounded at posterior margin. Aedeagus as in Fig. 29, large and elongate, basale strongly hook-shaped in lateral view. Gonopore armature arranged into one 'garland', constituting pieces elongate-papillate in basal portion of armature, becoming very dense, spine-like, closely attached to one another in apical portion of aedeagus.

\section{Sexual dimorphism}

Female is unknown.

\section{Ecology}

Collected at 2830 m elevation.

\section{Distribution}

Known only from southern part of Sichuan Province, SW China.

Macrotomoderus mirabilis Telnov, 2018

\section{New material}

CHINA • 2 specimens; "CHINA, Yunnan, SSE Shuangjiang Town, 2425-2570 m, 20.vi.2011 Belousov,

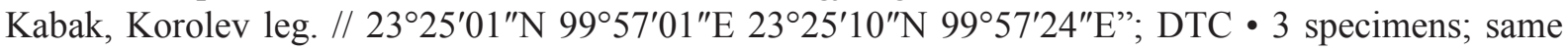
labels as for preceding; ZIN.

\section{Note}

Previously only known from Xue Mountains of Yunnan Province, SW China and the new record is from adjacent area.

Macrotomoderus muli sp. nov. urn:1sid:zoobank.org:act:87629CA2-F57D-48D4-BADB-F46123D350EB

Figs 30-31

\section{Differential diagnosis}

See key to species below.

\section{Etymology}

Named after Muli Tibetan Autonomous County in Sichuan, where this species was first collected. Noun in apposition.

\section{Type material}

\section{Holotype}

CHINA - O'; "CHINA, Sichuan, S of Muli, 3975-4120 m, 22.v.2012 Belousov, Davidian, Kabak \& Korolev leg. // $27^{\circ} 43^{\prime} 16^{\prime \prime} \mathrm{N} 101^{\circ} 15^{\prime} 13^{\prime \prime} \mathrm{E} 27^{\circ} 43^{\prime} 03^{\prime \prime} \mathrm{N} 101^{\circ} 15^{\prime} 05^{\prime \prime} \mathrm{E} " ;$ ZIN.

Paratype (1 specimen)

CHINA • 1 क; same labels as for holotype; DTC. 


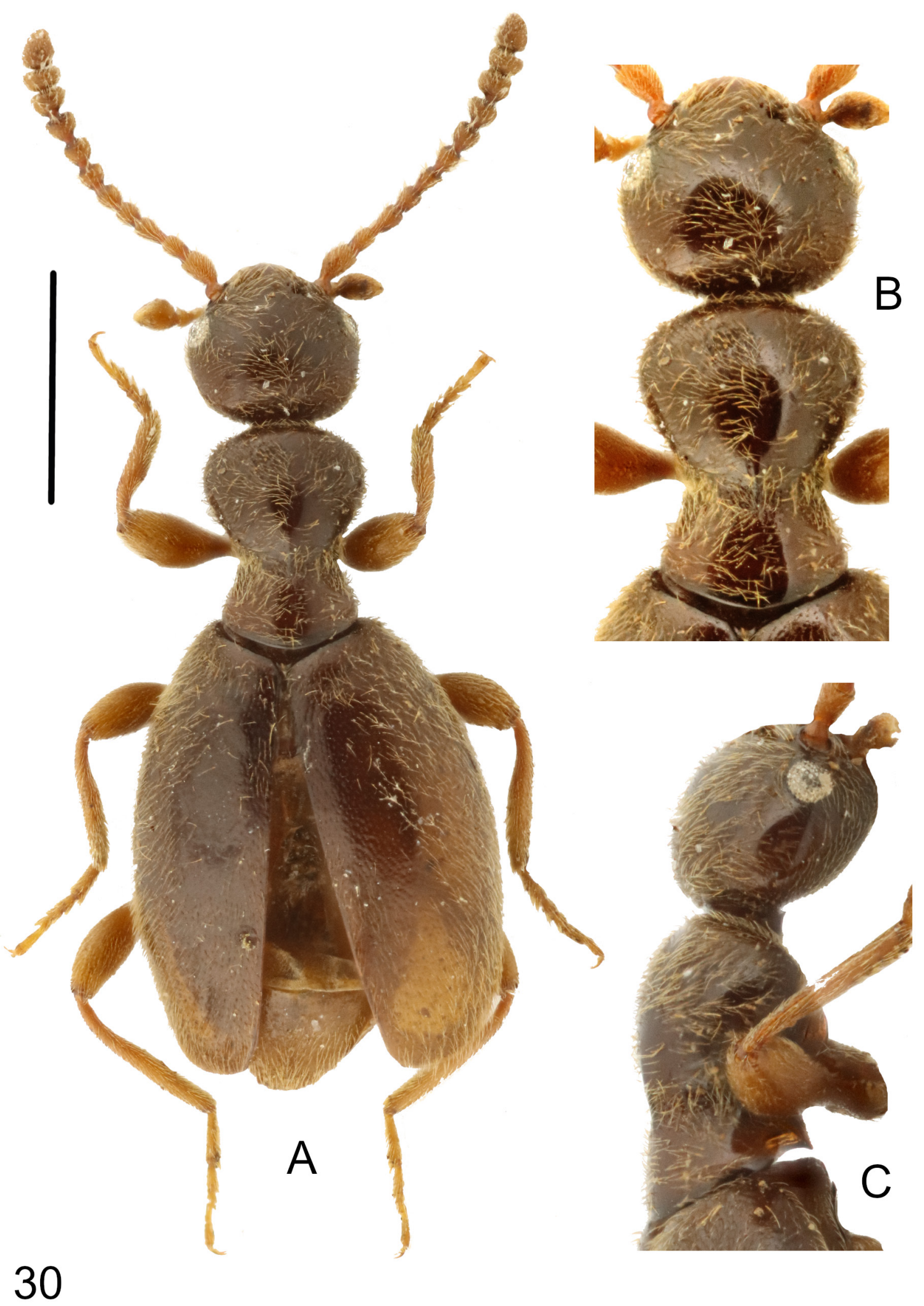

Fig. 30. Macrotomoderus muli sp. nov., holotype, $\widehat{\partial}$ (ZIN). A. Habitus, dorsal view. B. Forebody, dorsal view. C. Ditto, lateral view. Scale bar: $A=1 \mathrm{~mm} ; \mathrm{B}-\mathrm{C}=$ not to scale. 

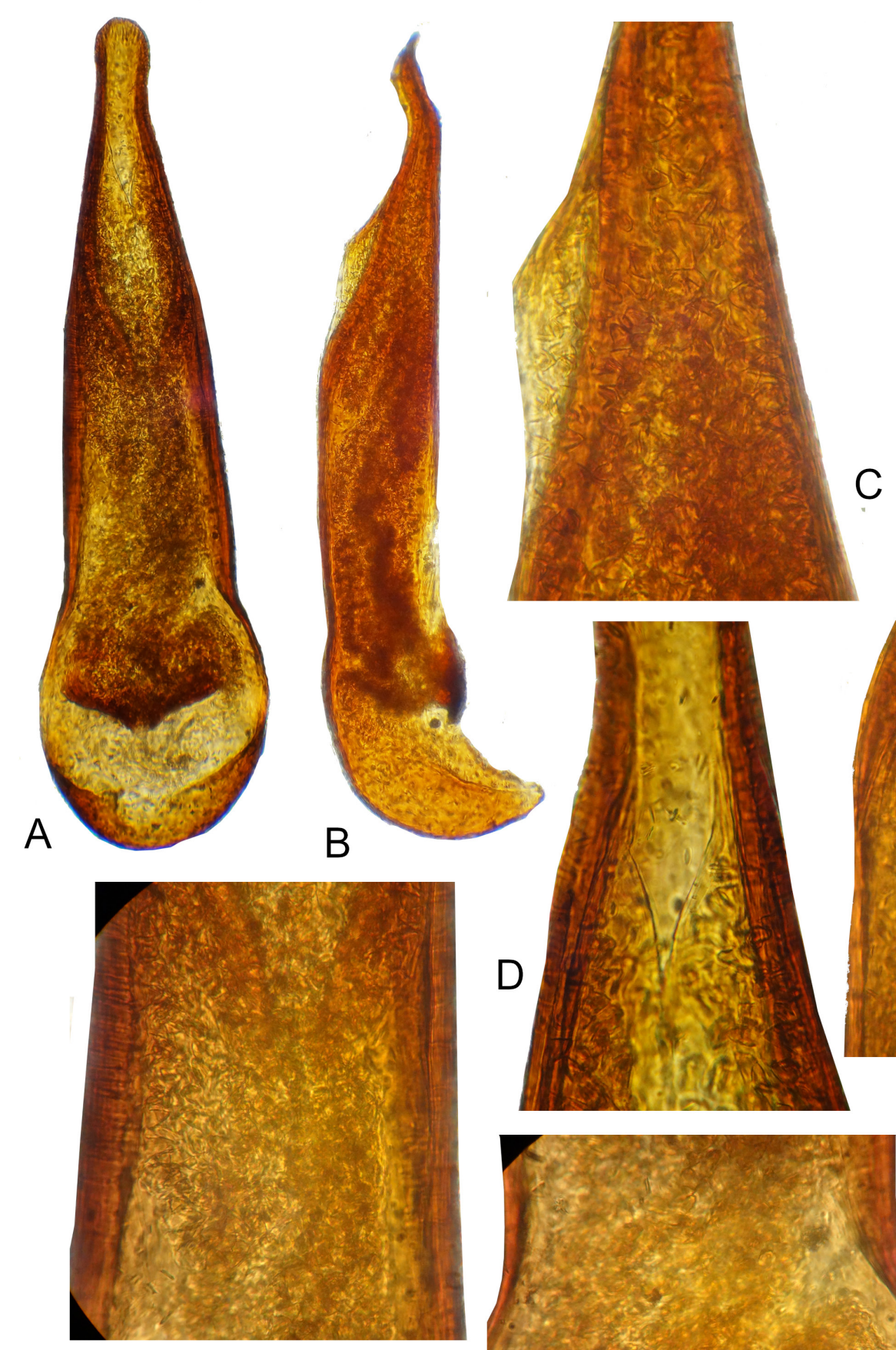

$\mathrm{E}$

31
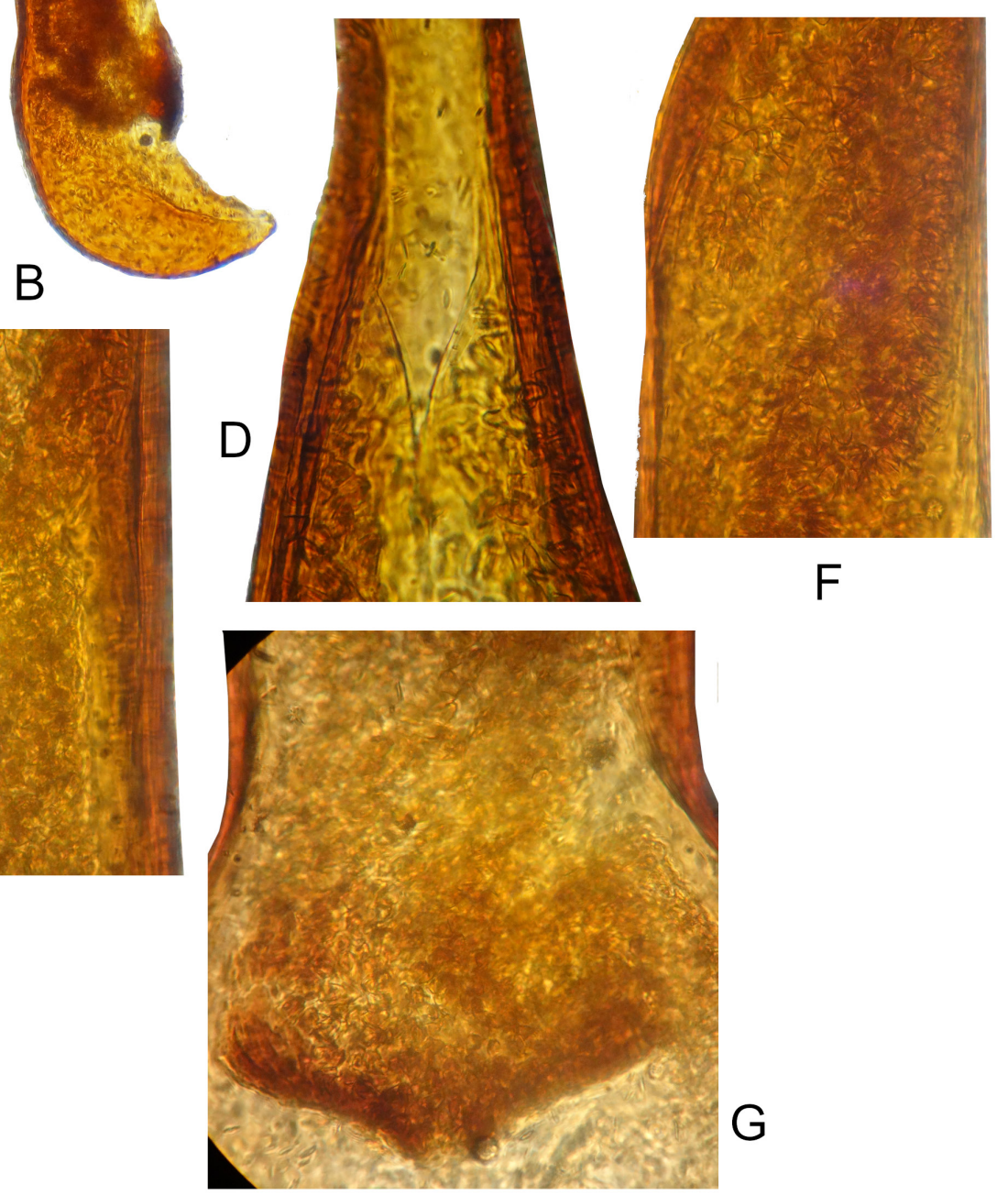

Fig. 31. Macrotomoderus muli sp. nov., holotype, ô (ZIN), aedeagus. A-B. General view, different positions. C. Gonopore armature, apical portion of apicale. D. Ditto, different position. E. Median portion of apicale. F. Ditto, different position. G. Basale. Not to scale. 


\section{Description}

Measurements. Holotype, total body length $3.93 \mathrm{~mm}$; head $0.83 \mathrm{~mm}$ long, across eyes $0.8 \mathrm{~mm}$ broad, pronotum $1 \mathrm{~mm}$ long, maximum width $0.7 \mathrm{~mm}$, minimum width $0.45 \mathrm{~mm}$, elytra $2.1 \mathrm{~mm}$ long, $1.4 \mathrm{~mm}$ combined wide. Female paratype is $4.25 \mathrm{~mm}$ long.

Dorsum and venter uniformly brown. Mouthparts, antennae, palps and legs paler brown. Head ovoid with small, ovoid compound eyes, which are not or slightly protruding beyond head outline laterally. Tempora twice or more as long as dorsal eye length, slightly constricted posteriad. Head base broadly rounded. Head dorsal punctures minute and inconspicuous. Head dorsal setae moderately dense. Antennae extending towards base of pronotum. Antennomere three about 1.1.-1.2 $\times$ as long as antennomere two, antennomeres 4-5 shortened, ovoid, antennomeres 7-10 transverse, of them 9-10 strongly transverse. Terminal antennomere broadly triangular with obtuse angulate apex, about $1.6-1.7 \times$ as long as penultimate antennomere. Terminal maxillary palpomere slightly securiform, nearly triangular. Pronotum with broad and medially moderately deeply notched postmedian lateral constriction. Front margin of anterior lobe very broadly rounded, dorsally without anterior rim (Fig. 30B). Anterior lobe barely convex in lateral view (Fig. 30C). Lateral constriction barely continues onto disc in lateral view, very shallow (Fig. 30C). Lateral pronotal fovea moderately broad at lower external margin of pronotum, widens upwards towards pronotal disc in lateral view, external margins protruding into a pair of obtuse (in lateral view), rather narrowly separated denticles (in lateral view). Cavity in lateral wall of pronotum between lateral denticles not observed since the area laterally concealed by dense, golden setae. In dorsal view, lateral pronotal fovea broad, anterior and posterior pair of denticles appear obtusely angulate, glabrous, dorsally and ventrally concealed with long, rather dense setae from adjoining portions of lateral constriction (Fig. 30B). Pronotal punctures minute on disc; lateral constriction dorsally with gentle, short median longitudinal carina and dense, moderately large, irregularly shaped punctures. Dorsal pronotal setae moderately dense. Scutellar shield minute, triangular. Elytra dorsally elongate, flattened in lateral view, slightly widened laterally prior to middle, shoulders obsolete (apterous species). Elytral punctures ovoid, shallow, rather dense, becoming smaller or sparser towards apices. Intervening spaces on anterior half of elytra about same wide as punctures. Elytral setae long and sparse, suberect. Male tergite and morphological sternite VII broadly rounded at posterior margin. Aedeagus as in Fig. 31, large and robust, with elliptical basale. Apicale filled with very dense, irregularly shaped and positioned, in part spinose gonopore armature. Constituting pieces of armature in basale distinctly elliptical, not spinose compared to those in apical portion of gonopore armature.

\section{Sexual dimorphism}

Not indicated externally.

\section{Ecology}

Collected at 3975-4120 m elevation.

\section{Distribution}

Known only from Muli Tibetan Autonomous County, southern part of Sichuan Province, central China.

Macrotomoderus negator Telnov, 2007

\section{New material}

CHINA • 2 specimens; "CHINA, Yunnan, SSE Shuangjiang Town, 2425-2570 m, 20.vi.2011 Belousov,

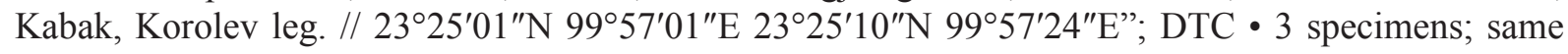
labels as for preceding; ZIN - 2 specimens; "CHINA, Chongquing, Dabashan MtR, NE Heyu Vill., 2510-1790 m, 16.v.2010 Belousov, Kabak \& Korolev leg. // 31 $55^{\prime} 17^{\prime \prime} \mathrm{N} 109^{\circ} 04^{\prime} 37^{\prime \prime} \mathrm{E} 31^{\circ} 54^{\prime} 53^{\prime \prime} \mathrm{N}$ 
10903'27"E”; ZIN • 1 specimen; "CHINA, Chongquing, Dabashan MtR, S Gaoguan Vill., 1845-2005

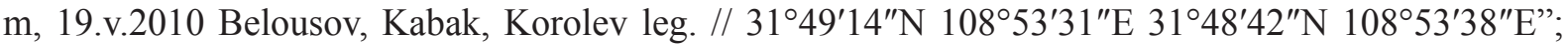
ZIN • 2 specimens; "CHINA, Chongquing, Dabashan MtR, S Gaoguan Vill., 1730-1845 m, 18.v.2010

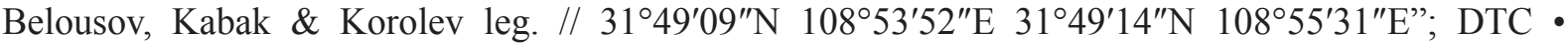
1 specimen; same labels as for preceding; ZIN.

\section{Note}

Previously only known from Xue Mountains of Yunnan Province, SW China and the new record is from adjacent area. Previously only known from Daba Mountains of Shaanxi / Sichuan provinces, central China and the new records are from adjacent area.

Macrotomoderus palaung sp. nov. urn:1sid:zoobank.org:act:A5AC11E9-9F42-4822-8ECB-76DB1CC6946D

Figs $32-33$

\section{Differential diagnosis}

This species is readily different from all congeners in the slightly declivous anterior margin of the male pronotum. Also see key to species below.

\section{Etymology}

Named after Palaung (also known as Palong), a Mon-Khmer ethnic minority in Shan State of Myanmar, Yunnan Province of China, and Northern Thailand. In China, they are usually referred to as the De'ang. Noun in apposition.

\section{Type material}

\section{Holotype}

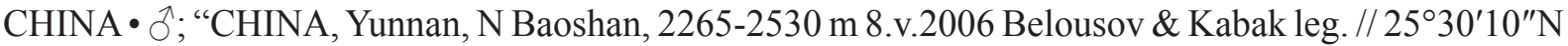
$99^{\circ} 06^{\prime} 40^{\prime \prime} \mathrm{E} 25^{\circ} 29^{\prime} 26^{\prime \prime} \mathrm{N} 99^{\circ} 06^{\prime} 16^{\prime \prime} \mathrm{E} "$; ZIN.

Paratypes (4 specimens)

CHINA • 2 우; same labels as for holotype; ZIN 1 ô, 1 q; same labels as for holotype; DTC.

\section{Description}

MeAsurements. Holotype, total body length $3.7 \mathrm{~mm}$; head $0.8 \mathrm{~mm}$ long, across eyes $0.78 \mathrm{~mm}$ broad, pronotum $1 \mathrm{~mm}$ long, maximum width $0.75 \mathrm{~mm}$, minimum width $0.3 \mathrm{~mm}$, elytra $1.9 \mathrm{~mm}$ long, $1.4 \mathrm{~mm}$ combined wide. Selected paratypes are $3.6 \mathrm{~mm}(+), 3.8 \mathrm{~mm}$ and $3.9 \mathrm{~mm}$ long.

Dorsum and venter uniformly brown, pronotum slightly paler. Mouthparts, antennae, palps and legs yellowish-brown. Head ovoid with rather small, ovoid compound eyes, which are not protruding beyond head outline laterally. Head rounded in broad arc posterior to eyes. Head dorsal punctures minute, moderately deep. Intervening spaces glossy and glabrous twice to $4 \times$ as large as punctures. Head dorsal setae inconspicuous, moderately dense. Antennae extending slightly beyond base of elytra. Antennomere three about $1.5 \times$ as long as antennomere two, antennomeres $7-10$ transverse, of them 9-10 strongly transverse. Terminal antennomere triangular with pointed apex, about $1.7-1.8 \times$ as long as penultimate antennomere. Terminal maxillary palpomere securiform. Pronotum with broad and medially deeply notched postmedian lateral constriction. Anterior lobe distinctly wider than posterior. Front margin of anterior lobe truncate in male (Fig. 32B), subtruncate in female, in male slightly declivous anteriad medially, in both sexes dorsally without anterior rim. Anterior lobe convex in lateral view (Fig. 32C). Lateral constriction continues onto disc in lateral view, rather shallow (Fig. 32C). Lateral 

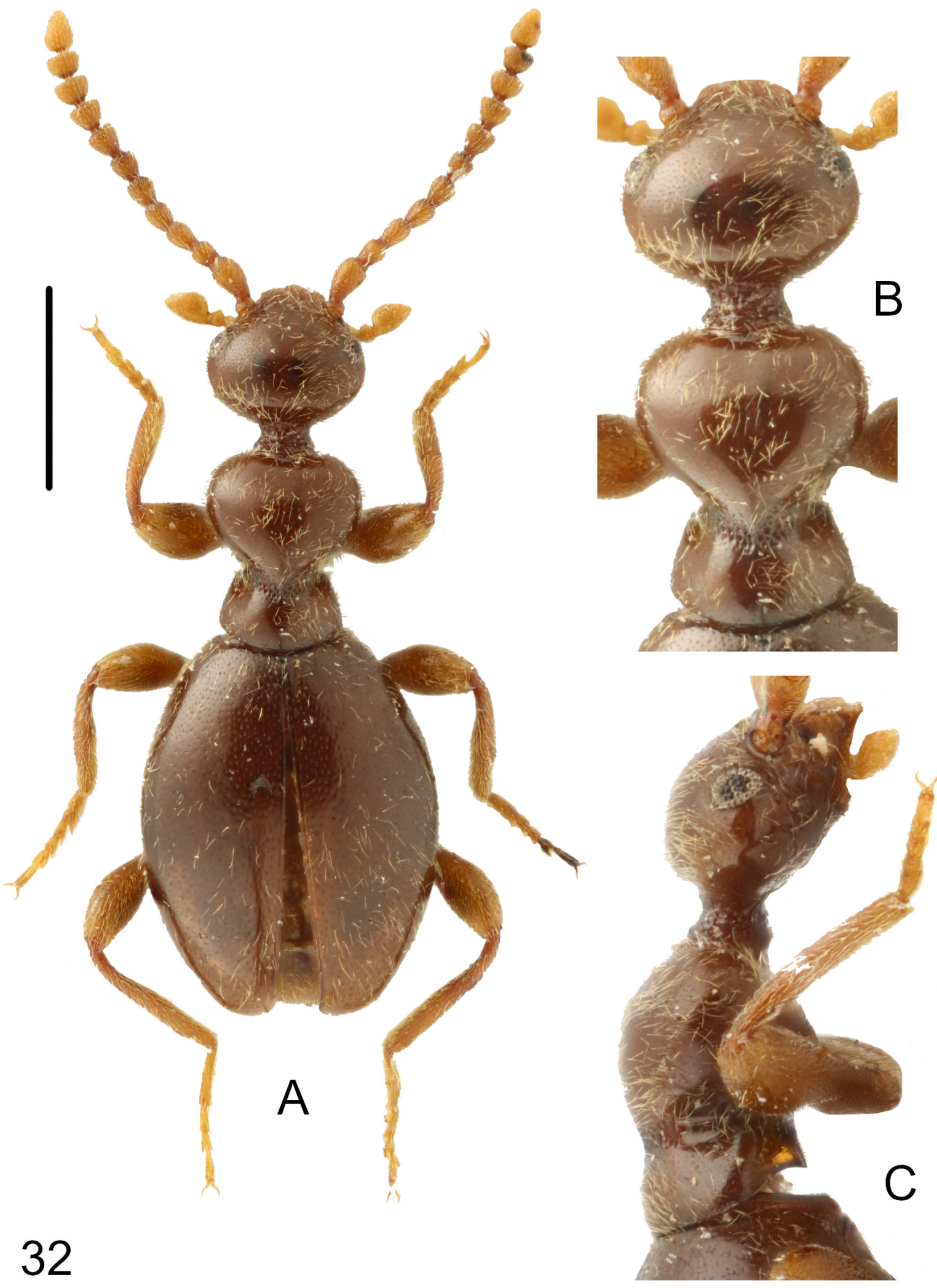

Fig. 32. Macrotomoderus palaung sp. nov., holotype, $\widehat{\curlywedge}(\mathrm{ZIN})$. A. Habitus, dorsal view. B. Forebody, dorsal view. C. Ditto, lateral view. Scale bar: $A=1 \mathrm{~mm}$; $B-C=$ not to scale. 

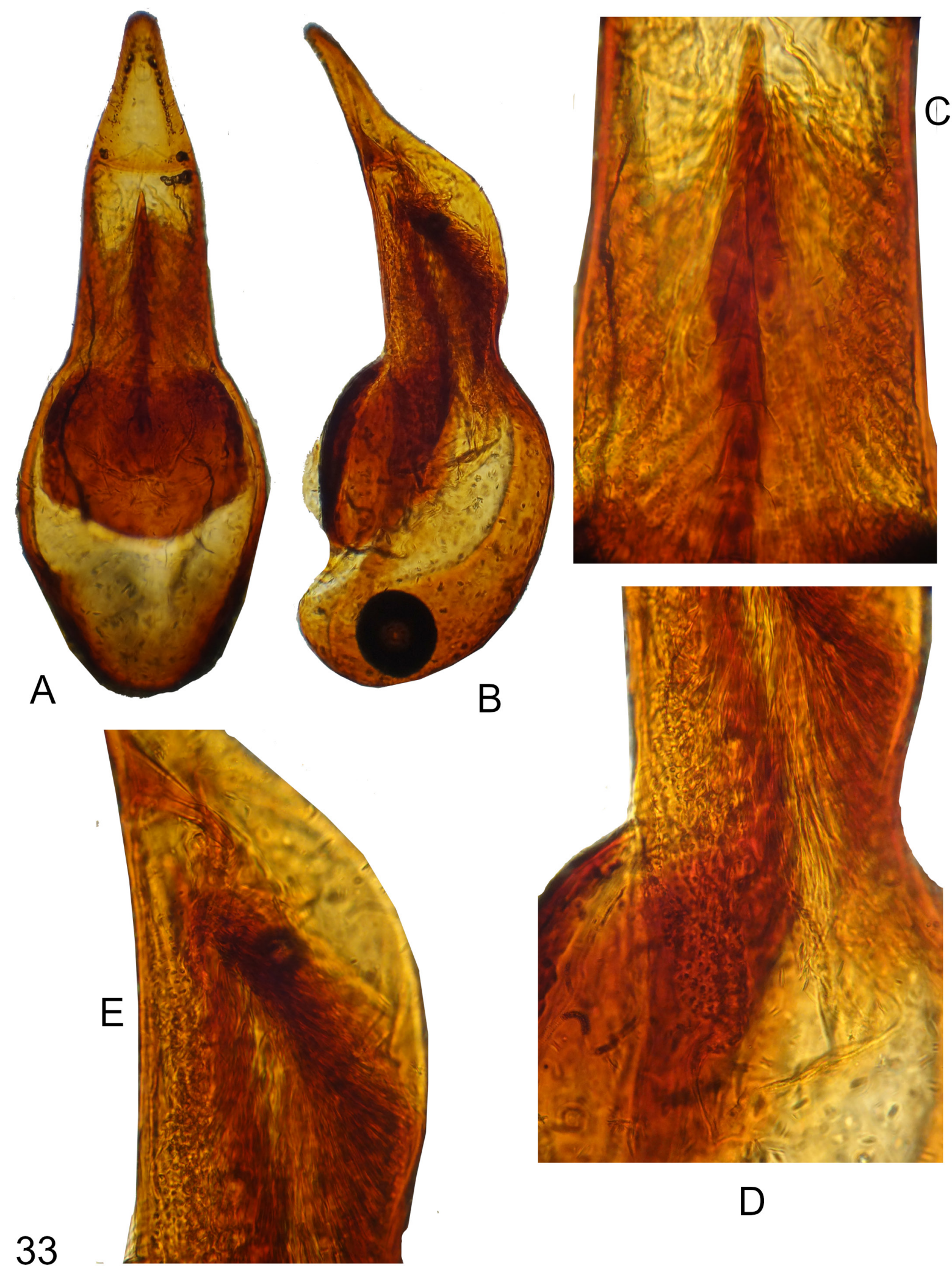

Fig. 33. Macrotomoderus palaung sp. nov., holotype, $\widehat{\partial}(\mathrm{ZIN})$, aedeagus. A-B. General view, different positions. C. Gonopore armature, median portion of apicale. D. Ditto, basal portion of apicale. E. Median portion of apicale, different position. Not to scale. 
pronotal fovea broad at lower external margin of pronotum, widens upwards towards pronotal disc in lateral view, external margins protruding into a pair of obtuse (in lateral view), widely separated denticles (in lateral view). Cavity in lateral wall of pronotum between lateral denticles not observed. In dorsal view, lateral pronotal fovea broad and deep, anterior and posterior pair of denticles appear obtusely angulate, glabrous, dorsally partially concealed with setae from adjoining portions of lateral constriction (Fig. 32B). Pronotal punctures generally stronger but similarly sparse as those on head. Lateral constriction dorsally with elongate, large and very dense, coarse, irregularly shaped punctures. Dorsal pronotal setae inconspicuous, moderately long. Scutellar shield minute, apically rounded. Elytra dorsally shortly elliptical, flattened in lateral view, strongly widened laterally in median third, lateral margins of elytra broadly rounded, shoulders obsolete (apterous species). Elytral punctures stronger than those on anterior lobe of pronotum moderately deep, sparse, becoming slightly shallower towards apices. Intervening spaces generally $2-10 \times$ as large as punctures. Elytral setae long and sparse, suberect. Male tergite and morphological sternite VII broadly rounded at posterior margin. Aedeagus as in Fig. 33, short and broad, bigibbose in lateral view, with peculiar gonopore armature consisting of a median "vertebra" of elongate-triangular, acute constituting pieces laterally enclosed into broad tube of less prominent, elongate, dense constituting pieces. Apical portion of apicale without armature.

\section{Sexual dimorphism}

Female externally similar to male, anterior margin of pronotum is evenly convex, not declivous.

\section{Ecology}

Collected in pitfall traps at 2265-2530 m elevation.

\section{Distribution}

Known only from western part of Yunnan Province, SW China.

Macrotomoderus perforatus Telnov, 2018

\section{New material}

CHINA • 1 o; “CHINA, Yunnan, ENE Lincang Town, 2354'38"N 100¹8'33"E 2190 m, 25.vi.2011 Belousov, Kabak, Korolev leg.”; ZIN.

\section{Note}

This species was originally described from Lincang Prefecture, the new locality is within the known range of this species.

Macrotomoderus similis sp. nov. urn:lsid:zoobank.org:act:6E0B08FA-F336-4902-9E72-767D78C5FA95

Figs $34-35$

\section{Differential diagnosis}

This species appears similar to Macrotomoderus truncatulus sp. nov. (see description below) primarily due to the similar modification present at the anterior pronotal margin. However, the head base is stronger truncate with the obtuse but well-visible temporal angles in M. truncatulus sp. nov., the setae of the upper margin of the anterior wall of the antero-median pronotal impression are distinctly curved and pointed anteriad (not or slightly curved in M. similis sp. nov.), the pronotal constriction dorsally with a track of the longitudinal median carina (not observed in M. similis sp. nov.), and the lateral margins of the antero-median pronotal impression are stronger raised, slightly denticulate in dorsal view (not or almost not raised, not denticulate-like produced in M. similis sp. nov.). Also see key to species below. 


\section{Etymology}

Named from the Latin 'similis' ('similar') to highlight its morphological similarity with Macrotomoderus truncatulus sp. nov. (see description below).

\section{Type material}

\section{Holotype}

CHINA • ${ }^{\top}$; “CHINA, Yunnan, SSE Shuangjiang Town, 2540 m, 22.vi.2011 Belousov, Kabak, Korolev leg. // 2322'22"N 9954'47"E”; ZIN.

\section{Description}

MEasurements. Holotype, total body length $3.35 \mathrm{~mm}$; head $0.8 \mathrm{~mm}$ long, across eyes $0.75 \mathrm{~mm}$ broad, pronotum $0.9 \mathrm{~mm}$ long, maximum width $0.7 \mathrm{~mm}$, minimum width $0.4 \mathrm{~mm}$, elytra $1.65 \mathrm{~mm}$ long, $1.5 \mathrm{~mm}$ combined wide.

Dorsum and venter uniformly pale brown. Mouthparts, antennae, palps and legs yellowish-brown. Head ovoid with small, ovoid compound eyes, which are not or slightly protruding beyond head outline laterally. Tempora rounded and converging towards head base, temporal angles broadly rounded. Head base subtruncate; occiput somewhat declivous posteroventrally above insertion of cranial neck (in posterodorsal view head base appear medially truncate). Head dorsal punctures minute and inconspicuous. Head dorsal setae inconspicuous, sparse. Antennae extending towards base of pronotum. Antennomere three nearly same length as antennomere two, antennomeres 8-10 transverse, of them 9-10 strongly transverse. Terminal antennomere shortly triangular with obtusely pointed apex, about $2.1-2.2 \times$ as long as penultimate antennomere. Terminal maxillary palpomere securiform. Pronotum with broad and medially shortly notched postmedian lateral constriction. Front margin of anterior lobe broadly rounded, in male shallowly and broadly impressed mesally opposite median part of head base; anterolateral margins of this impression not or almost not raised in dorsal aspect, not produced into denticles (Fig. 34B-C). Anterior edge of pronotum in front of anterior impression in male with thin, moderately high and short median wall that is provided with few golden, short, in part anteriadpointing setae (Fig. 34C). Lateral angles of this wall on each side with a few long, apically curved erect setae; both groups of lateral setae are meeting apically over the wall in $\Pi$-shaped arc (Fig. 34B). Pronotum dorsally with narrow anterior rim. Anterior and posterior lobe slightly convex in lateral view (Fig. 34C). Lateral constriction continues onto disc in lateral view, shallow (Fig. 34C). Lateral pronotal fovea moderately broad at lower external margin of pronotum, widens upwards towards pronotal disc in lateral view, external margins protruding into a pair of strongly obtuse (in lateral view), moderately widely separated denticles (in lateral view). Cavity in lateral wall of pronotum between lateral denticles not studied due to the blocking position of anterior legs. In dorsal view, lateral pronotal fovea narrow, anterior and posterior pair of denticles small, appear obtusely angulate, glabrous, poorly visible from above since partially concealed by setae from adjoining portions of pronotum (Fig. 34B). Pronotal punctures minute on disc; lateral constriction dorsally somewhat denser and coarser punctured than anterior lobe. Dorsal pronotal setae rather long, appressed, at least in part concealing disc of posterior pronotal lobe. Scutellar shield small, apically rounded. Elytra dorsally elongate elliptical, slightly convex in lateral view, widened laterally around midlength and broadly rounded at lateral margins, shoulders obsolete (apterous species). Elytral punctures moderately large and deep, sparse, becoming smaller and shallower towards apices. Intervening spaces on basal half of elytra about 2-4× as large as punctures. Elytral setae long and sparse, suberect. Male tergite and morphological sternite VII broadly rounded at posterior margin. Aedeagus as in Fig. 35, large and elongate, basale hook-shaped. Gonopore armature very delicate, arranged into tube-enclosed 'garland', constituting pieces elongate and narrow, spine-like, closed attached to one another in apical portion of apicale, becoming smaller near apex of aedeagus. 


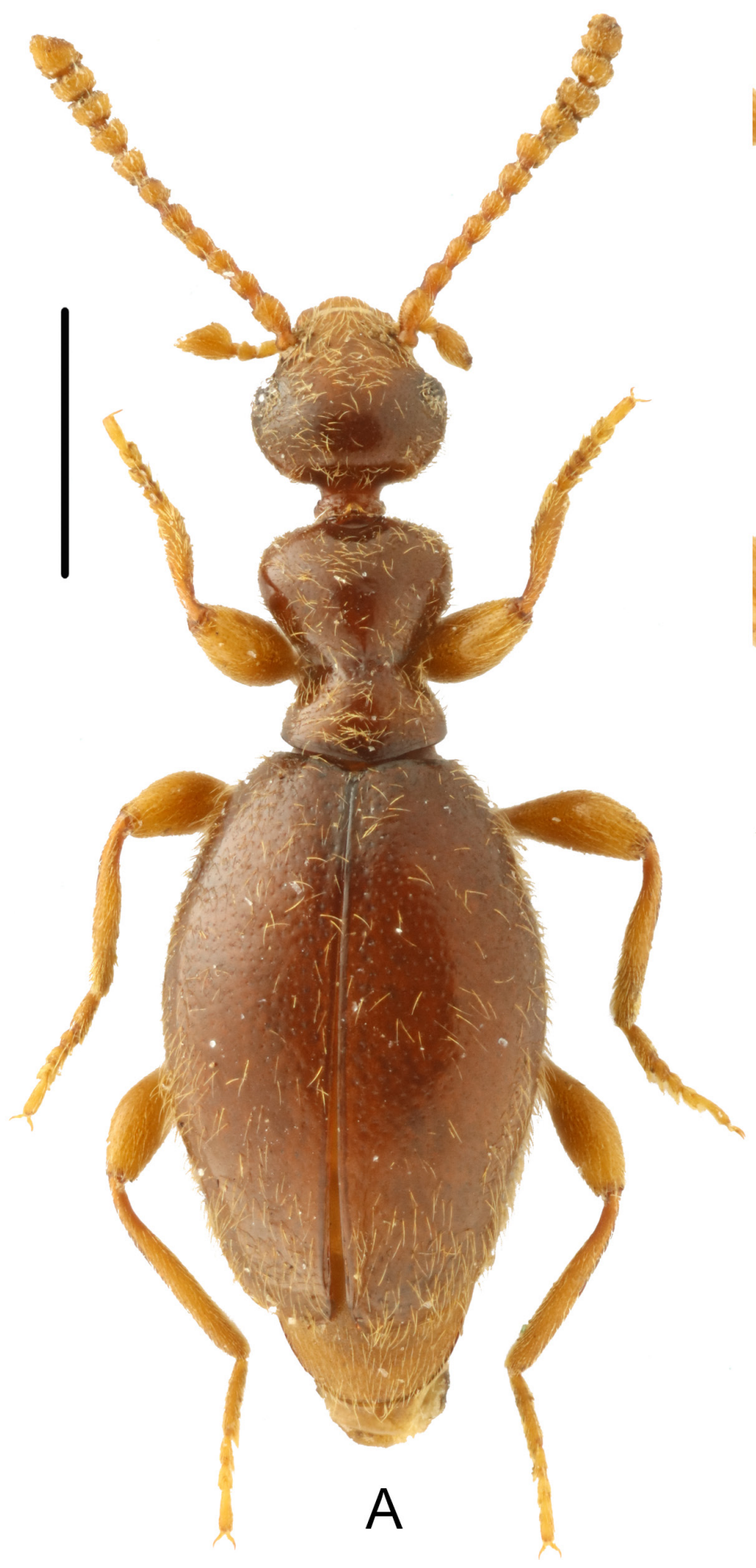

34
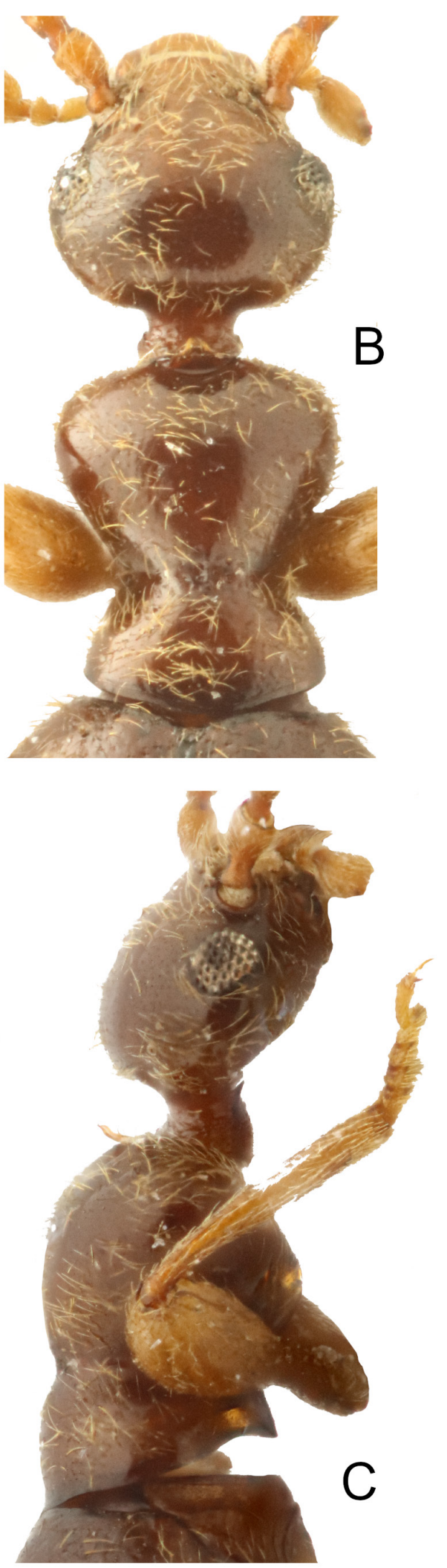

Fig. 34. Macrotomoderus similis sp. nov., holotype, $\widehat{\partial}(\mathrm{ZIN})$. A. Habitus, dorsal view. B. Forebody, dorsal view. C. Ditto, lateral view. Scale bar: A $=1 \mathrm{~mm}$; $B-C=$ not to scale. 


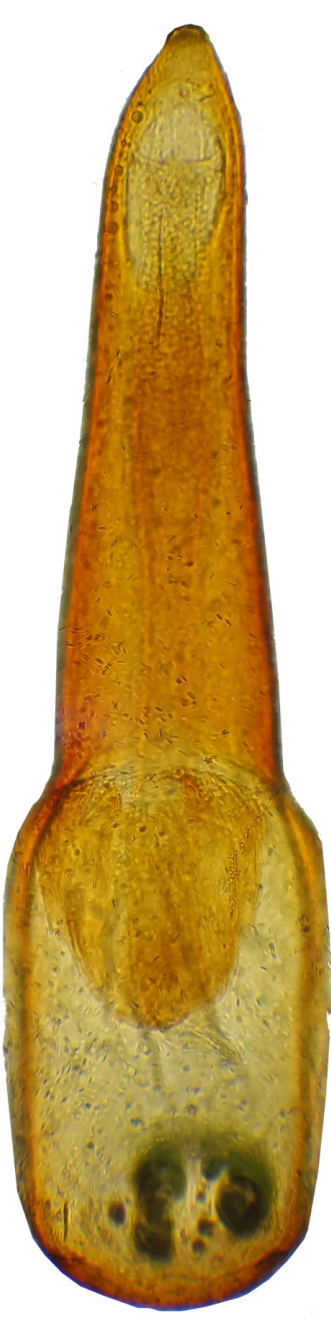

A

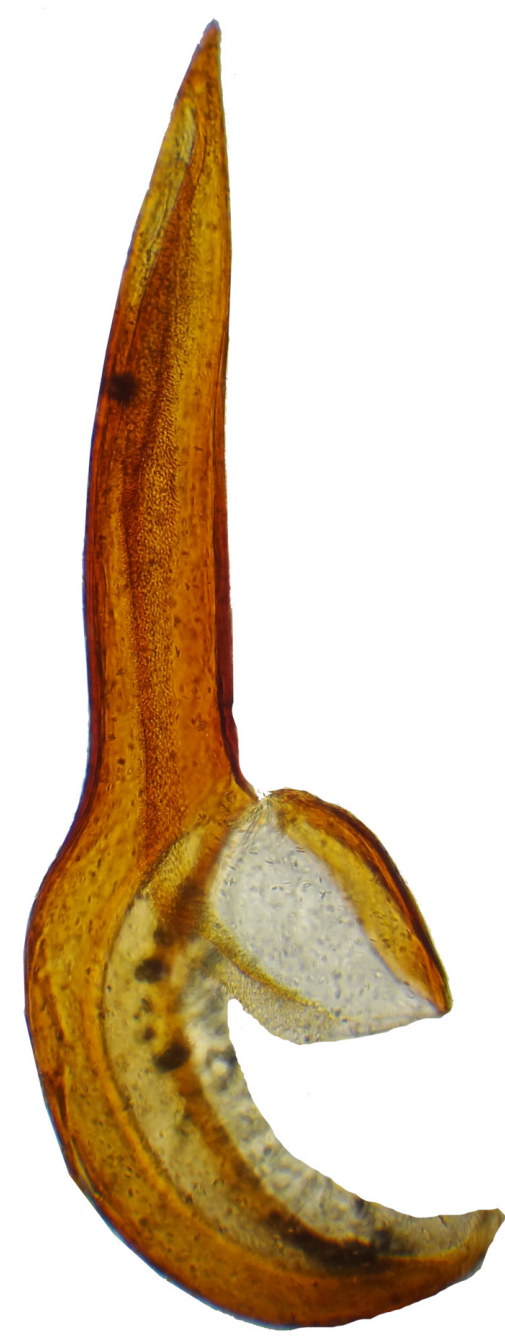

$\mathrm{B}$

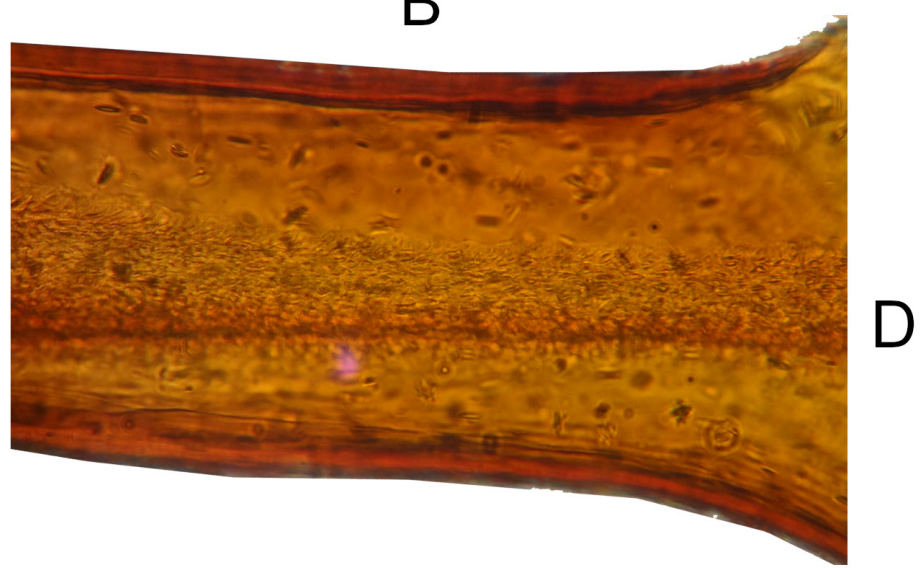

Fig. 35. Macrotomoderus similis sp. nov., holotype, $\widehat{\jmath}(\mathrm{ZIN})$, aedeagus. A-B. General view, different positions. C. Gonopore armature, median portion of apicale. D. Ditto, basal portion of apicale. Not to scale. 


\section{Sexual dimorphism}

Female is unknown.

\section{Ecology}

Collected at $2540 \mathrm{~m}$ elevation.

\section{Distribution}

Known only from southern part of Yunnan Province, SW China.

$$
\begin{aligned}
& \text { Macrotomoderus tenuis sp. nov. } \\
& \text { urn:lsid:zoobank.org:act:1FBCCE43-12EC-4B87-B137-019143D05164 }
\end{aligned}
$$

Figs $36-37$

\section{Differential diagnosis}

This species falls in a informative group of species from continental China with lateral foveae of pronotum not or only poorly visible in dorsal view, not forming deep notches. Among these species, pronotum is medially longitudinally carinate at constriction area in M. bukejsi Telnov, 2018 and M. chingpo Telnov, 2018 but not carinate in M. tenuis sp. nov. Pronotum is peculiarly modified in M. gracilis Telnov, 2018, with anterior margin somewhat elevated and strongly projecting anteriad, provided with a group of T-shaped (bent) anteriad-pointed setae; these modifications are not observed in $M$. tenuis sp. nov. Also see above diagnosis of $M$. angelinii sp. nov.

\section{Etymology}

Named from the Latin 'tenuis' ('slender') to referring to the slender, elongate pronotum of this species.

\section{Type material}

\section{Holotype}

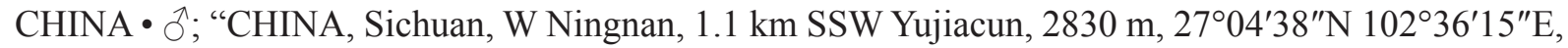
1.vii.2018 Belousov \& Kabak lg.”; ZIN.

\section{Description}

MEAsurements. Holotype, total body length $3.05 \mathrm{~mm}$; head $0.65 \mathrm{~mm}$ long, across eyes $0.55 \mathrm{~mm}$ broad, pronotum $0.7 \mathrm{~mm}$ long, maximum width $0.5 \mathrm{~mm}$, minimum width $0.2 \mathrm{~mm}$, elytra $1.7 \mathrm{~mm}$ long, $1.5 \mathrm{~mm}$ combined wide.

Dorsum and venter pale brown, head slightly darker. Mouthparts, antennae, palps and legs yellow. Head ovoid with moderately large, ovoid compound eyes, which are slightly protruding beyond head outline laterally. Head rounded in broad arc posterior to eyes. Head dorsal punctures minute and inconspicuous. Head dorsal setae inconspicuous, sparse. Antennae extending towards base of pronotum. Antennomere three $1.1-1.2 \times$ as long as antennomere two, antennomeres 9-10 transverse. Terminal antennomere asymmetrically triangular with pointed apex, twice as long as penultimate antennomere. Terminal maxillary palpomere securiform. Pronotum elongate, with broad lateral constriction. Front margin of anterior lobe broadly rounded, in male medially with a bunch of golden, moderately long and dense, anteriad-pointed to apically C-like curved setae (Fig. 36B-C). Pronotum dorsally with narrow anterior rim. Anterior and posterior lobe convex in lateral view (Fig. 36C). Lateral constriction continues onto disc in lateral view, moderately deep (Fig. 36C). Lateral pronotal fovea moderately broad at lower external margin of pronotum, strongly widens upwards towards pronotal disc in lateral view, external margins protruding into a pair of obtuse (in lateral view), moderately widely separated denticles (in lateral view). Cavity in lateral wall of pronotum between lateral denticles moderately large, rectangular. 

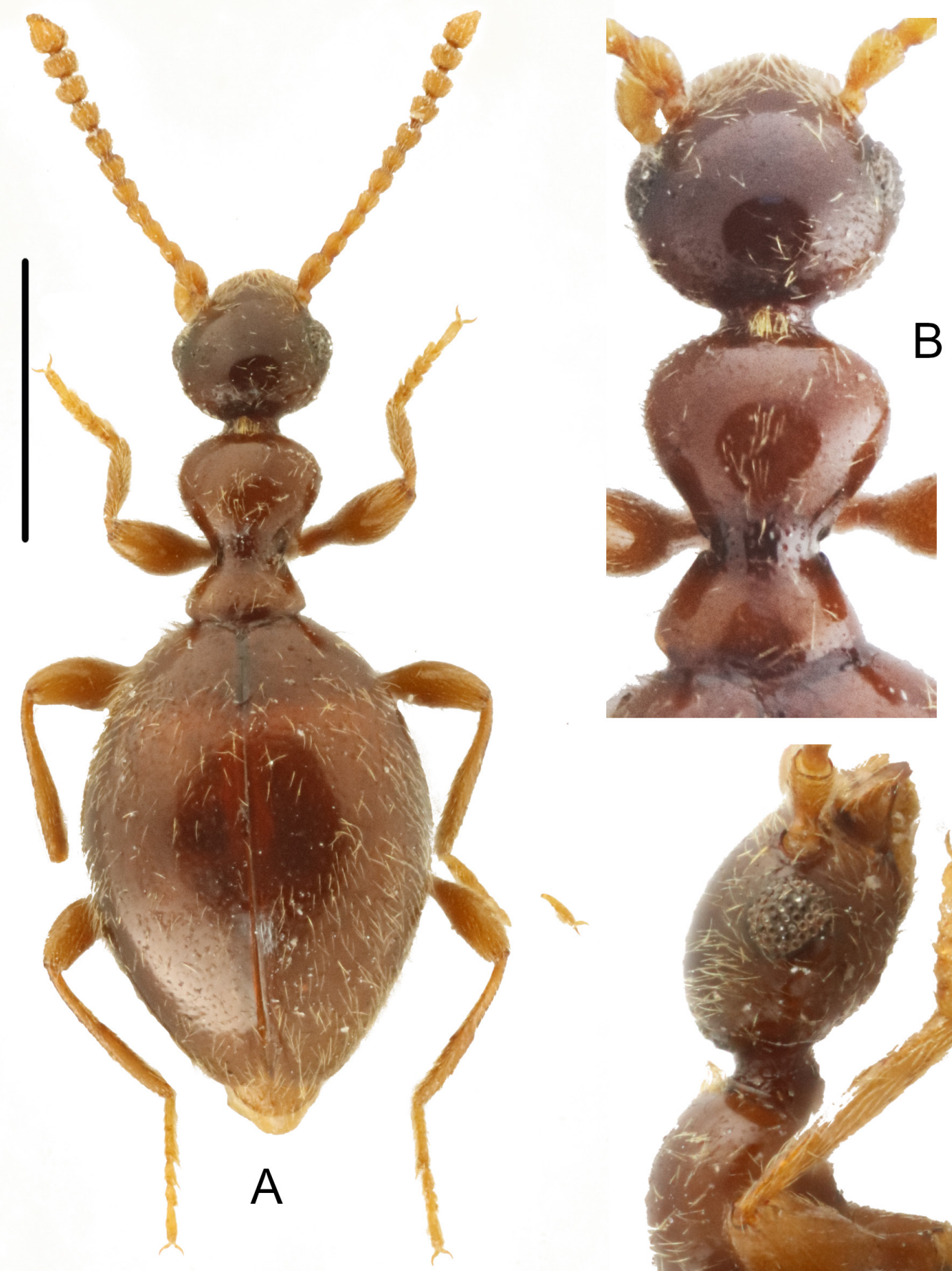

\section{6}

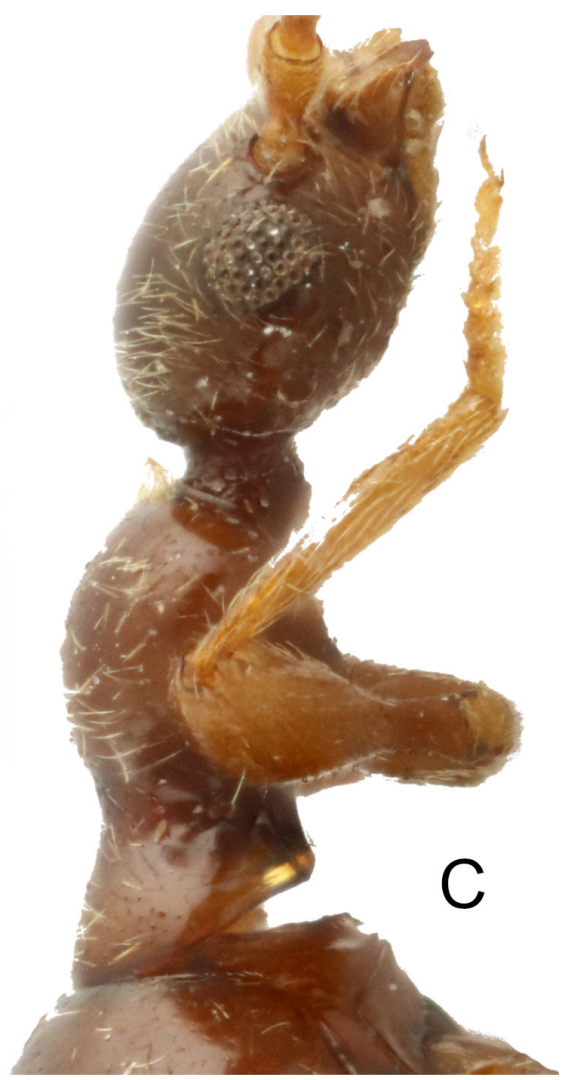

Fig. 36. Macrotomoderus tenuis sp. nov., holotype, §̊ (ZIN). A. Habitus, dorsal view. B. Forebody, dorsal view. C. Ditto, lateral view. Scale bar: $A=1 \mathrm{~mm} ; \mathrm{B}-\mathrm{C}=$ not to scale. 
In dorsal view, lateral pronotal fovea short and narrow, denticles small in dorsal view (Fig. 36B). Pronotal punctures minute on disc; lateral constriction dorsally with dense, irregularly sized, generally circular punctures. Dorsal pronotal setae rather long, appressed, at least in part concealing disc of posterior pronotal lobe. Scutellar shield small, apically rounded. Elytra dorsally elliptical, convex in

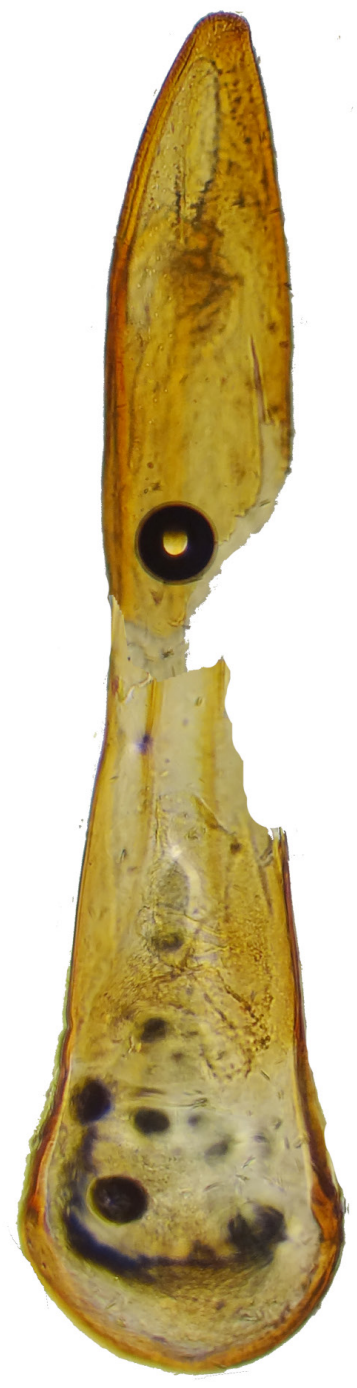

A

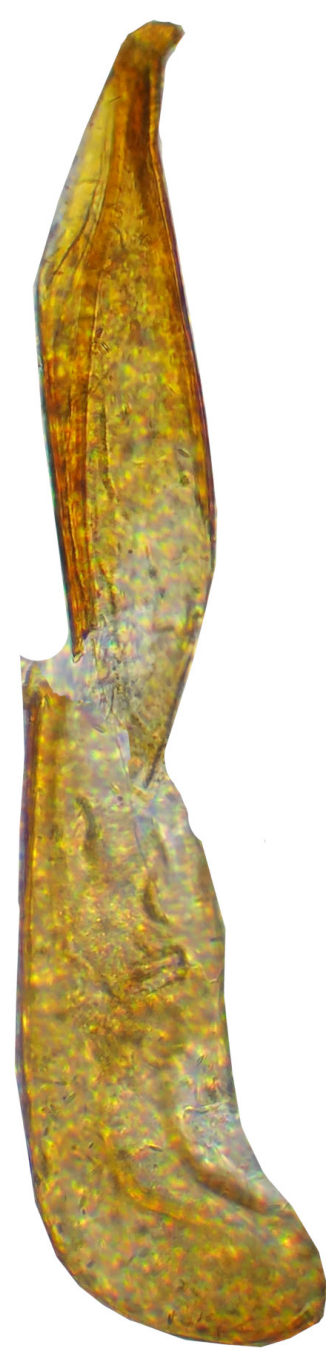

B

\section{7}
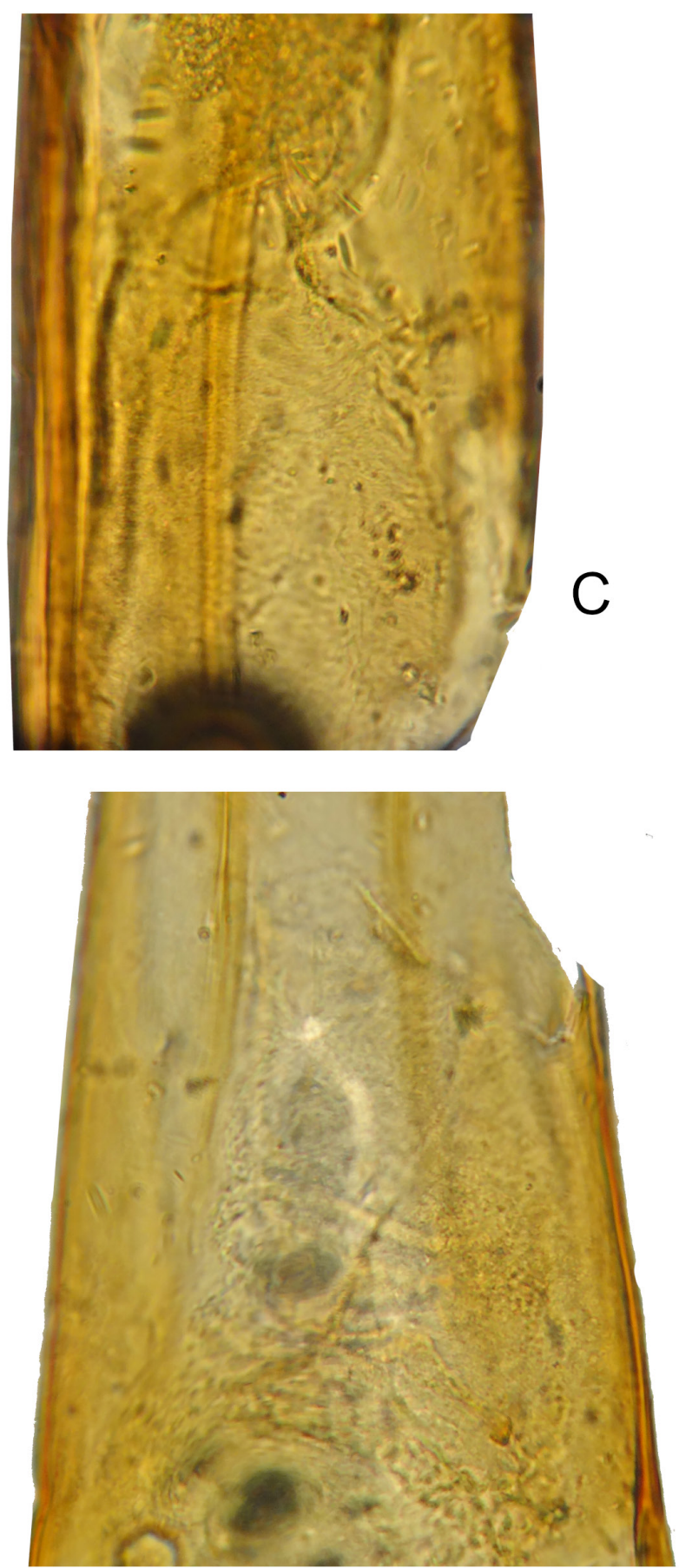

Fig. 37. Macrotomoderus tenuis sp. nov., holotype, $\widehat{\partial}(\mathrm{ZIN})$, aedeagus. A-B. General view, different positions. C. Gonopore armature, apical portion of apicale. D. Ditto, median portion of apicale. Not to scale. 
lateral view, broadly rounded laterally, shoulders obsolete (apterous species). Elytral punctures rather small, moderately dense, becoming smaller and sparser towards apices. Elytral setae long and sparse, suberect. Male tergite and morphological sternite VII broadly rounded at posterior margin. Aedeagus as in Fig. 37, elongate, rather narrow, with extremely delicate, poorly visible gonopore armature.

\section{Sexual dimorphism}

Female is unknown.

\section{Ecology}

Collected at 2830 m elevation.

\section{Distribution}

Known only from the southern part of Sichuan Province, SW China.

Macrotomoderus transitans sp. nov. urn:1sid:zoobank.org:act:D09B8E41-E71A-49A3-BE31-905D3F6E4C42

Figs 38-39

\section{Differential diagnosis}

This species appears similar to the Indo-Chinese congeners with anteriorly excavate and medially longitudinally carinate pronotum, like Macrotomoderus humerifer (Uhmann, 1994) (N Vietnam), M. perforatus Telnov, 2019 (China: Yunnan), and M. yunnanus (Telnov, 1998) (China: Yunnan). The new species has obsolete humeri (humeri angulate in M. humerifer, this species is macropterous) and the anterior pronotal impression without peculiar, high frontal wall and peculiar, thick golden setae as in M. yunnanus. In M. perforatus the aedeagus is rather similar to that of $M$. transitans sp. nov., but the head is rounded at the base and delicately punctured (the head base subtruncate, the head dorsal punctures are conspicuous, large), the pronotum is generally slenderer and the anterior emargination larger and deeper than in $M$. transitans sp. nov., the compound eyes comparatively smaller than those of M. transitans sp. nov. and the antennal club is less heavy.

\section{Etymology}

Named from the Latin 'transitans' ('passing through') to point on the area of occurrence of this species that might be transitional to Oriental fauna.

\section{Type material}

\section{Holotype}

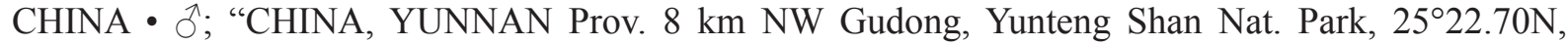
9824.38E, J. Hájek \& J. J. Růžička leg. // (Ch19) 29.v.2018, 1850 m, sift \#15, secondary broad-leaved forest with shrubs, above lower cable car station"; NMP.

\section{Description}

MeAsurements. Holotype, total body length $3.96 \mathrm{~mm}$; head $0.8 \mathrm{~mm}$ long, across eyes $0.8 \mathrm{~mm}$ broad, pronotum $0.95 \mathrm{~mm}$ long, maximum width $0.75 \mathrm{~mm}$, minimum width $0.2 \mathrm{~mm}$, elytra $2.2 \mathrm{~mm}$ long, $1.65 \mathrm{~mm}$ combined wide.

Dorsum and venter uniformly brown to reddish-brown. Mouthparts, antennae, palps and legs yellowishbrown. Head subtriangular with moderately large, ovoid compound eyes, which are slightly protruding beyond head outline laterally. Tempora converging towards head base (slightly rounded), temporal angles broadly rounded. Head base subtruncate in dorsal view; in posterodorsal view head base appears 


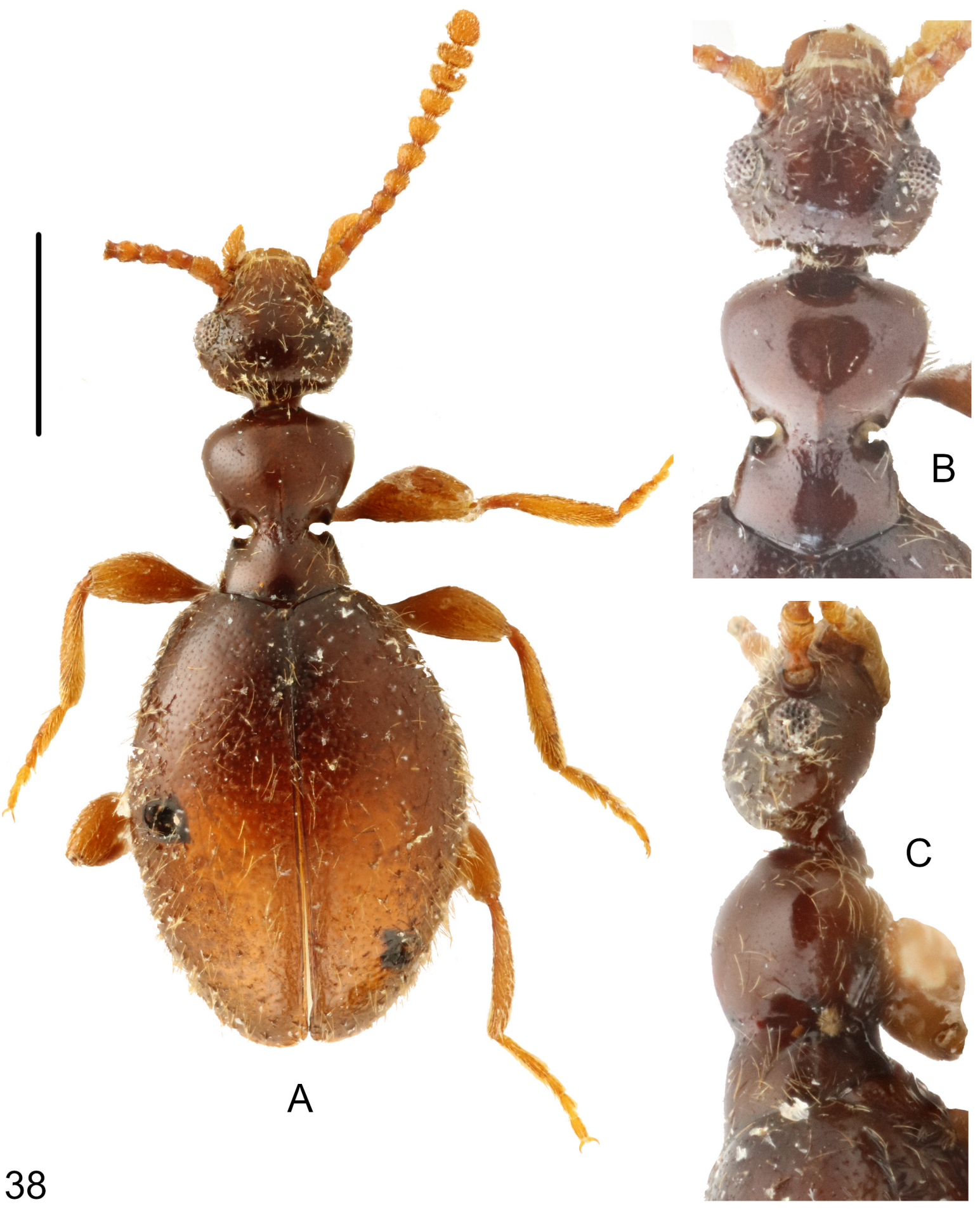

Fig. 38. Macrotomoderus transitans sp. nov., holotype, $\widehat{\partial}$ (NMP). A. Habitus, dorsal view. B. Forebody, dorsal view. C. Ditto, lateral view. Scale bar: $A=1 \mathrm{~mm} ; \mathrm{B}-\mathrm{C}=$ not to scale. 
truncate at least medially since occiput is somewhat flattened posteroventrally above insertion of cranial neck. Head dorsal punctures small but distinct, rather deep, moderately dense. Intervening spaces glossy and glabrous, about same size as to $3 \times$ as large as punctures. Head dorsal setae moderately dense. Antennae barely touching base of pronotum. Antennomere three nearly same length as antennomere two, antennomeres 4-5 shortened, ovoid, antennomeres 6-10 transverse, of them 9-10 strongly transverse. Terminal antennomere short and broadly triangular with rounded apex, about $1.7-1.8 \times$ as long as penultimate antennomere. Terminal maxillary palpomere securiform. Pronotum with broad and medially deeply and broadly notched postmedian lateral constriction. Front margin of anterior lobe very broadly rounded (subtruncate), in male moderately deeply and broadly impressed mesally opposite median part of head base; anterolateral margins of this impression raised in dorsal aspect, produced into acute denticles (Fig. 38B). Anterior edge of pronotum in male in front of anterior impression with thick, rather low median wall that is provided with 2-4 stout, erect setae. Pronotum dorsally without anterior rim. Anterior lobe slightly convex in lateral view (Fig. 38C). Lateral constriction continues onto disc in lateral view, shallow (Fig. 38C). Lateral pronotal fovea broad at lower external margin of pronotum, strongly widens upwards towards pronotal disc in lateral view, external margins protruding into a pair of obtuse (in lateral view), widely separated denticles (in lateral view). Cavity in lateral wall of pronotum between lateral denticles not observed since the area laterally concealed by dense, whitish setae. In dorsal view, lateral pronotal fovea broad, anterior and posterior pair of denticles appear obtusely angulate, glabrous laterally (Fig. 38B), each with a bunch of dense, golden dorsal setae. Anterior lobe gently medially longitudinally carinate all along. Pronotal punctures minute on disc; lateral constriction dorsally dense and coarse, irregularly punctured. Dorsal pronotal setae inconspicuous. Scutellar shield very small, apically rounded. Elytra dorsally elongate elliptical, convex in lateral view, widened laterally around midlength and broadly rounded at lateral margins, shoulders obsolete (apterous species). Elytral punctures moderately large and deep, moderately dense on basal half of elytra, becoming smaller and shallower towards apices. Intervening spaces on basal half of elytra about 2-3× as large as punctures. Elytral setae long and rather dense, suberect. Male tergite and morphological sternite VII broadly rounded at posterior margin. Aedeagus as in Fig. 39, large and robust, basale arch-shaped. Gonopore armature 'garland'-like, with consisting pieces very densely attached to one another, moderately large, spinose.

\section{Sexual dimorphism}

Female is unknown.

\section{Ecology}

Collected from leaf litter in a secondary broad-leaved forest at $1850 \mathrm{~m}$ elevation.

\section{Distribution}

Known only from western part of Yunnan Province, SW China.

Macrotomoderus truncatulus sp. nov. urn:1sid:zoobank.org:act:103D0B56-52BD-40E6-8373-8DBAF4775303

Figs 40-41

\section{Differential diagnosis}

This species readily differs from all Palaearctic congeners in the truncate head base and obtusely angulate (not rounded) temporal angles. The modifications of anterior margin of the pronotum are similar to those as in M. lapidarius sp. nov. (see description above), but specifically different in the less prominent and obtusely angulate lateral denticles of the anterior pronotal impression (the denticles stronger raised in 


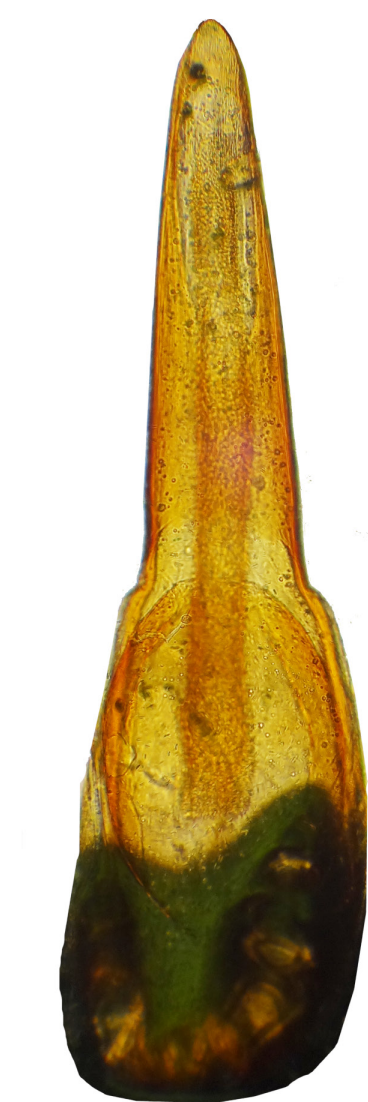

A

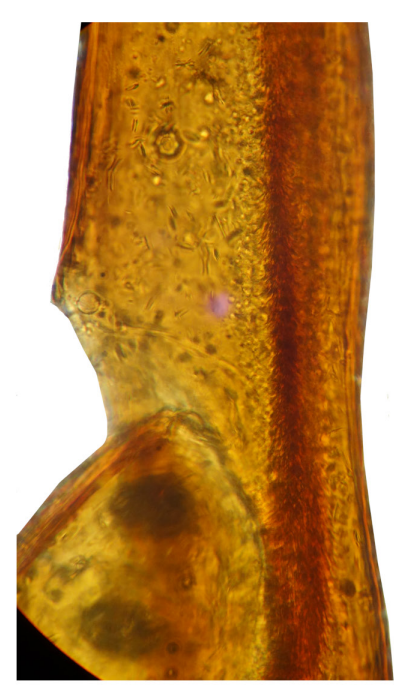

$\mathrm{E}$

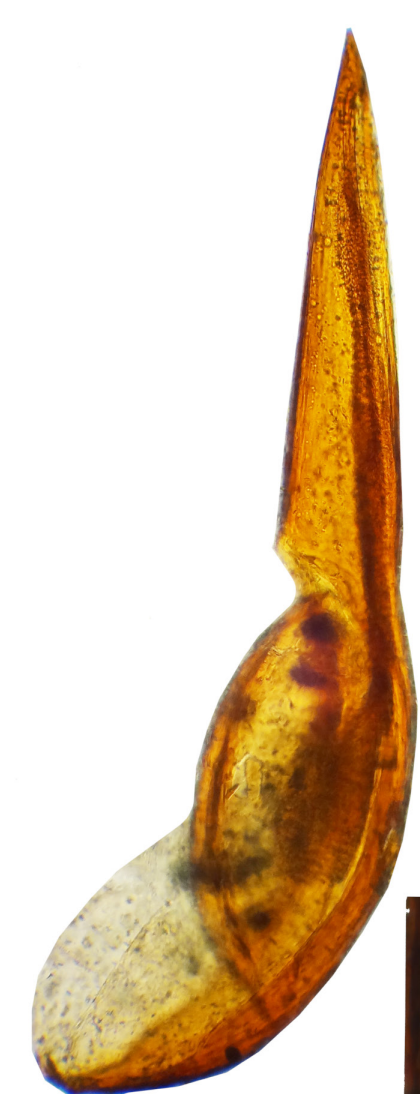

B

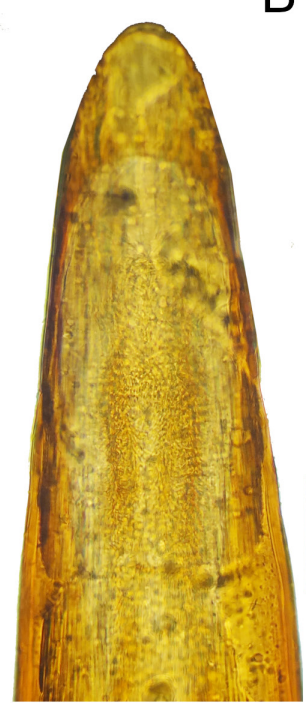

G

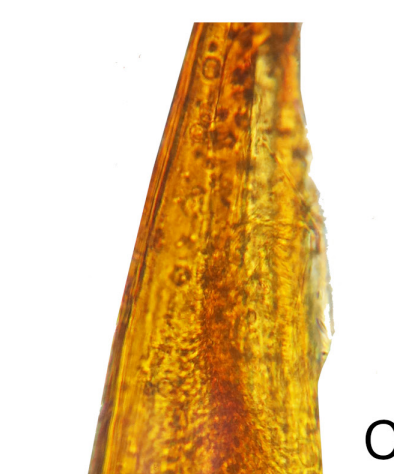

C
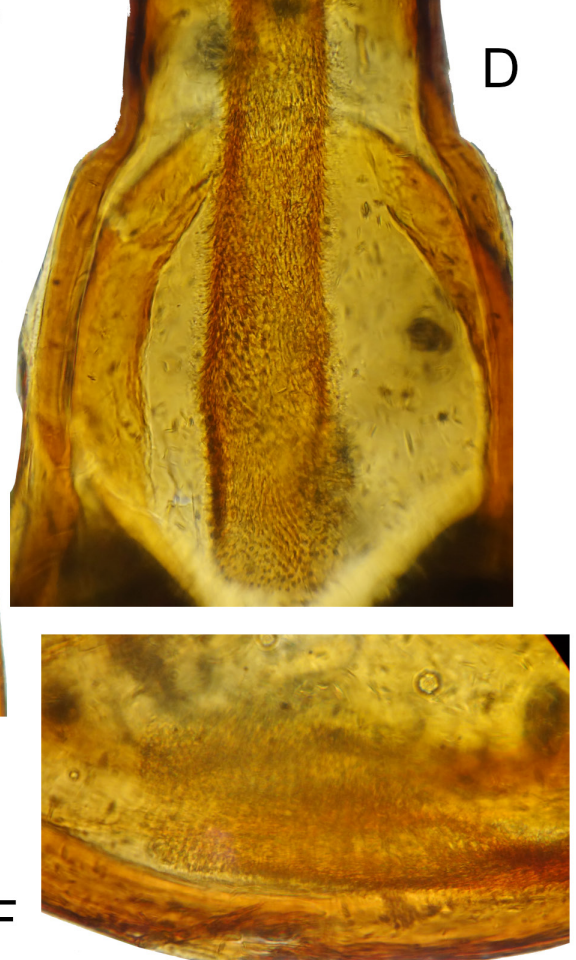

Fig. 39. Macrotomoderus transitans sp. nov., holotype, ô (NMP), aedeagus. A-B. General view, different positions. C. Gonopore armature, apical portion of apicale. D. Ditto, basale and basal portion of apicale. E. Ditto, different position. F. Median portion of basale. G. Apical portion. Not to scale. 
dorsal aspect, either acute in M. lapidarius sp. nov.) and the less prominent anterior wall of the pronotal impression (the wall is higher in M. lapidarius sp. nov.). See also diagnosis of M. similis sp. nov. above.

\section{Etymology}

Named from the Latin 'truncatulus' ('slightly truncate') to point on truncate head base.

\section{Type material}

Holotype

CHINA • O'; “CHINA, Yunnan, Wuliangshan Mt. Range 2270 m, 12.vi.2011 Belousov, Kabak \& Korolev

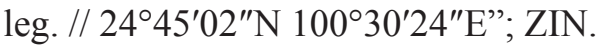

\section{Description}

Measurements. Holotype, total body length $4.15 \mathrm{~mm}$; head $0.85 \mathrm{~mm}$ long, across eyes $0.8 \mathrm{~mm}$ broad, pronotum $1 \mathrm{~mm}$ long, maximum width $0.75 \mathrm{~mm}$, minimum width $0.4 \mathrm{~mm}$, elytra $2.3 \mathrm{~mm}$ long, $1.6 \mathrm{~mm}$ combined wide.

Dorsum and venter uniformly pale brown. Mouthparts, antennae, palps and legs yellowish-brown. Head ovoid with moderately large, ovoid compound eyes, which are not or slightly protruding beyond head outline laterally. Tempora converging towards obtusely angulate temporal angles; head base truncate. Occiput somewhat declivous posterodorsally. Head dorsal punctures minute and inconspicuous. Head dorsal setae inconspicuous, sparse. Antennae extending towards base of pronotum. Antennomere three about $1.2 \times$ as long as antennomere two, antennomeres 8-10 transverse, of them 9-10 strongly transverse. Terminal antennomere shortly triangular with rounded apex, twice as long as penultimate antennomere. Terminal maxillary palpomere securiform. Pronotum shortly cylindrical with broad and medially shortly notched postmedian lateral constriction. Front margin of anterior lobe broadly rounded, in male shallowly and broadly impressed mesally opposite median part of head base; anterolateral margins of this impression are slightly raised in dorsal aspect, obtuse denticulate (Fig. 40B-C). Anterior edge of pronotum in front of anterior impression with gentle, low and short median wall that in male is provided with golden, long, in part curved, anteriad-pointing setae (Fig. 40B-C). Lateral angles of this wall on each side with a few long, apically curved, erect setae; both groups of lateral setae are meeting apically in a $\Pi$-shaped arc over anterior wall (Fig. 40B). Pronotum dorsally without anterior rim. Anterior lobe slightly convex in lateral view (Fig. 40C). Lateral constriction slightly continues onto disc in lateral view, shallow (Fig. 40C). Lateral pronotal fovea moderately broad at lower external margin of pronotum, widens upwards towards pronotal disc in lateral view, external margins protruding into a pair of obtuse (in lateral view), widely separated denticles (in lateral view). Cavity in lateral wall of pronotum between lateral denticles elliptical. In dorsal view, lateral pronotal fovea moderately broad, anterior and posterior pair of denticles appear obtusely angulate, poorly visible from above, dorsally each with a bunch of short setae (Fig. 40B). Pronotal punctures minute on disc; lateral constriction dorsally with dense, irregularly shaped and variably sized punctures, some of which are large. A track of short median longitudinal carina present on lateral constriction area in dorsal view. Dorsal pronotal setae rather long, appressed, at least in part obscuring surface of posterior pronotal lobe. Scutellar shield small, apically rounded. Elytra dorsally elongate elliptical, slightly convex in lateral view, widened laterally around midlength, shoulders obsolete (apterous species). Elytral punctures moderately large, rather dense, becoming smaller and sparser towards apices. Elytral setae long and sparse, suberect. Male tergite and morphological sternite VII broadly rounded at posterior margin. Aedeagus as in Fig. 41, large and robust, with delicate, moderately large needle-shaped and tube-enclosed gonopore armature. Constituting pieces attached closely to one another. 


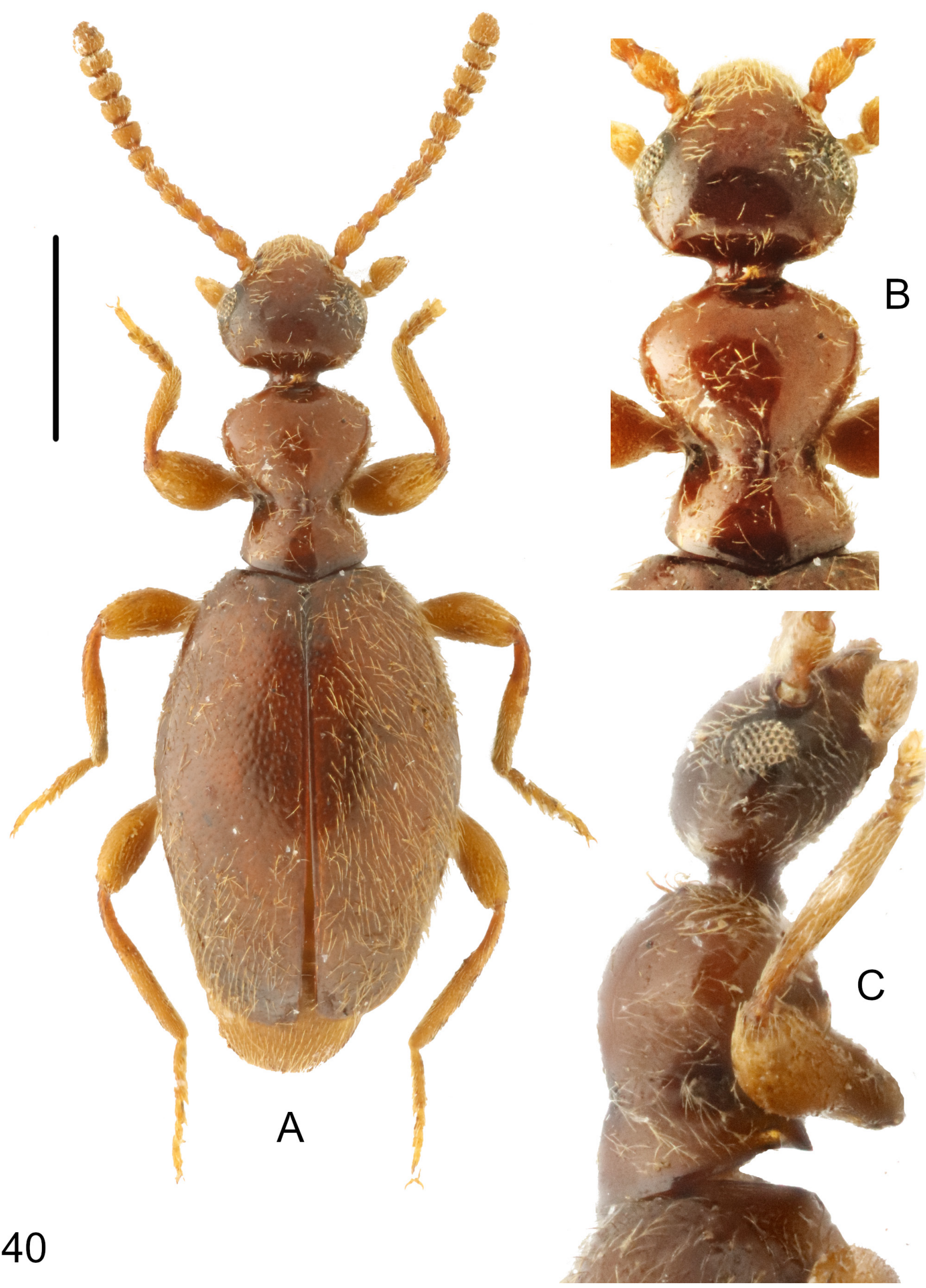

Fig. 40. Macrotomoderus truncatulus sp. nov., holotype, $\widehat{\partial}(\mathrm{ZIN})$. A. Habitus, dorsal view. B. Forebody, dorsal view. C. Ditto, lateral view. Scale bar: $A=1 \mathrm{~mm} ; \mathrm{B}-\mathrm{C}=$ not to scale. 


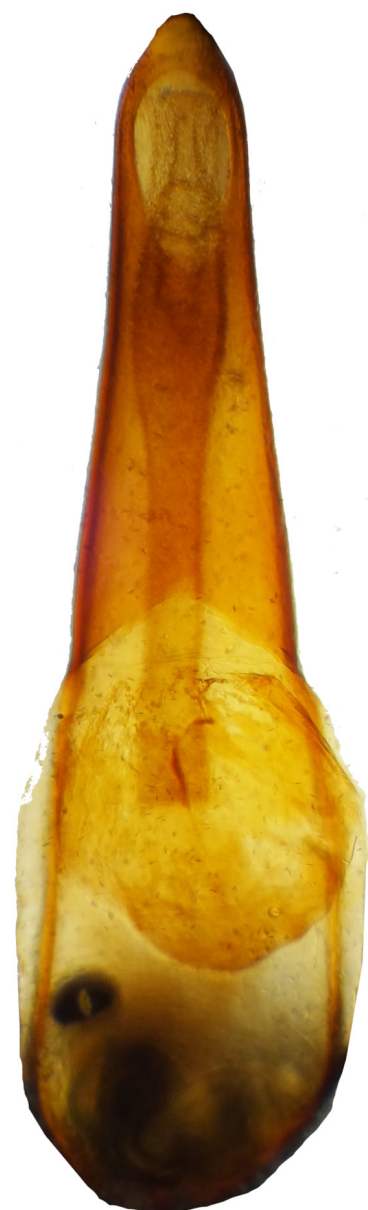

A

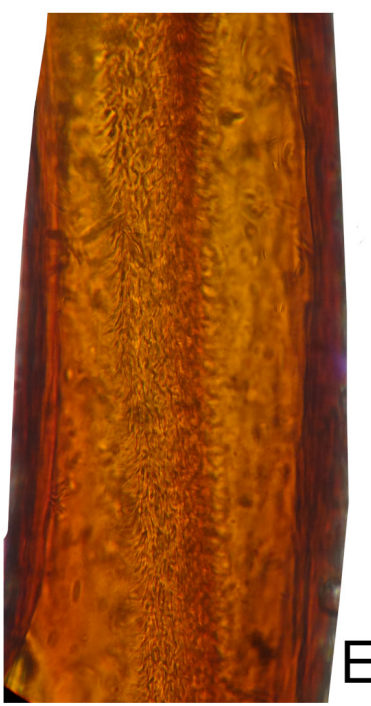

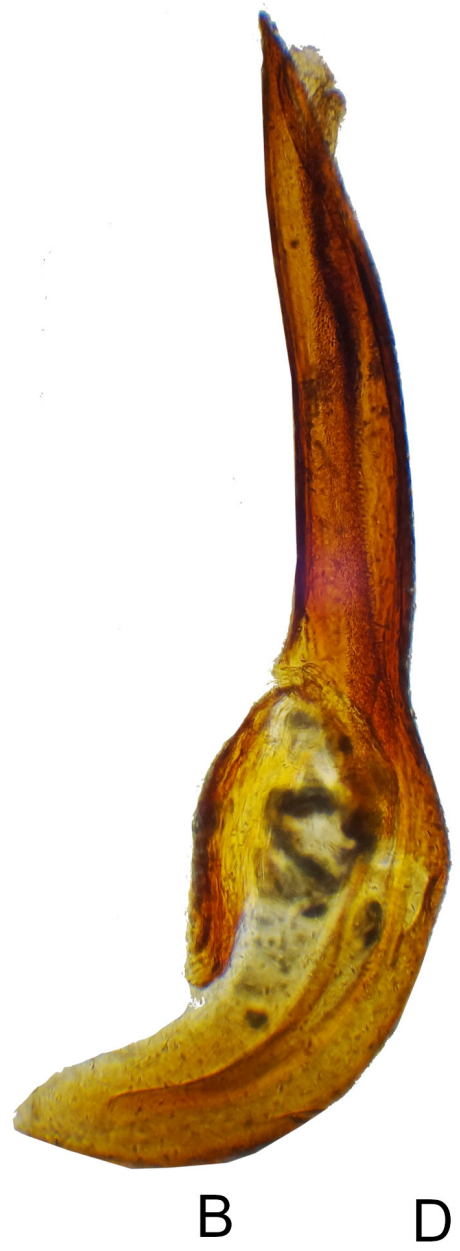

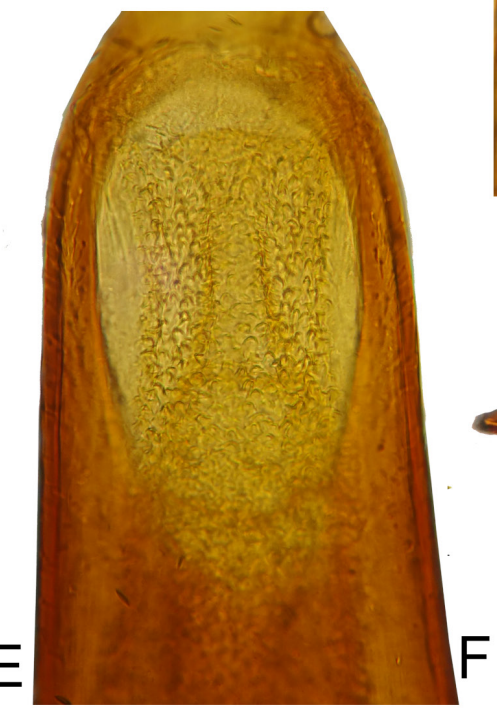

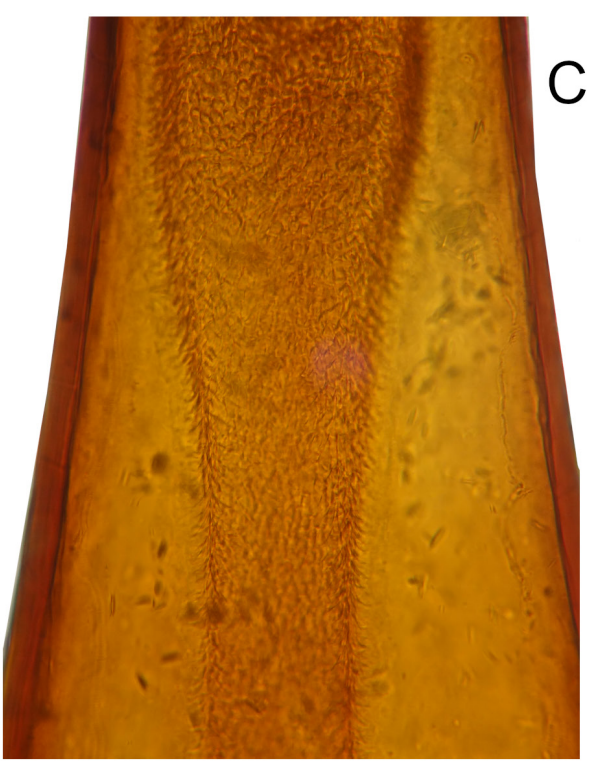
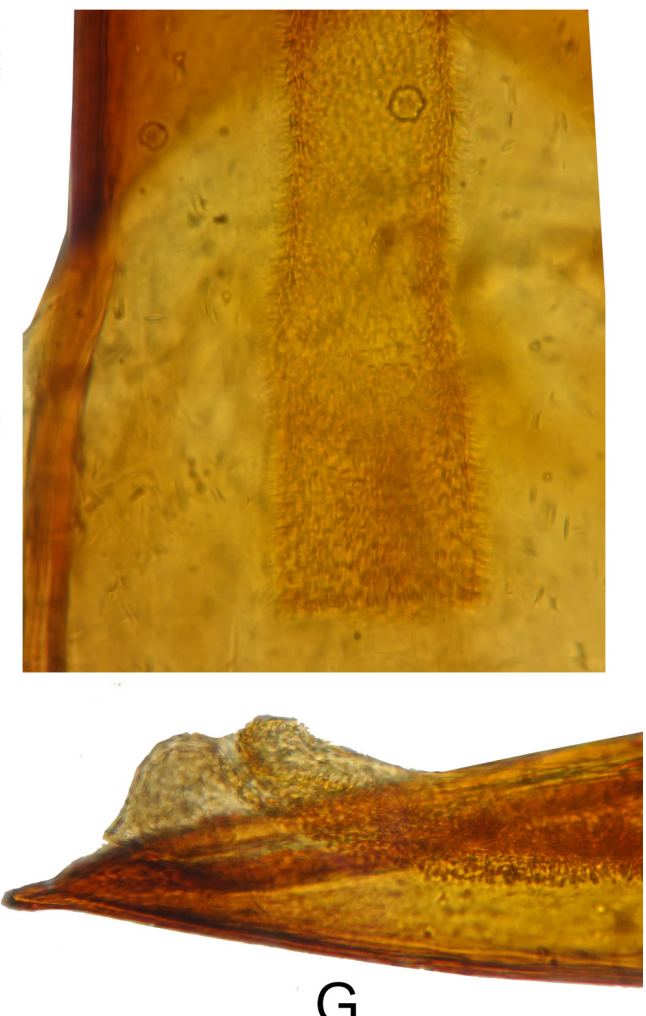

G

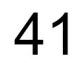

Fig. 41. Macrotomoderus truncatulus sp. nov., holotype, ô (ZIN), aedeagus. A-B. General view, different positions. C. Gonopore armature, median portion of apicale. D. Ditto, basal portion of apicale and apical portion of basale. E. Median portion of apicale, different position. F. Apical portion. G. Ditto, different position. Not to scale. 


\section{Sexual dimorphism}

Female is unknown.

\section{Ecology}

Collected at $2270 \mathrm{~m}$ elevation.

\section{Distribution}

Known only from Wuliang Mountains in central part of Yunnan Province, SW China.

Macrotomoderus usitatus sp. nov. urn:1sid:zoobank.org:act:A5F0A7F7-2B29-42C7-83C4-D4893D0E0BF6

Figs $42-43$

\section{Differential diagnosis}

See diagnosis of Macrotomoderus korolevi sp. nov. above and key to species below.

\section{Etymology}

Named from the Latin 'usitatus' ('common, ordinary') since this species does not display any peculiar external features.

\section{Type material}

\section{Holotype}

CHINA • ${ }^{\prime}$; “CHINA, Yunnan, SSE Shuangjiang Town, 2322'22"N 9944'47"E, 2540 m, 22.vi.2011 Belousov, Kabak \& Korolev leg."; ZIN.

Paratypes ( 9 specimens)

CHINA $\bullet 4$ specimens; same label as for holotype; ZIN $\bullet 5$ specimens; same label as for holotype; DTC.

\section{Description}

Measurements. Holotype, total body length $4.1 \mathrm{~mm}$; head $0.95 \mathrm{~mm}$ long, across eyes $0.9 \mathrm{~mm}$ broad, pronotum $1 \mathrm{~mm}$ long, maximum width $0.8 \mathrm{~mm}$, minimum width $0.35 \mathrm{~mm}$, elytra $2.15 \mathrm{~mm}$ long, $1.7 \mathrm{~mm}$

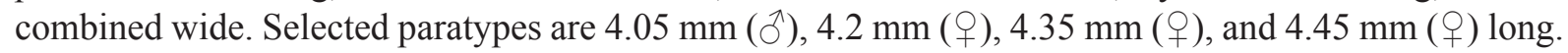

Dorsum and venter uniformly reddish-brown. Mouthparts, antennae, palps and legs yellowish-brown. Head ovoid with small, ovoid compound eyes, which are not protruding beyond head outline laterally. Tempora rounded in broad arc, head base medially subtruncate. Head dorsal punctures minute and inconspicuous. Head dorsal setae inconspicuous, sparse. Antennae long, extending towards base of elytra. Antennomere three about 1.4-1.5 $\times$ as long as antennomere two, antennomeres 6-10 transverse, of them 8-10 strongly transverse. Terminal antennomere triangular with obtusely angulate apex, $1.6-1.7 \times$ as long as penultimate antennomere. Terminal maxillary palpomere securiform. Pronotum with broad and medially deeply notched postmedian lateral constriction. Front margin of anterior lobe broadly rounded, dorsally without anterior rim (Fig. 42B). Anterior and posterior lobe slightly convex in lateral view (Fig. 42C). Lateral constriction continues onto disc in lateral view, shallow (Fig. 42C). Lateral pronotal fovea moderately broad at lower external margin of pronotum, widens upwards towards pronotal disc in lateral view, external margins protruding into a pair of strongly obtuse (in lateral view), broadly separated denticles (in lateral view). Cavity in lateral wall of pronotum between lateral denticles small, elliptical. In dorsal view, lateral pronotal fovea broad, anterior and posterior pair of denticles appear obtusely angulate, glabrous (Fig. 42B). Pronotal punctures minute on disc; lateral constriction dorsally with some dense, irregularly shaped, moderately large punctures and conspicuous, large, strongly 

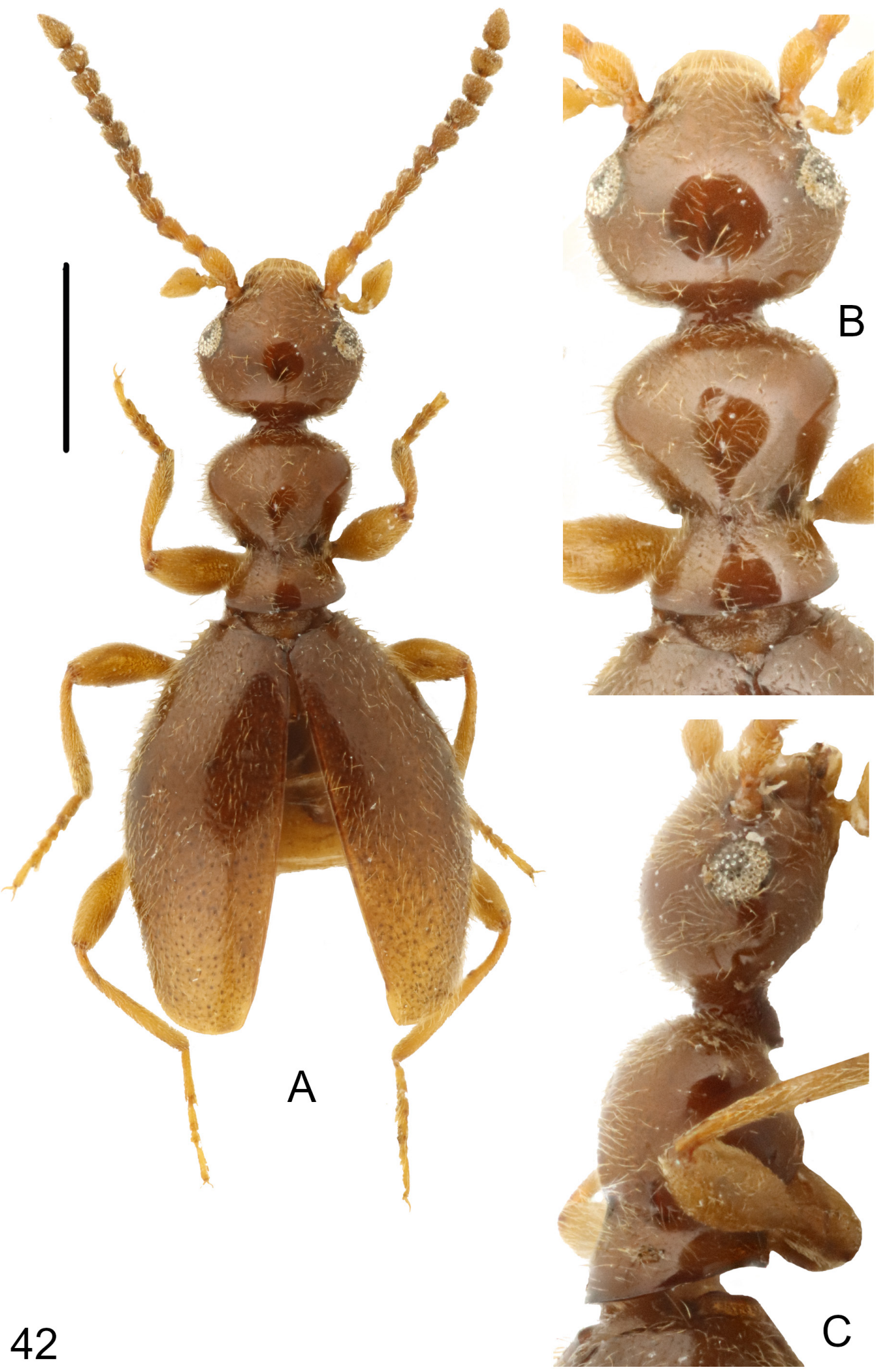

Fig. 42. Macrotomoderus usitatus sp. nov., holotype, ${ }_{\widehat{O}}(\mathrm{ZIN})$. A. Habitus, dorsal view. B. Forebody, dorsal view. C. Ditto, lateral view. Scale bar: $A=1 \mathrm{~mm} ; \mathrm{B}-\mathrm{C}=$ not to scale. 

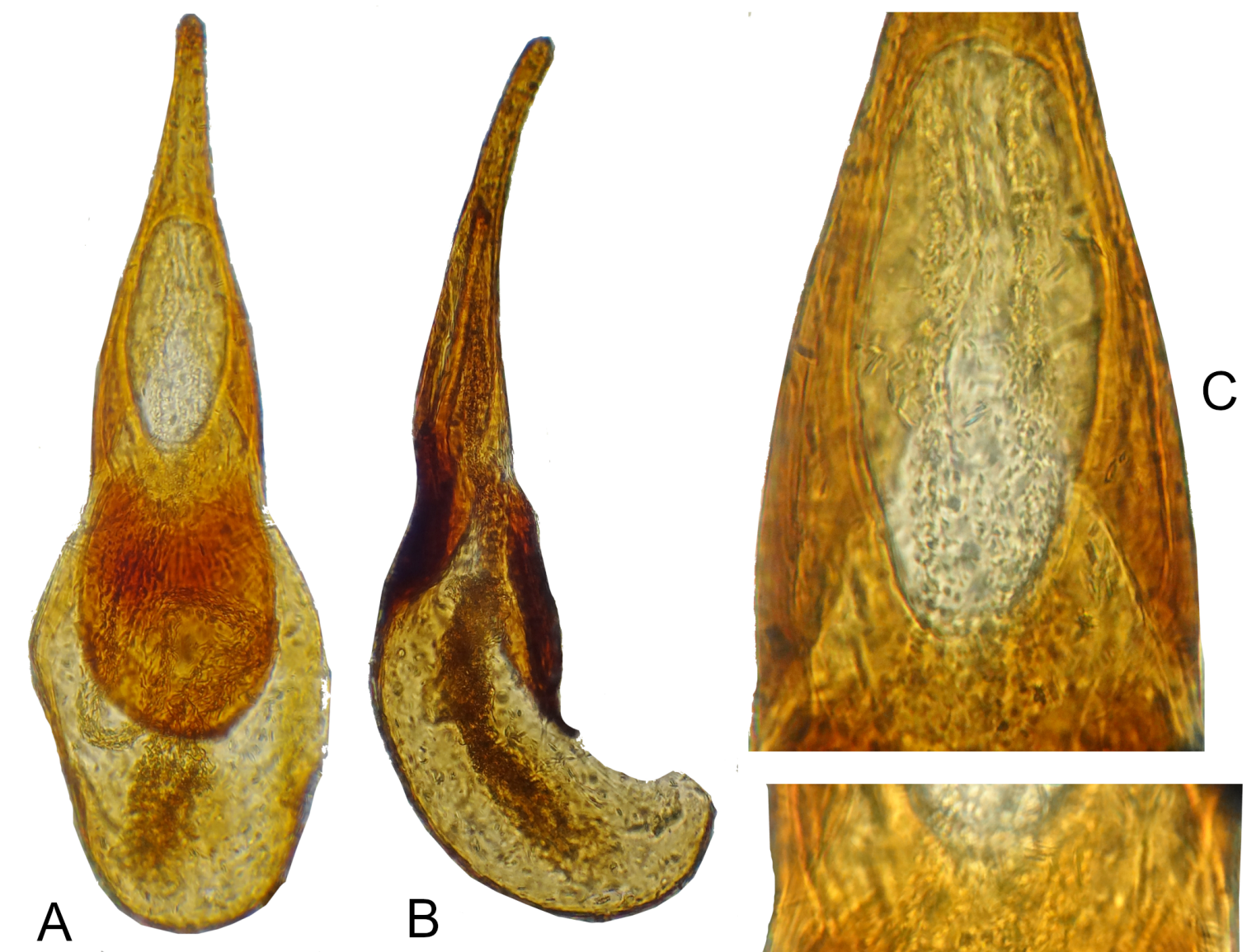

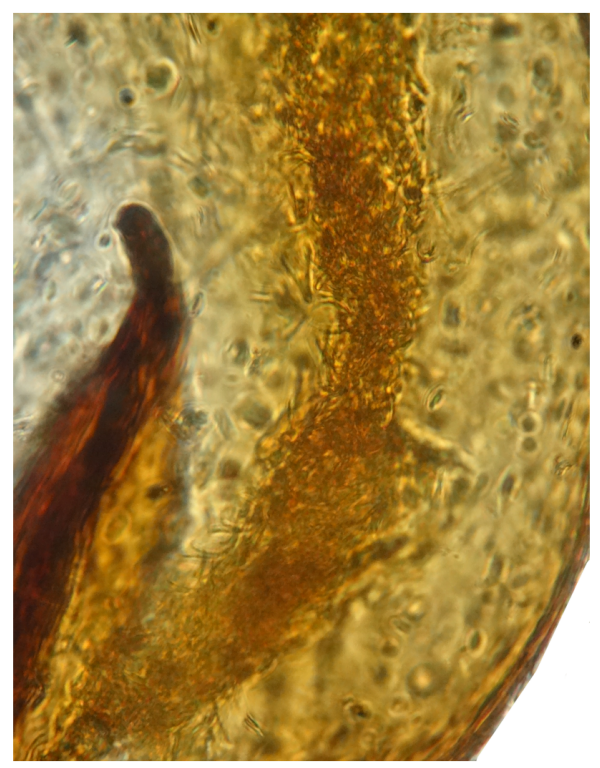

43

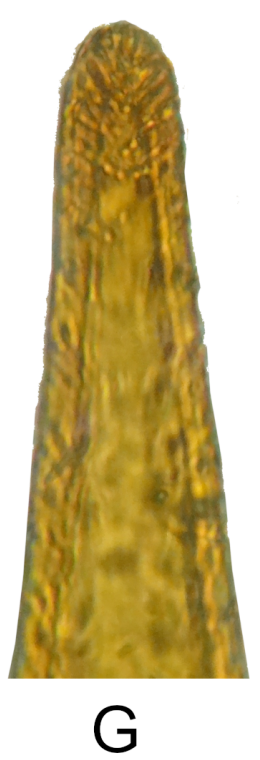

$\mathrm{E}$
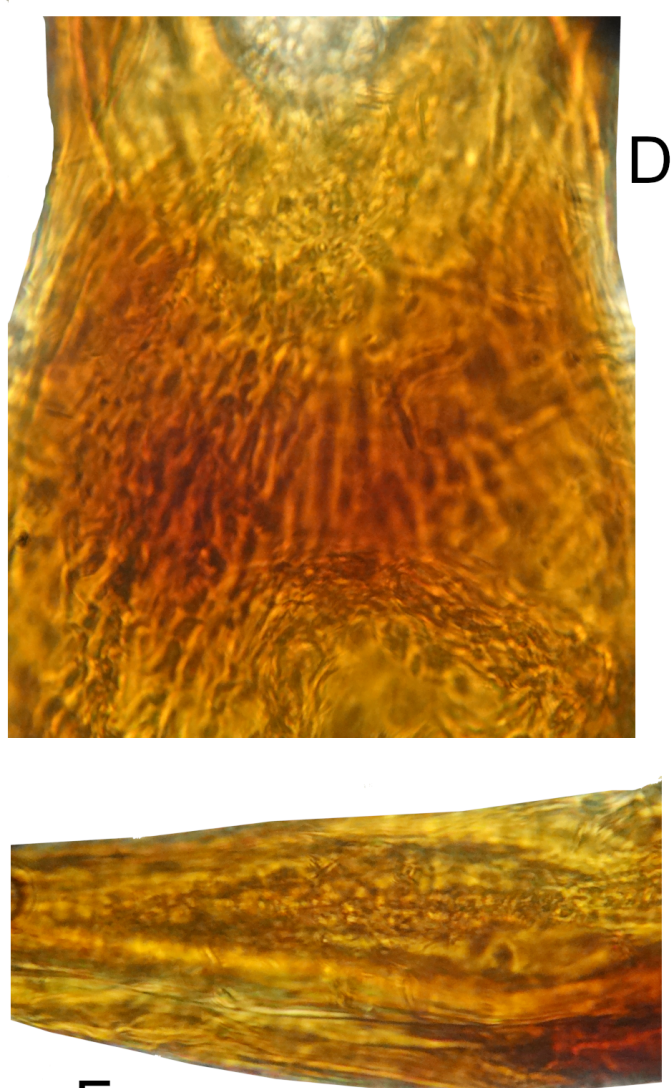

$\mathrm{F}$

Fig. 43. Macrotomoderus usitatus sp. nov., holotype, $\widehat{\partial}(\mathrm{ZIN})$, aedeagus. A-B. General view, different positions. C. Gonopore armature, median portion of apicale. D. Ditto, basal portion of apicale. E. Median portion of basale. F. Median portion of apicale, different position. G. Apical portion. Not to scale. 
elongate, median longitudinal notch (Fig. 42B) (interrupted by transverse rugules in some paratypes). Intervening spaces on lateral constriction between some close-aligned punctures may appear carinate. Dorsal pronotal setae inconspicuous, moderately long. Scutellar shield minute, rounded apically. Elytra dorsally elongate elliptical, flattened in lateral view, widened laterally around midlength, lateral margins broadly rounded, shoulders obsolete (apterous species). Elytral punctures much stronger and larger than those on dorsal forebody, becoming less prominent on posterior third of elytra. Intervening spaces on anterior half of elytra about as large to twice as large as punctures. Elytral setae long and moderately dense, suberect. Male tergite and morphological sternite VII broadly rounded at posterior margin. Aedeagus as in Fig. 43, large and robust, strongly constricted towards narrower apex, with delicate, poorly visible, irregularly shaped and positioned gonopore armature with foam-like constituting pieces at least in apical portion of armature.

\section{Sexual dimorphism}

Female externally similar to male.

\section{Ecology}

Collected at 2540 m elevation.

\section{Distribution}

Known only from southern part of Yunnan Province, SW China.

Macrotomoderus wudu sp. nov. urn:lsid:zoobank.org:act:958A2C60-1BAD-4544-8C3A-3DDCFE7C9A52

Figs 44-45

\section{Differential diagnosis}

This species readily differs from all congeners primarily due to the presence of the strongly curved golden setae on the median part of the anterior margin of the male pronotum, the unique shape of the male aedeagus and the partially longitudinally carinate anterior lobe of pronotum. Also see key to species below.

\section{Etymology}

Toponymic. Named after Wudu, the type locality of this species. Noun in apposition.

\section{Type material}

\section{Holotype}

CHINA • ${ }^{\lambda}$; "China, S Gansu, WSW Wudu, SE Guazigou vill., 11. VII. 2004 I.Belousov \& I.Kabak leg. // 2483 m (3319'04"N; 10444'07"E)"; ZIN.

Paratypes ( 8 specimens)

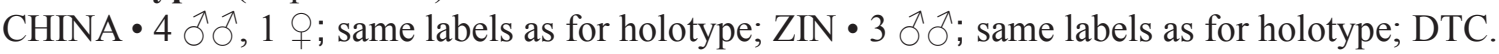

\section{Description}

Measurements. Holotype, total body length $4.2 \mathrm{~mm}$; head $0.8 \mathrm{~mm}$ long, across eyes $0.82 \mathrm{~mm}$ broad, pronotum $1.1 \mathrm{~mm}$ long, maximum width $0.8 \mathrm{~mm}$, minimum width $0.28 \mathrm{~mm}$, elytra $2.2 \mathrm{~mm}$ long, $1.45 \mathrm{~mm}$ combined wide. Selected paratypes $3.6 \mathrm{~mm}, 3.8 \mathrm{~mm}, 3.95 \mathrm{~mm}$ long.

Dorsum and venter uniformly brown. Mouthparts, antennae, palps and legs yellowish-brown. Head subtriangular with rather small, asymmetrically ovoid compound eyes, which laterally are slightly 
protruding beyond head outline. Head rounded in broad arc posterior to eyes, head base subtruncate medially. Occiput slightly declivous posterodorsally. Head dorsal punctures minute, rather dense, intervening spaces glossy, about $2-4 \times$ as large as punctures. Head dorsal setae inconspicuous, rather dense, suberect. Some setae on median area of head base pointed posteromediad. Antennae in both sexes extending towards base of pronotum. Antennomere three about $1.25 \times$ as long as antennomere two, antennomere six about as long as wide, antennomeres $7-10$ strongly transverse. Terminal antennomere asymmetrically triangular with rounded apex, $2-2.2 \times$ as long as penultimate antennomere. Terminal maxillary palpomere securiform. Pronotum hourglass-shaped, slightly less wide than head across eyes. Postmedian lateral constriction broad and medially deeply notched. Front margin of anterior lobe very broadly rounded, dorsally without anterior rim. Front margin of anterior lobe in male with a group of golden, dense, moderately long and strongly P-like curved setae pointing towards a declivous portion of head base, touching or nearly touching cranial neck but not head base (Fig. 44B-C). Anterior lobe slightly convex in lateral view (Fig. 44C). Lateral constriction slightly continues onto disc in lateral view (Fig. 44C). Posterior portion of anterior lobe with obtuse, weak median longitudinal carina that in some specimens continues to lateral constriction area. Lateral pronotal fovea moderately broad at lower external margin of pronotum, widens upwards towards pronotal disc in lateral view, external margins protruding into a pair of obtuse, moderately widely separated denticles (in lateral view). In lateral view both anterior and posterior denticle are strongly obtuse, nearly glabrous. In dorsal view, lateral pronotal fovea broad, anterior and posterior pair of denticles appear subacutely angulate, glabrous (Fig. 44B). Pronotal fovea in part effectively concealed dorsally and laterally by long, moderately dense, whitish setae (Fig. 44B). Pronotal punctures minute on disc; lateral constriction dorsally with much denser, larger, generally strongly elongate to irregularly shaped but still rather small punctures. Intervening spaces on lateral constriction area generally narrower than punctures. Dorsal pronotal setae rather long, moderately dense. Scutellar shield minute, triangular. Elytra dorsally elongate elliptical, flattened to slightly convex in lateral view, widened laterally around midlength, lateral margins very broadly rounded, shoulders obsolete (apterous species). Epipleura very broad at median part of elytra. Elytral punctures rather small, about same size to (in basal third) slightly larger than those in pronotal constriction area, moderately dense, becoming smaller and sparser towards apices. Elytral setae long and sparse, suberect. Mesotibia distinctly thickened. Basal metatarsomere in both sexes much shorter than combined length of remaining metatarsomeres. Male tergite and morphological sternite VII broadly rounded at posterior margin. Female tergite and morphological sternite VII broadly rounded at posterior margin. Aedeagus as in Fig. 45, robust and large, apex distinctly sinuous in lateral view, most of apicale and basale filled with conspicuous, moderately large and dense, irregularly shaped gonopore armature.

\section{Sexual dimorphism}

Female terminal antennomere is shorter, broader conical than that of male, anterior margin of pronotum without group of sense golden setae, instead with small, glabrous, mesal patch opposing elongate setae on head base.

\section{Ecology}

Collected at 2483 m elevation.

\section{Distribution}

Known only from the southern part of Gansu Province, north-central China. This is the north westernmost record of the genus Macrotomoderus. 

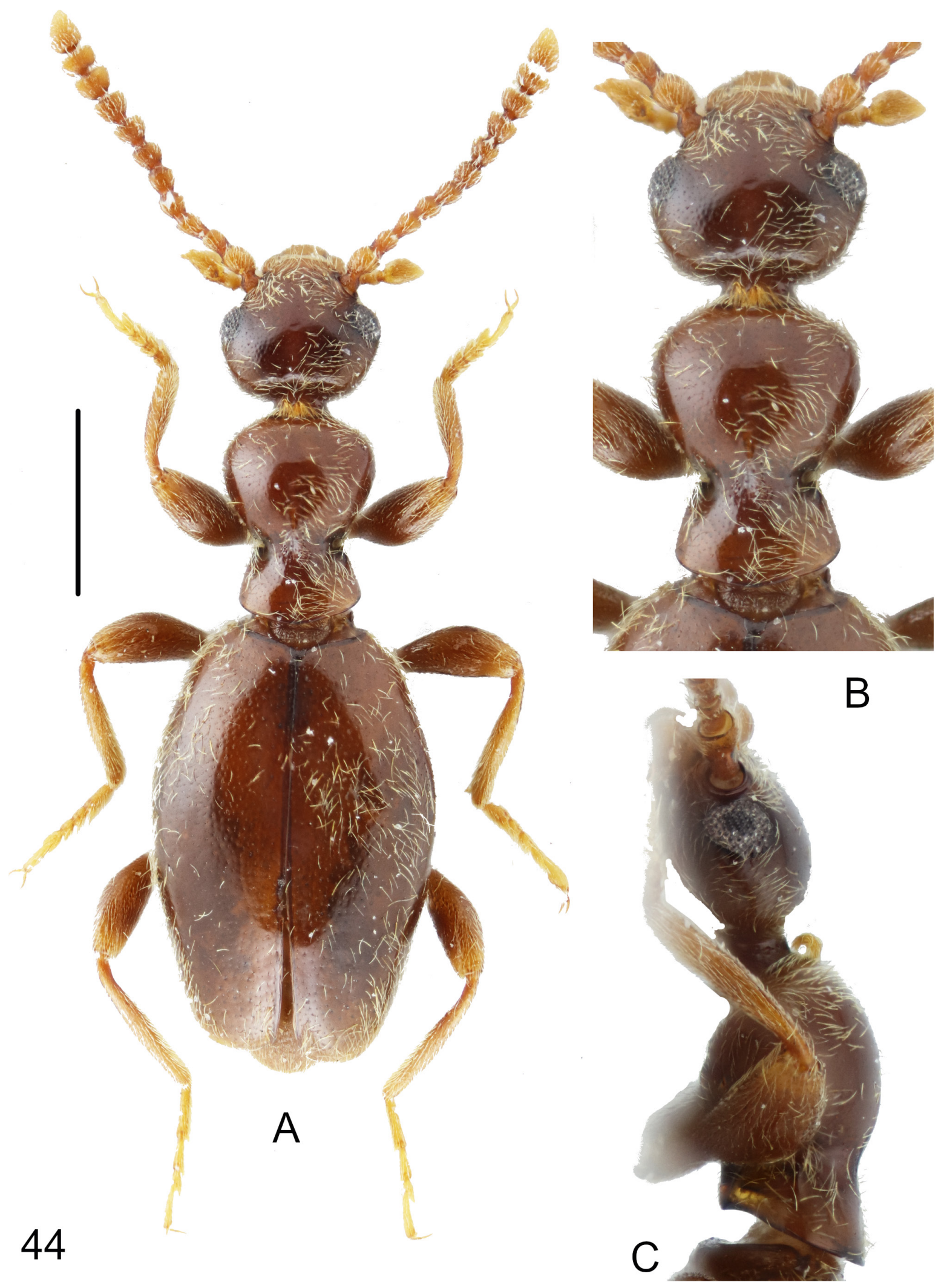

Fig. 44. Macrotomoderus wudu sp. nov., paratype, §ิ (ZIN). A. Habitus, dorsal view. B. Forebody, dorsal view. C. Ditto, lateral view. Scale bar: $A=1 \mathrm{~mm}$; $B-C=$ not to scale. 

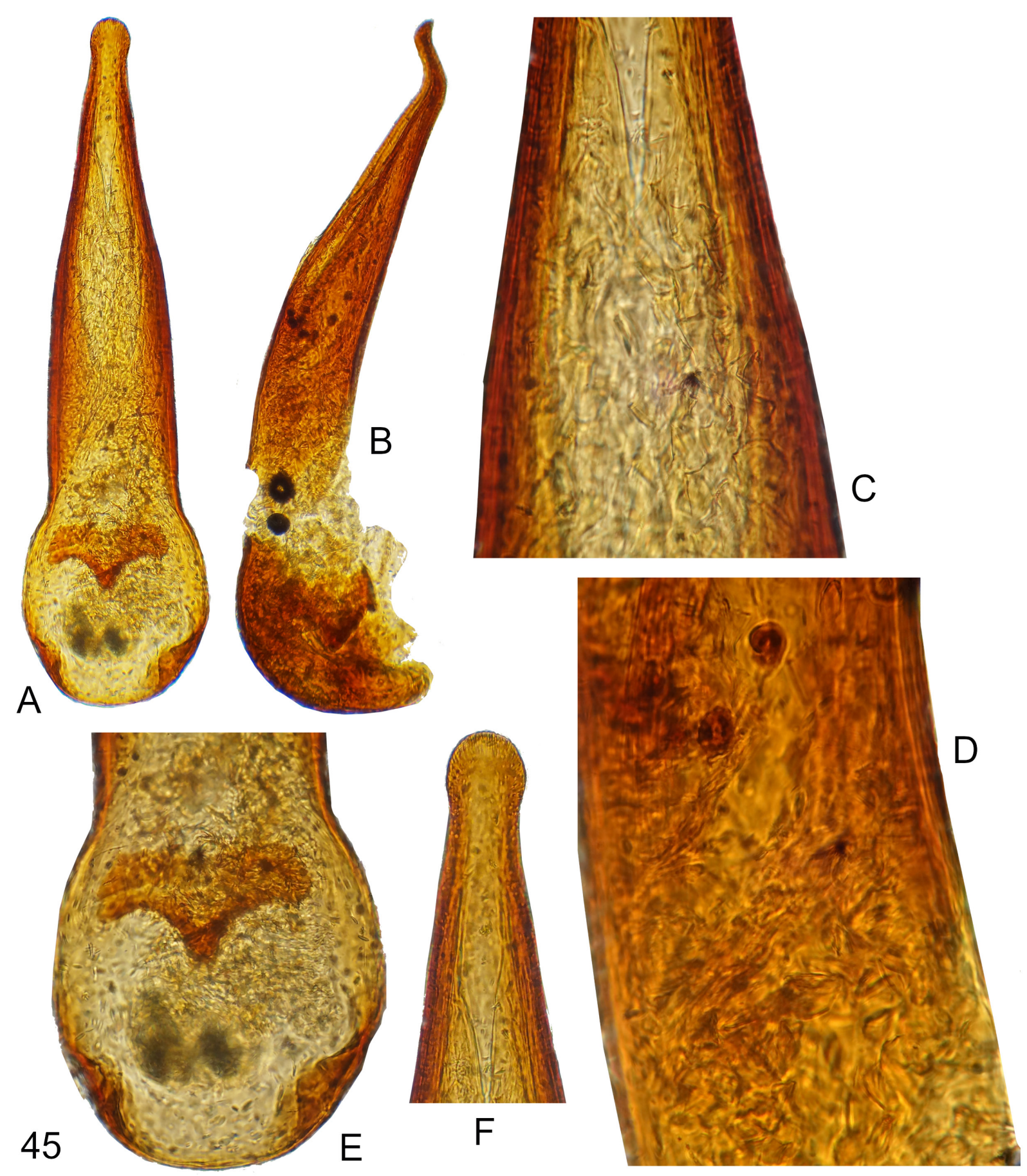

Fig. 45. Macrotomoderus wudu sp. nov., paratypes, $\widehat{\partial} \partial^{\hat{\gamma}}(\mathrm{ZIN})$, aedeagus. A-B. General view, different positions. C-D. Gonopore armature, median portion of apicale. E. Basale. F. Apical portion. Not to scale. 


\section{Supplemented and updated key to species of Macrotomoderus from China, the Japanese Archipelago, and Taiwan}

Female features alone are generally insufficient for species delimitation, therefore the present key is mainly based on male features.

1. Head distinctly constricted posterior to compound eyes, conical

M. conus Telnov, 2018

- Head rounded, subtruncate or truncate posterior to compound eyes, not conical

2. Male metafemur with conspicuous, large, apically acutely pointed denticle at posterior margin .......

- Posterior margin of metafemur in both sexes without modifications

M. femoridens sp. nov.

3. Head base in male with conspicuous, median triangular projection

- Head base in male without median projection

4. Anterior margin of male pronotum with broad mesal impression facing median part of head base, anterolateral margins of impressed area moderately strongly raised in dorsal aspect, appear denticulate; anterior edge of pronotum in front of anterior impression in male forms thin median wall that is covered with conspicuous, golden, in part curved, anteriad-pointing setae

M. lapidarius sp. nov.

- Anterior margin of pronotum different, without anterolateral denticles if impressed 5

5. Anterior margin of male pronotum truncate, with shallow mesal impression; projection of head base comparatively large; head with distinct tempora, compound eyes twice as long as tempora; head base subtruncate

M. monstrificabilis Telnov, 2018

- Anterior margin of male pronotum broadly rounded, not impressed; projection of head base less conspicuous, smaller; head rounded in broad arc posterior to eyes, tempora not delimited

M. mirabilis Telnov, 2018

6. Male head base truncate when observing directly from above, temporal angles present, obtuse angulate; anterior margin of male pronotum with broad mesal impression facing median part of head base, anterolateral margins of impressed area slightly raised in dorsal aspect, appear obtuse denticulate; anterior edge of male pronotum in front of anterior impression forms thin, low median wall covered with conspicuous, golden, in part curved, anteriad-pointing setae

M. truncatulus sp. nov.

- Combination of features different; male head base rounded, subtruncate or truncate but temporal angles never appear angulate

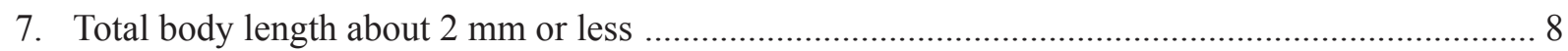

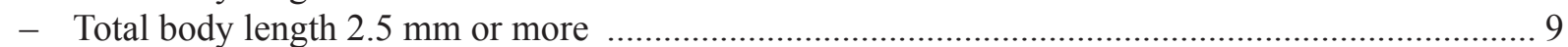

8. Species from Okinawa (Ryukyu Islands); anterior lobe of pronotum dorsally with inconspicuous, median longitudinal carina; anterior margin of male pronotum without modifications,

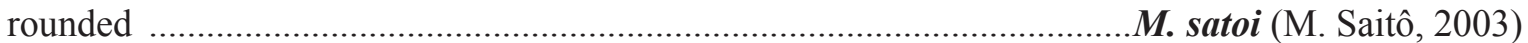

- Species from Yunnan (continental China); pronotum dorsally not carinate; anterior margin of male pronotum with mesal impression that holds small frontal projection

M. microscopicus Telnov, 2018

9. Anterior margin of male pronotum with modifications - mesally impressed or projected anteriad or provided with conspicuous, grouped, dense setae

- Anterior margin of male pronotum ordinary rounded, subtruncate or truncate, without modifications or group(s) of peculiar setae, at most slightly impressed mesally 
10. Anterior lobe of pronotum distinctly wider than head across eyes ...............................................11

- Anterior lobe of pronotum nearly as wide as or narrower than head across eyes .......................... 15

11. Head base truncate; eyes conspicuously large and laterally convex; tempora distinct, much shorter than dorsal eye length M. boops sp. nov.

- Head rounded in broad arc posterior to comparatively smaller, more or less strongly flattened eyes; tempora not delimited (rounded) but not much shorter than dorsal eye length

12. Male occiput not declivous or impressed posteroventrally (above insertion of cranial neck); anterior rim of pronotum narrow dorsally in male; anterior margin of male pronotum slightly impressed both sides of median projection; male antenna comparatively shorter, not extending towards median third of elytra M. hengduan sp. nov.

- Male occiput slightly declivous posterodorsally or shallowly impressed posteroventrally above insertion of cranial neck; male antenna extending or almost extending towards median third of elytra

13. Male occiput slightly declivous posterodorsally; anterior margin of pronotum without median projection M. dali sp. nov.

- Male occiput shallowly impressed posteroventrally above insertion of cranial neck; anterior margin of pronotum with distinct, median triangular projection

14. Anterior margin of pronotum truncate; lateral constriction area of pronotum dorsally with inconspicuous, short, median longitudinal carina, densely and roughly punctures both sides of carina, intervening spaces much smaller than punctures

M. imitator sp. nov.

- Anterior margin of pronotum subtruncate; lateral constriction area of pronotum dorsally not carinate, with rather large and sparse punctures and wide, glossy, and glabrous intervening spaces

M. monstratus Telnov, 2018

15. Lateral foveae of pronotum not or marginally visible in dorsal view, not forming deep notches in pronotal constriction; denticles of lateral foveae of pronotum not or partially visible in dorsal view 16

- Lateral foveae of pronotum clearly visible in dorsal view in a form variably deep notches in sides of pronotum at constriction; denticles of lateral foveae of pronotum generally well-visible in dorsal view

16. Lateral constriction of pronotum dorsally with more or less prominent median longitudinal carina M. chingpo Telnov, 2018

- Lateral constriction of pronotum dorsally not carinate

17. Anterior margin of male pronotum without modifications, broadly rounded, with a group of C-shaped (curved) posteriad-pointed setae; head base without bunch of setae M. angelinii sp. nov.

- Anterior margin of pronotum in male medially elevated and projecting anteriad 18

18. Frontal projection of pronotum with a group of 7 -shaped (bent) anteriad-pointed setae; head base medially with a bunch of dense golden setae; pronotum slender, elongate, narrower than head across eyes M. gracilis Telnov, 2018

- Anterior margin of pronotum without peculiar setae; pronotum rather broad, same wide as head across eyes M. kawa Telnov, 2018

19. Dorsum of anterior lobe of pronotum or its lateral constriction area or both medially longitudinally carinate

- Pronotum dorsally not carinate 24 
20. Anterior lobe of pronotum dorsally with median longitudinal carina (almost complete but not touching anterior margin of pronotum, or restricted to posterior half of anterior lobe), projecting or not on lateral constriction area

- Pronotum only carinate on lateral constriction area; anterior lobe of pronotum without dorsal carina

21. Anterior margin of male pronotum not excavated, mesally provided with a group of golden, dense, strongly P-like curved setae M. wudu sp. nov.

- Anterior margin of male pronotum excavated, without a median group of dense, curved setae ... 22

22. Aedeagus as in Fig. 39, basale large, bulbous

M. transitans sp. nov.

- Aedeagus as in Fig. 9, basale smaller, not bulbous M. bordonii sp. nov.

23. Lateral constriction area of pronotum dorsally with three carinae, of which both lateral carinae less prominent and shorter than median one; lateral pronotal foveae in dorsal view comparatively less deep and less broadly notched; dorsal setae or pronotum moderately long

M. yunnanus (Telnov, 1998)

- Lateral constriction area of pronotum dorsally medially unicarinate; lateral pronotal foveae in dorsal view deeply and broadly notched; dorsal setae or pronotum long M. perforatus Telnov, 2018

24. Anterior margin of male pronotum without modifications, broadly rounded, medially with a bunch of golden, rather short and dense, apically C-shaped (curved) setae M. tenuis sp. nov.

- Anterior margin of male pronotum with median impression or projection 25

25. Anterior margin of male pronotum truncate, with small and shallow median impression; anterior wall of this impression with a group of 7 -shaped (bent), anteriad-pointed setae raised from one pore M. schuelkei Telnov, 2018

- Anterior margin of male pronotum rounded to broadly rounded 26

26. Anterior margin of male pronotum with paired bunch of long, strongly P-like curved setae touching neck and head base; occiput slightly declivous posterodorsally; head base broadly rounded

M. bicrispus sp. nov.

- Anterior margin of male pronotum mesally impressed; anterior margin of this cavity laterally with a few long, apically curved, erect setae which are meeting apically in $\Pi$-shaped arc over anterior wall of pronotum

M. similis sp. nov.

27. Lateral constriction of pronotum dorsally with two rather large, elongate ovoid pores and 2-3 obtuse, transverse sulci M. negator Telnov, 2007

- Sculpture of lateral pronotal constriction different 28

28. Setae conspicuously dense in pronotal constriction area, in dorsal view effectively concealing structure of constriction and its notches

- Setae more or less sparse in pronotal constriction, structure of constriction and its notches clearly visible through setae in dorsal view

29. Aedeagus as in Fig. 31, basale not bulbous; head posterior to compound eyes with rather long, slightly constricted posteriad tempora, broadly rounded at base only; distribution - Sichuan Province (China) M. muli sp. nov.

- Aedeagus not as in Fig. 31, shorter and broader, basale strongly bulbous; head posterior to compound eyes rather evenly broadly rounded in arc; distribution - Zhejiang Province (China) ... 
TELNOV D., New species of Macrotomoderus, with a key to the Palaearctic taxa

30. Lateral constriction of pronotum dorsally more or less prominently medially longitudinally carinate (sometimes only visible by sufficient light!); median carina projected or not on anterior lobe ..... 31

- Lateral constriction of pronotum dorsally more or less prominently punctate or rugulose, not carinate

31. Dorsal median longitudinal carina of pronotal constriction projected to anterior lobe of pronotum for about half its length

- Dorsal median longitudinal carina of pronotal constriction restricted to lateral constriction area or (at maximum) also its anterior and posterior slopes

31. Basal half of elytra strongly punctate; pronotum paler than dark brown head and elytra

M. andibani Telnov, 2007

- Basal half of elytra distinctly less strongly punctate; dorsal body uniformly brown

33. Male antennomeres 9-10 as in Fig. 3D; anterior lobe of pronotum convex in lateral view; anterodorsal margin of clypeus emarginate; elytra comparatively longer, apically rounded; dorsal body generally paler brown

M. belousovi sp. nov.

- Male antennomeres 9-10 as in Fig. 24D; anterior lobe of pronotum flattened in lateral view; anterodorsal margin of clypeus truncate; elytra comparatively shorter, apically subtruncate; dorsal body generally dark brown

M. kabaki sp. nov.

34. Terminal antennomere broadly triangular, apically rounded; head darker than rest of body

M. bukejsi Telnov, 2018

- Terminal antennomere elongate triangular, apically pointed; head not darker than rest of body ... 35

35. At least elytra dark brown; spiculum gastrale distinctly sinuous; in dorsal view lateral constriction area of pronotum with dense, rough punctures continue on sides (slopes) of lateral fovea

M. spurisi Telnov, 2018

- Dorsum uniformly pale brown, elytra not darker than rest of body; spiculum gastrale arched or slightly sinuous; in dorsal view sides (slopes) of lateral fovea of lateral constriction area of pronotum smooth, not densely punctured

36. Basale of aedeagus strongly bulbous; anterior margin of pronotum broadly rounded; lateral pronotal fovea dorsally deep and broad, lateral denticles prominent, well visible

M. jiuhuanus Telnov, 2007

- Basale of aedeagus widened but not bulbous; anterior margin of pronotum subtruncate; lateral pronotal fovea dorsally rather narrow, lateral denticles less conspicuous, not prominent, poorly visible

M. periclitatus Telnov, 2018

37. Lateral fovea of pronotal constriction on each side with two pairs of lateral denticles (anterior and posterior, upper and lower) 38

- Lateral fovea of pronotal constriction on each side with single pair of lateral denticles (anterior and posterior) on each side

38. Upper posterior denticle of lateral fovea of pronotal constriction with a brush of short, dense, golden setae (in lateral and dorsal view); lateral constriction continues onto pronotal disc, rather deep in lateral view; compound eyes moderately large

M. sichuanus (Telnov, 1998)

- No brush of setae on denticle of lateral fovea; lateral constriction vaguely continues onto disc, flat in lateral view; compound eyes small

M. darrenmanni Telnov, 2018 
39. Species from Japanese Archipelago (Honshu, Shikoku)

- Species from Taiwan M. nigripennis (Uhmann, 1994)

- Species from mainland China 40

40. Denticles of lateral pronotal fovea not visible in dorsal view

- Denticles of lateral pronotal fovea clearly visible in dorsal view

M. daxiangling sp. nov.

41. Transition of lateral constriction fovea to the disc of pronotum is even; transverse section of constriction area is $n$-shaped (arc)

- Transition of lateral constriction fovea to the disc of pronotum is delimited by expanded sides of pronotal disc; transverse section of constriction area is either slightly T-shaped

42. Terminal antennomere elongate, nearly regularly triangular; pronotal constriction area comparatively wider (dorsal view); elytra comparatively shorter; aedeagus without apical projection, apex pointed

M. wuliangshan Telnov, 2018

- Terminal antennomere small, asymmetrical; pronotal constriction area comparatively narrower(dorsal view); elytra comparatively more elongate; aedeagus with apical projection, apex subtruncate

M. silvicolus Telnov, 2018

43. At least one denticle of lateral pronotal fovea in pair (when visible in dorsal view) with brush of very dense, short setae

- Denticles of lateral pronotal fovea glabrous or with few sparse, long setae

44. Species from Hubei; anterior pronotal lobe dorsally minutely punctured; lateral pronotal fovea in dorsal view rather short and narrow

M. kurbatovi (Telnov, 1998)

- Species from Guangdong; anterior pronotal lobe dorsally with sparse, large and deep punctures; lateral pronotal fovea in dorsal view broad and deep

M. hajeki sp. nov.

45. Lateral constriction area of pronotum dorsally smooth and glossy, no or only tracks of sculpture present

M. uhmanni (Telnov, 1998)

- Lateral constriction area of pronotum dorsally distinctly punctured, glossy or subopaque 46

46. Anterior margin of pronotum truncate (Fig. 32A-B), medially slightly declivous anteriad; aedeagus strongly bigibbose in lateral view (Fig. 33)

M. palaung sp. nov.

- Anterior margin of pronotum broadly rounded to subtruncate, not declivous anteriad; aedeagus in lateral view not as in Fig. 33

47. Dorsal body dark brown; aedeagus as in Fig. 19

M. hartmanni sp. nov.

- Dorsal body pale brown; aedeagus not as in Fig. 19

48. Lateral constriction area of pronotum dorsally with large, strongly elongate, median longitudinal notch (Fig. 42A-B); dorsal punctures on lateral constriction area of pronotum comparatively smaller and less rough; aedeagus as in Fig. 43

M. usitatus sp. nov.

- Lateral constriction area of pronotum dorsally without large, elongate, median longitudinal notch (Fig. 26B); dorsal punctures on lateral constriction area of pronotum comparatively larger and rougher; aedeagus as in Fig. 27

M. korolevi sp. nov. 
Annotated list of the Palaearctic Macrotomoderus Pic, 1901

Genus Macrotomoderus Pic, 1901

Macrotomoderus Pic, 1901: 741. Type species: Macrotomoderus latipennis Pic, 1901: 741 by monotypy. Derarimus Bonadona, 1978: 655, synonymy proposed by Telnov (2007a). Type species: Derarimus carinatus Bonadona, 1978: 655, original designation.

Macrotomoderus andibani Telnov, 2007

Macrotomoderus andibani Telnov, 2007b: 90, 93, 101, 103 (description, illustrations, key, checklist, map).

Macrotomoderus andibani - Telnov 2018: 466-467, 482-484, 486, 490 (illustrations, key, checklist, map).

Note

This species is omitted from the $2^{\text {nd }}$ edition of the Palaearctic Catalogue (Telnov 2020).

\section{Distribution}

Shaanxi / Sichuan frontier area (Daba Mountains).

\section{Elevation}

1700-1800 m.

Macrotomoderus angelinii sp. nov.

Described above.

\section{Distribution}

Yunnan (Gaoligong Mountains).

\section{Elevation}

$3405 \mathrm{~m}$.

Macrotomoderus belousovi sp. nov.

Described above.

\section{Distribution}

W Yunnan.

\section{Elevation}

$2950 \mathrm{~m}$.

Macrotomoderus bicrispus sp. nov.

Described above.

\section{Distribution}

NW Yunnan.

\section{Elevation}

$3225 \mathrm{~m}$. 
Macrotomoderus boops sp. nov.

Described above.

\section{Distribution}

Sichuan (Mount Emei).

\section{Elevation}

$2410 \mathrm{~m}$.

Macrotomoderus bordonii sp. nov.

Described above.

\section{Distribution}

W Yunnan.

\section{Elevation}

$1290 \mathrm{~m}$

Macrotomoderus bukejsi Telnov, 2018

Macrotomoderus bukejsi Telnov, 2018: 465-467, 481, 483-484, 486, 490 (description, illustrations, key, checklist, map).

Macrotomoderus bukejsi - Telnov 2020: 623 (checklist).

\section{Distribution}

Yunnan (Wuilang Mountains).

\section{Elevation}

$2350 \mathrm{~m}$.

\section{Macrotomoderus chingpo Telnov, 2018}

Macrotomoderus chingpo Telnov, 2018: 465-467, 481, 483-484, 486, 488, 490 (description, illustrations, key, checklist, map).

Macrotomoderus chingpo - Telnov 2020: 624 (checklist).

\section{Distribution}

Yunnan (Gaoligong \& Diancang mountains) and SSW vicinities of Liuku.

\section{Elevation}

2700-3150 m.

Macrotomoderus clavipes (Champion, 1890)

Tomoderus clavipes Champion, 1890: 325 (description).

Derarimus besucheti Uhmann, 1990: 140 [synonymy by Uhmann (1994c: 655)]. 
Tomoderus clavipes - Lewis 1895: 428, 446, pl. 8 (record, illustration). — Pic 1911: 23 (checklist). Nomura 1963: 265, pl. 133 (checklist, illustration, diagnosis). — Winkler 1927: 836 (checklist). Miyatake 1959: 30-31 (record). — Sakai 1989: 413 (checklist).

Derarimus clavipes - Sakai 1986: 250 (new combination); 1998: 417, pl. 71 (checklist, diagnosis, illustration); 2000: 562 (records). - Uhmann 1994c: 655 (synonymy); 1998: 493 (faunal composition). - Lafer 1996: 36 (key, distribution). — Furihata \& Nomura 1998: 32 (record).

Macrotomoderus clavipes - Telnov 2007b: 101, 103 (new combination, key, checklist, map); 2020: 624 (checklist). - Chandler et al. 2008: 454 (checklist). — Wang \& Wang 2014: 253 (checklist, erroneously mentioned for China (Anhui)).

\section{Note}

Record by Telnov (2001) from Anhui Province, continental China refers to M. jiuhuanus Telnov, 2007.

\section{Distribution}

Honshu, Shikoku.

\section{Elevation}

$8 \mathrm{~m}$ [unpublished record].

\section{Macrotomoderus conus Telnov, 2018}

Macrotomoderus conus Telnov, 2018: 466-467, 481, 483-484, 486, 490 (description, illustrations, key, checklist, map).

Macrotomoderus conus - Telnov 2020: 624 (checklist).

\section{Distribution}

Yunnan (Gaoligong Mountains).

\section{Elevation}

$3150 \mathrm{~m}$

\section{Macrotomoderus dali sp. nov.}

Described above.

\section{Distribution}

Yunnan (Mount Laoheshang).

\section{Elevation}

$2620 \mathrm{~m}$.

\section{Macrotomoderus darrenmanni Telnov, 2018}

Macrotomoderus darrenmanni Telnov, 2018: 466, 468, 481, 483-484, 486, 488, 490 (description, illustrations, key, checklist, map).

Macrotomoderus darrenmanni - Telnov 2020: 624 (checklist).

\section{Distribution}

Yunnan (Ailao Mountains).

\section{Elevation}

$2300 \mathrm{~m}$. 
Macrotomoderus daxiangling sp. nov.

Described above.

\section{Distribution}

Sichuan (Mount Emei).

\section{Elevation}

$2900 \mathrm{~m}$.

Macrotomoderus femoridens sp. nov.

Described above.

\section{Distribution}

Guangdong (Dadong Mountains, Nanling nature reserve).

\section{Elevation}

$770 \mathrm{~m}$

Macrotomoderus gracilis Telnov, 2018

Macrotomoderus gracilis Telnov, 2018: 466, 468-469, 481, 483-484, 486, 488, 490 (description, illustrations, key, checklist, map).

Macrotomoderus gracilis - Telnov 2020: 624 (checklist).

\section{Distribution}

Yunnan (Gaoligong \& Zhemo mountains).

\section{Elevation}

2870-3000 m.

Macrotomoderus hajeki sp. nov.

Described above.

\section{Distribution}

Guangdong (Heishiding nature reserve).

\section{Elevation}

190-260 m.

Macrotomoderus hartmanni sp. nov.

Described above.

\section{Distribution}

N Yunnan.

\section{Elevation}

$2835 \mathrm{~m}$. 
Macrotomoderus hengduan sp. nov.

Described above.

\section{Distribution}

Yunnan (Hengduan Mountains).

\section{Elevation}

$2580 \mathrm{~m}$.

Macrotomoderus imitator sp. nov.

Described above.

\section{Distribution}

W Yunnan.

\section{Elevation}

2125-2170 m.

Macrotomoderus jiuhuanus Telnov, 2007

Macrotomoderus jiuhuanus Telnov, 2007b: 92-93, 101-103 (description, illustrations, key, checklist, map).

Macrotomoderus jiuhuanus - Telnov 2018: 468, 471, 482-484, 486, 490 (illustrations, key, checklist, map); 2020: 624 (checklist).

\section{Distribution}

Anhui (Mount Jiuhua).

\section{Elevation}

$900,1000 \mathrm{~m}$.

Macrotomoderus kabaki sp. nov.

Described above.

\section{Distribution}

N Yunnan.

\section{Elevation}

$3460 \mathrm{~m}$

Macrotomoderus kawa Telnov, 2018

Macrotomoderus kawa Telnov, 2018: 466, 468, 470, 481-484, 486, 488, 490-491 (description, illustrations, key, checklist, map).

Macrotomoderus kawa - Telnov 2020: 624 (checklist). 


\section{Distribution}

Yunnan (Laobie Mountains).

\section{Elevation}

$2375 \mathrm{~m}$.

Macrotomoderus korolevi sp. nov.

Described above.

\section{Distribution}

Central Yunnan.

\section{Elevation}

$2965 \mathrm{~m}$.

\section{Macrotomoderus kurbatovi (Telnov, 1998)}

Derarimus kurbatovi Telnov, 1998: 82-83 (description, illustrations, map).

Macrotomoderus kurbatovi - Telnov 2007b: 101-103 (new combination, key, checklist, map); 2018: 466, 471, 482-484, 486, 491 (illustrations, key, checklist, map); 2020: 624 (checklist). — Chandler et al. 2008: 454 (checklist). — Wang \& Wang 2014: 253 (checklist).

\section{Distribution}

Hubei.

\section{Elevation}

$2000-2200 \mathrm{~m}$. Elevation of " $2000-2500 \mathrm{~m}$ " as given in the original description (Telnov 1998) is incorrect.

\section{Macrotomoderus lapidarius sp. nov.}

Described above.

\section{Distribution}

S Sichuan (Daliang Mountains).

\section{Elevation}

$2830 \mathrm{~m}$.

\section{Macrotomoderus makarovi Telnov, 2018}

Macrotomoderus makarovi Telnov, 2018: 470, 471, 482-484, 486, 490 (description, illustrations, key, checklist, map).

Macrotomoderus makarovi - Telnov 2020: 624 (checklist).

\section{Distribution}

Zhejiang. 


\section{Elevation}

$620-1200 \mathrm{~m}$.

Macrotomoderus microscopicus Telnov, 2018

Macrotomoderus microscopicus Telnov, 2018: 466, 471-472, 481, 483-484, 486, 490 (description, illustrations, key, checklist, map).

Macrotomoderus microscopicus - Telnov 2020: 624 (checklist).

\section{Distribution}

Yunnan (Gaoligong Mountains).

\section{Elevation}

$2150,2350 \mathrm{~m}$.

Macrotomoderus mirabilis Telnov, 2018

Macrotomoderus mirabilis Telnov, 2018: 466, 472-473, 482-483, 485-486, 488, 490 (description, illustrations, key, checklist, map).

Macrotomoderus mirabilis - Telnov 2020: 624 (checklist).

\section{Distribution}

Yunnan (Xue Mountains).

\section{Elevation}

$2150 \mathrm{~m}$.

\section{Macrotomoderus monstratus Telnov, 2018}

Macrotomoderus monstratus Telnov, 2018: 466, 473, 482-483, 485, 487-488, 491 (description, illustrations, key, checklist, map).

Macrotomoderus monstratus - Telnov 2020: 624 (checklist).

\section{Distribution}

Yunnan (Xue Mountains).

\section{Elevation}

$2510 \mathrm{~m}$.

Macrotomoderus monstrificabilis Telnov, 2018

Macrotomoderus monstrificabilis Telnov, 2018: 466, 473-474, 482-483, 485, 487, 489, 491 (description, illustrations, key, checklist, map).

Macrotomoderus monstrificabilis - Telnov 2020: 624 (checklist). 


\section{Distribution}

Yunnan (Gaoligong Mountains).

\section{Elevation}

$2350 \mathrm{~m}$.

\section{Macrotomoderus muli sp. nov.}

Described above.

\section{Distribution}

S Sichuan.

\section{Elevation}

3975-4120 m

Macrotomoderus negator Telnov, 2007

Macrotomoderus negator Telnov, 2007b: 93-94, 100, 102-103 (description, illustrations, key, checklist, map).

Macrotomoderus negator - Telnov 2018: 466, 471, 481, 483, 485, 487 (illustrations, key, checklist, map); 2020: 624 (checklist).

\section{Distribution}

Shaanxi / Sichuan frontier area.

\section{Elevation}

$1700-1800 \mathrm{~m}$.

Macrotomoderus nigripennis (Uhmann, 1994)

Derarimus nigripennis Uhmann, 1994c: 663, 676.

Derarimus nigripennis - Uhmann 1996b: 748 (key).

Macrotomodereus nigripennis - Telnov 2007b: 100, 102-103 (new combination, key, checklist, map); 2018: 471, 473, 482-483, 485 (illustrations, key, checklist, map); 2020: 624 (checklist). — Chandler et al. 2008: 454 (checklist). — Wang \& Wang 2014: 253 (checklist).

\section{Distribution}

Taiwan

\section{Elevation}

$1610,1650,2130 \mathrm{~m}$.

Macrotomoderus palaung sp. nov.

Described above. 


\section{Distribution}

Yunnan (Gaoligong Mountains).

\section{Elevation}

$2265-2530 \mathrm{~m}$.

\section{Macrotomoderus perforatus Telnov, 2018}

Macrotomoderus perforatus Telnov, 2018: 466, 475, 482, 485, 487, 489, 491 (description, illustrations, key, checklist, map).

Macrotomoderus perforatus - Telnov 2020: 624 (checklist).

\section{Distribution}

Yunnan (Gaoligong \& Bangma mountains).

\section{Elevation}

$1600-2280 \mathrm{~m}$.

\section{Macrotomoderus periclitatus Telnov, 2018}

Macrotomoderus periclitatus Telnov, 2018: 466, 475-476, 482, 485, 487, 489, 491 (description, illustrations, key, checklist, map).

Macrotomoderus periclitatus - Telnov 2020: 624 (checklist).

\section{Distribution}

Yunnan (Gaoligong Mountains).

\section{Elevation}

$2730-3150 \mathrm{~m}$.

Macrotomoderus satoi (M. Saitô, 2003)

Tomoderus satoi Saitô, 2003: 321-322.

Macrotomoderus satoi - Telnov 2007b: 93, 100, 102-103 (new combination, redescription, illustration, record, key, checklist, map); 2020: 624 (checklist). — Chandler et al. 2008: 454 (checklist).

\section{Distribution}

Ryukyu Islands.

\section{Elevation}

$100-300 \mathrm{~m}$.

\section{Macrotomoderus schuelkei Telnov, 2018}

Macrotomoderus schuelkei Telnov, 2018: 466, 475, 477, 481-482, 485, 487, 489-491 (description, illustrations, key, checklist, map).

Macrotomoderus schuelkei - Telnov 2020: 624 (checklist). 


\section{Distribution}

Yunnan (Gaoligong Mountains).

\section{Elevation}

$2350 \mathrm{~m}$.

Macrotomoderus sichuanus (Telnov, 1998)

Derarimus sichuanus Telnov 1998: 83-84 (description, illustrations, map)

Macrotomoderus sichuanus - Telnov 2007b: 101-103 (new combination, key, checklist, map); 2018: 466, 475, 481, 485, 487, 489-490 (illustrations, key, checklist, map); 2020: 624 (checklist). Chandler et al. 2008: 454 (checklist). — Wang \& Wang 2014: 253 (checklist);

\section{Distribution}

Sichuan.

\section{Elevation}

$1400 \mathrm{~m}$.

\section{Macrotomoderus silvicolus Telnov, 2018}

Macrotomoderus silvicolus Telnov, 2018: 466, 477-478, 482, 485, 487, 490-491 (description, illustrations, key, checklist, map).

Macrotomoderus silvicolus - Telnov 2020: 624 (checklist).

\section{Distribution}

Yunnan (Gaoligong Mountains).

\section{Elevation}

$2150 \mathrm{~m}$.

Macrotomoderus similis sp. nov.

Described above.

\section{Distribution}

SW Yunnan (Daxue Mountains).

\section{Elevation}

$2540 \mathrm{~m}$.

\section{Macrotomoderus spurisi Telnov, 2018}

Macrotomoderus spurisi Telnov, 2018: 466, 478, 482, 485, 487, 490-491 (description, illustrations, key, checklist, map).

Macrotomoderus spurisi - Telnov 2020: 624 (checklist). 


\section{Distribution}

Yunnan (Cangshan (Diancang) \& Jizu mountains).

\section{Elevation}

2450, 2630-2660, 2750, 2870-2970, 2900-3000, 3000-3200 m.

Macrotomoderus tenuis sp. nov.

Described above.

\section{Distribution}

S Sichuan (Daliang Mountains).

\section{Elevation}

$2830 \mathrm{~m}$.

Macrotomoderus transitans sp. nov.

Described above.

\section{Distribution}

W Yunnan.

\section{Elevation}

$1850 \mathrm{~m}$.

Macrotomoderus truncatulus sp. nov.

Described above.

\section{Distribution}

Yunnan (Wuliang Mountains).

\section{Elevation}

$2270 \mathrm{~m}$.

Macrotomoderus uhmanni (Telnov, 1998)

Derarimus uhmanni Telnov, 1998: 85-86, 91 (description, illustrations, map)

Macrotomoderus uhmanni - Telnov 2007b: 100, 102-103 (new combination, key, checklist, map); 2018: 468, 478, 482, 485, 487, 490 (illustrations, key, checklist, map); 2020 (checklist). - Chandler et al. 2008: 454 (checklist). — Wang \& Wang 2014: 253 (checklist).

\section{Note}

This species was originally described from three female specimens from Hubei (holotype) and Sichuan (two paratypes). After careful re-examination it appeared that the specimens from Sichuan belong to a different, hitherto undescribed species and therefore should not be considered paratypes of M. uhmanni (see key to species above for critical features of this species). 


\section{Distribution}

Hubei.

\section{Elevation}

2000-2200 m. Elevation of "2000-2500 m" as given in the original description (Telnov 1998) and of "1400 m" as in Telnov (2018) is incorrect.

Described above.

Macrotomoderus usitatus sp. nov.

\section{Distribution}

SW Yunnan.

\section{Elevation}

$2540 \mathrm{~m}$

Macrotomoderus wudu sp. nov.

Described above.

\section{Distribution}

S Gansu.

Elevation

$2483 \mathrm{~m}$.

Macrotomoderus wuliangshan Telnov, 2018

Macrotomoderus wuliangshan Telnov, 2018: 466, 478-480, 482, 487, 491 (description, illustrations, key, checklist, map).

Macrotomoderus wuliangshan - Telnov 2020: 624 (checklist).

\section{Distribution}

Yunnan (Wuliang Mountains).

\section{Elevation}

$2200 \mathrm{~m}$.

\section{Macrotomoderus yunnanus (Telnov, 1998)}

Derarimus yunnanus Telnov, 1998: 83, 87 (description, illustrations, map).

Macrotomoderus yunnanus - Telnov 2007b: 100, 102-103 (new combination, key, checklist, map); 2018: 466, 480, 482, 487, 490-491 (illustrations, key, checklist, map); 2020: 624 (checklist). Chandler et al. 2008: 454 (checklist); Wang \& Wang 2014: 253 (checklist).

\section{Distribution}

Yunnan.

\section{Elevation}

$500 \mathrm{~m}$. 
TELNOV D., New species of Macrotomoderus, with a key to the Palaearctic taxa

Table 1. Palaearctic species of Macrotomoderus Pic, 1901 recorded for altitudinal zones.

\begin{tabular}{lc}
\hline Zones & Number of species \\
\hline Lowland zone (0-700 m / 200 m zone overlap) & 4 \\
Lower montane zone (701-1800 m / 200 m overlap) & 5 \\
Species shared between lowland \& lower montane zones & 1 \\
Mid montane zone (1801-2900 m / 200 m overlap) & 27 \\
Species shared between lower and mid montane zones & 2 \\
Upper montane zone (2901-3900 m / 200 m overlap) & 7 \\
Species shared between mid \& upper montane zones & 4 \\
\hline
\end{tabular}

\section{Discussion}

Telnov (2018) recently discussed the peculiarities of distribution, species richness, endemism, and conservation challenges of Chinese Macrotomoderus. The present publication supports the previous statement that, on one hand, species of Macrotomoderus may be threatened or endangered due to the forest loss and habitat conversion, while on the other hand, at least some species seem be able to tolerate highly modified environments and survive in isolated patches of natural and seminatural forest vegetation as demonstrated by this and previous (Telnov 2018) reviews. It is remarkable that in the Palaearctic realm only a handful, or four, of a total of 47 species of Macrotomoderus recorded from continental China are known from lowland areas (Table 1). On the contrary, in the Oriental realm and, particularly, in the insular systems of Southeast Asia, Macrotomoderus are widely represented in lowland areas (for instance, Telnov 2004, 2007a). As pointed on recently by Telnov (2018), this paradox is possibly explained by lack or severe degradation of suitable habitats at lower elevations in China.

Hypothetically, Macrotomoderus must be present on Hainan Island, although no records are yet known. Hainan is now separated from mainland Asia by the Hainan (or Quingzhou) Strait, on average $30 \mathrm{~km}$ wide, but recent palaeobotanical, palaeomagnetic and volcanism studies (e.g., Zhu 2016) suggest it could have been adjacent to northern Vietnam and Guangxi in the Eocene.

Generally, Palaearctic species of Macrotomoderus are rather uniform morphologically and the identification of species is often challenging. The "classic" approach by earlier authors (for instance, Uhmann 1993, 1994a, 1994c, 1996b, 1998) mainly focused on external morphology, considering male genital organs too uniform to be useful for taxonomic purposes. As revealed in the present publication, male aedeagi of Macrotomoderus contain unique microstructures of high taxonomic value. However, the shape of the male genitalia alone is usually not sufficient for delimiting species of Macrotomoderus, and needs to be supplemented with microscopic anatomy of their gonopore armature in combination with peculiarities of external morphology (usually more prominent in males), such as modifications on head base and pronotum. The "classic" approach particularly focused on dorsal sculpture of lateral pronotal constriction area of pronotum, such as shape and density of punctures and presence or absence of carina(e). Among the Palaearctic species this feature seems relatively stable, however, as is widely known and common in beetle morphology, the dorsal sculpture of the body is a also subject of variation. Therefore, it is suggested to the further research to use the aforementioned combination of various characters for species delimitation. 


\section{Acknowledgements}

Igor' A. Belousov, Ilya I. Kabak (both All-Russian Institute of Plant Protection, St Petersburg, Russia) and Rostislav Filimonov (The Russian Entomological Society, St Petersburg, Russia) are thanked for providing highly interesting material for the present paper and for donation of selected specimens.

\section{References}

Bonadona P. 1978. Les Tomoderini subendogés d'Afrique centrale et de l'Inde méridionale (Col. Anthicidae). Revue suisse de Zoologie 85 (3): 645-656. https://doi.org/10.5962/bhl.part.82253

Champion G.C. 1890. On a new species of Tomoderus from Japan. The Entomologist's Monthly Magazine 26: 325-326.

Chandler D.S. 2010. 11.26. Anthicidae Latreille, 1819. In: Leschen R.A.B., Beutel R.G. \& Lawrence J.F. (eds) Coleoptera, Beetles. Volume 2: Morphology and Systematics (Elateroidea, Bostrichiformia, Cucujiformia partim). Arthropoda Insecta. Handbook of Zoology: 729-741. De Gruyter, Berlin \& New York. https://doi.org/10.1515/9783110911213.729

Chandler D.S., Uhmann G., Nardi G. \& D. Telnov 2008. Family Anthicidae Latreille, 1819. In: Löbl I. \& Smetana A. (eds) Catalogue of Palaearctic Coleoptera. Volume 5: 421-455. Apollo Books, Stenstrup.

Furihata Y. \& Nomura S. 1998. A review of soil beetles collected from Matsumoto city, Nagano Prefecture, Central Japan and its adjacent area. New Entomologist 47 (1/2): 27-32.

Lafer G.S. 1996. 100a, 101. Сем. Anthicidae (Pedilidae) - быстрянки [100a, 101. Fam. Anthicidae (Pedilidae) - Ant-like Flower Beetles]. In: Ler P.A. (ed.) Определитель насекомых Дальнего Востока Poccuи [Determination keys to the insects of the Russian Far East]. Volume III. Жесткокрылье, или жуки [Coleoptera, or Beetles]. Part 3: 26-45. Nauka, Vladivostok.

Lewis G. 1895. On the Cistelidae and other heteromerous species of Japan. The Annals and Magazine of Natural History Series 615 (89): 422-448, pl. 8. https://doi.org/10.1080/00222939508677908

Miyatake M. 1959. A record of an interesting anthicid beetles of Japan. Ageha 7: 30-31 [in Japanese].

Nomura S. 1963. The Family Anthicidae. In: Nakane T., Ohbayashi K., Nomura S. \& Kurosawa Y. (eds) Iconographia Insectorum Japonicorum, Colore naturali edita. Volume 2: 263-266, pls 132-133. Hokuryukan, Tokyo.

Pic M. 1901. Hylophilidae de la Malaisie et nouveau genre d'Anthicidae de Sumatra. Annali del Museo Civico di Storia Naturale "Giacomo Doria” 2 (40): 737-742.

Pic M. 1911. Anthicidae. In: Schenkling, S. (ed.) Coleopterorum Catalogus Pars 36. W. Junk, Berlin. Available from https://www.biodiversitylibrary.org/page/48234645 [accessed 28 Jan. 2022].

Saitô M. 2003. A new species of the genus Tomoderus (Coleoptera: Anthicidae) from the Ryukyu Islands, Southwest Japan. Elytra 31: 321-323.

Sakai M. 1986. Studies on Anthicidae of Japan (Coleoptera), 1. Transactions of the Shikoku Entomological Society 17 (4): 247-251.

Sakai M. 1989. Anthicidae. In: Hirashima Y. (ed.) A Check List of Japanese Insects, I: 411-413. Entomological Laboratory, Faculty of Agriculture, Kyushu University and Japan Wildlife Research Center, Fukuoka and Tokyo.

Sakai M. 1998. Anthicidae. In: Kurosawa Y., Hisamatsu S. \& Sasaji H. (eds) The Coleoptera of Japan in Colour. Volume III: 415-423, pls 71-72. Hoikusha, Higashiosaka. 
Sakai M. 2000. Anthicidae and Aderidae of Odamiyama. Nature of the Mountain Massif, Odamiyama, 2: 561-565. Oda-cho, Ehime, Japan.

Telnov D. 1998. Anthicidae (Coleoptera) der Sammlung Sergej Kurbatov, mit Beschreibung von sechs neuen Arten aus der Orientalis. Bulletin de la Société royale belge d'Entomologie 134 (1): 81-100.

Telnov D. 2001. Zur Kenntnis asiatischer Anthicidae (Coleoptera) II. Entomologische Zeitschrift 111 (6): $182-186$.

Telnov D. 2004. Neue und wenig bekannte Anthicidae (Coleoptera) von dem malayischen Borneo. Entomologische Zeitschrift 114 (5): 209-222.

Telnov D. 2007a. Revision der Tomoderinae. Die Macrotomoderus gracilicollis-Artengruppe (Coleoptera: Anthicidae). Mitteilungen des Internationalen Entomologischen Vereins 32 (1/2): 1-25.

Telnov D. 2007b. Zur Kenntnis asiatischer Anthicidae, IV (Insecta: Coleoptera). Mitteilungen des Internationalen Entomologischen Vereins 32 (3/4): 89-105.

Telnov D. 2018. Revision of the Tomoderinae (Coleoptera: Anthicidae). Part II. Macrotomoderus Pic, 1901 species from China and Taiwan. Annales Zoologici 68 (3): 463-492.

https://doi.org/10.3161/00034541ANZ2018.68.3.008

Telnov D. 2020. Family Anthicidae Latreille, 1819. In: Iwan D. \& Löbl I. (eds) Catalogue of Palaearctic Coleoptera. Volume 5. Revised and Updated Second Edition. Tenebrionoidea: 575-625. Brill, Leiden \& Boston.

Uhmann G. 1990. Weitere Anthiciden verschiedener Regionen aus dem Museum in Genf (Coleoptera, Anthicidae). Revue suisse de Zoologie 97: 139-151. https://doi.org/10.5962/bhl.part.79730

Uhmann G. 1993. Anthiciden aus Sabah (Borneo) aus dem Naturhistorischen Museum in Genf (Coleoptera, Anthicidae). Revue suisse de Zoologie 110 (2): 373-404.

https://doi.org/10.5962/bhl.part.79867

Uhmann G. 1994a. Neue Anthicidae aus Borneo, Malaysia, von den Philippinen und aus Zambia (Coleoptera). Entomologische Zeitschrift 104 (11): 210-217.

Uhmann G. 1994b. Die von Rudolf Schuh in Asien gefundenen Anthiciden. Entomofauna 15 (35): 405416.

Uhmann G. 1994c. Südostasiatische Anthiciden aus dem Naturhistorischen Museum in Genf, 4 (Coleoptera, Anthicidae). Revue suisse de Zoologie 101 (3): 655-676.

https://doi.org/10.5962/bhl.part.79922

Uhmann G. 1996a. Anthiciden aus dem Naturhistorischen Museum in Wien (Coleoptera, Anthicidae). Entomologische Blätter 92 (1/2): 19-36.

Uhmann G. 1996b. Indo-australische Anthicidae (Coleoptera) im Naturhistorischen Museum in Genf. Revue suisse de Zoologie 103 (3): 737-748. https://doi.org/10.5962/bhl.part.79971

Uhmann G. 1998. Beschreibung von vier neuen Arten der Gattung Derarimus (Coleoptera, Anthicidae) aus Malaysia. Revue suisse de Zoologie 105 (2): 493-497. https://doi.org/10.5962/bhl.part.80048

Uhmann G. 1999. Neue Anthicidae aus der Sammlung von Jürgen Wiesner (Coleoptera, Anthicidae). Entomologische Blätter 95 (2/3): 145-156.

Wang X. \& Wang Z. 2014. List and faunal composition of China's Anthicidae (Coleoptera). Journal of Ningxia University (Natural Science Edition) 35 (3): 249-254. [In Chinese, English abstract.]

Winkler A. 1927. Catalogus Coleopterorum regionis palaearcticae. Pars. 7. Albert Winkler, Wien. 
Zhu H. 2016. Biogeographical evidences help revealing the origin of Hainan Island. PLoS One 11 (4): e0151941. https://doi.org/10.1371/journal.pone.0151941

Manuscript received: 17 August 2021

Manuscript accepted: 6 December 2021

Published on: 24 February 2022

Topic editor: Nesrine Akkari

Section editor: Max Barclay

Desk editor: Pepe Fernández

Printed versions of all papers are also deposited in the libraries of the institutes that are members of the EJT consortium: Muséum national d'histoire naturelle, Paris, France; Meise Botanic Garden, Belgium; Royal Museum for Central Africa, Tervuren, Belgium; Royal Belgian Institute of Natural Sciences, Brussels, Belgium; Natural History Museum of Denmark, Copenhagen, Denmark; Naturalis Biodiversity Center, Leiden, the Netherlands; Museo Nacional de Ciencias Naturales-CSIC, Madrid, Spain; Real Jardín Botánico de Madrid CSIC, Spain; Zoological Research Museum Alexander Koenig, Bonn, Germany; National Museum, Prague, Czech Republic. 